Portland State University

PDXScholar

Summer 8-14-2015

\title{
Assessing the Impact of Restrictiveness and \\ Placement Type on Transition-Related Outcomes for Youth With and Without Disabilities Aging Out of Foster Care
}

Jessica Danielle Schmidt

Portland State University

Follow this and additional works at: https://pdxscholar.library.pdx.edu/open_access_etds

Part of the Social Work Commons

Let us know how access to this document benefits you.

\section{Recommended Citation}

Schmidt, Jessica Danielle, "Assessing the Impact of Restrictiveness and Placement Type on TransitionRelated Outcomes for Youth With and Without Disabilities Aging Out of Foster Care" (2015). Dissertations and Theses. Paper 2481.

https://doi.org/10.15760/etd.2478

This Dissertation is brought to you for free and open access. It has been accepted for inclusion in Dissertations and Theses by an authorized administrator of PDXScholar. Please contact us if we can make this document more accessible: pdxscholar@pdx.edu. 
Assessing the Impact of Restrictiveness and Placement Type on Transition-Related Outcomes for Youth With and Without Disabilities Aging Out of Foster Care

by

Jessica Danielle Schmidt

A dissertation submitted in partial fulfillment of the requirements for the degree of

Doctor of Philosophy

in

Social Work and Social Research

Dissertation Committee:

Thomas Keller, Chair

Ann Fullerton

Sarah Geenen

Laurie Powers

Lew Bank

Portland State University

2015 


\begin{abstract}
Nearly 23,000 youth age out of the foster care system between the ages of 18 and 21 each year in a transition fraught with challenges and barriers. These young people often lack developmentally appropriate experiences and exposure to necessary knowledge, role modeling, skill building, and long-term social support to promote positive transitions to adulthood while in foster care. As a result, young people who exit care face an array of poor adult outcomes. Nearly $60 \%$ of transition-aged foster youth experience a disability, and as such, face compounded challenges exiting foster care. While the examination of young adult outcomes for youth with disabilities has been largely missing from the literature, available research documents that young adults with disabilities who had exited foster care were significantly behind their peers without disabilities in several key areas. Literature examining the experiences of transition-aged youth with disabilities in the general population also highlights gaps in young adult outcomes for young people with disabilities compared to their peers. Compounding the issue for youth in foster care, those who experience disabilities often reside in restrictive placement settings such as developmental disability (DD) certified homes, group homes, or residential treatment centers. Though limited, there is some evidence to suggest that these types of placements negatively impact young adult outcomes for those aging out of foster care. The rules and regulations in place to promote safety in these types of placements could further restrict youth from engaging in meaningful transition preparation engagement while in foster care. Therefore, youth with disabilities, whose needs necessitate a higher level of support towards transition preparation engagement,
\end{abstract}


may actually receive fewer opportunities than their peers in non-relative foster care and kinship care as they prepare to exit care into adulthood. The work in this dissertation provides knowledge to address gaps in the literature around transition preparation engagement during foster care for youth with disabilities, youth residing in restrictive foster care placements, and youth who report high levels of perceived restrictiveness as they prepare to enter into adulthood.

This dissertation is a secondary analysis of transition preparation engagement data collected at baseline for 294 transition-aged youth in foster care who participated in an evaluation of an intervention to promote self-determination and enhance young adult outcomes, called My Life. Transition preparation engagement in this study was represented by eight domains: youth perceptions of preparedness for adult life, postsecondary education preparation engagement, career preparation engagement, employment, daily life preparation engagement, Independent Living Program (ILP) participation, transition planning engagement, and self-determination. Transition preparation engagement domains were examined using hierarchical multiple regression analysis to explore differences by disability status, placement setting, and youth selfreport of perceptions of restrictiveness. In alignment with the literature, $58.8 \%$ of youth in this sample experienced a disability. Additional key demographics, including age, gender, and race, and foster care experiences, including length of time in care and placement instability, were entered into the regression models as covariates. Results indicated significantly less transition preparation engagement for 1) youth with disabilities compared to youth without disabilities, 2) youth residing in restrictive 
placements compared to youth in non-relative foster care and kinship care, and 3) youth who reported higher levels of perceived restrictiveness compared to youth who reported lower levels of perceived restrictiveness. Program, policy, and research recommendations are discussed that highlight the need to promote transition preparation engagement for this particularly vulnerable group of young people in foster care who experience disabilities, are residing in restrictive placement settings and who report high levels of perceived restrictiveness. 


\section{Dedication}

To Claudia, you never stop motivating me, inspiring me, teaching me, and pushing me to grow. I may never quite find the right words to truly reflect my gratitude. So, I will just say thank you. But, know that it comes from the depths of my heart. 


\section{Acknowledgements}

I would like to give a special thank you to the young people who had the courage to share their experiences so that this dissertation study could be possible. Thank you to the My Life team of assessors and coaches, I admire your tireless efforts and deep, heartfelt commitment to youth with experience in foster care. To my mentors, Laurie Powers and Sarah Geenen, thank you for dreaming up one of the most beautiful things of which I have ever been a part. My deepest gratitude for the endless support, encouragement, feedback, and knowledge that you both have shared with me.

To my chair, Tom Keller, thank you for walking with me on this journey from beginning to end. I will always be thankful that you were willing to delight right alongside me as I discovered how truly meaningful research can be. To Lew Bank, thank you for going above and beyond to support my learning as a student. I do not know many who would have taken the time to sit and explain things to me at the level you did. To Ann Fullerton, your passion for supporting young people is inspiring, thank you for sharing your beautiful heart.

And lastly, thank you to my family and friends. Mom, you modeled what it was to never give up on your academic goals, even when juggling much more than ever felt possible. And Dad, it has never gone unrecognized how hard you worked to support us all to make sure that she reached the finish line. In much the same way, my wife Liorah has cared for our family, picked me up when I felt I could not keep going, and even contributed to this work as one of my very best editors. Her support has truly been monumental. And finally, to my sons, you both inspire me. May you both always know, 
no matter how old you are or where your life takes you, we are forever a family and your journey will never be alone. 


\section{Table of Contents}

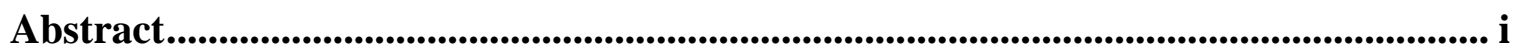

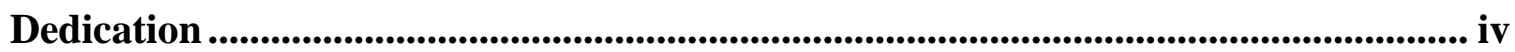

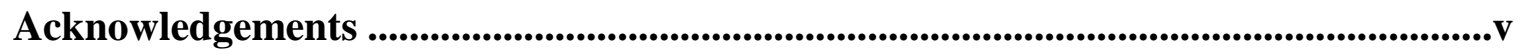

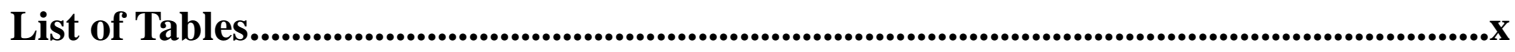

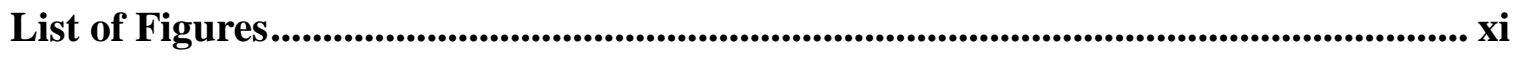

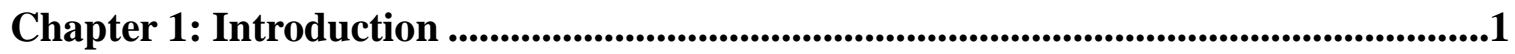

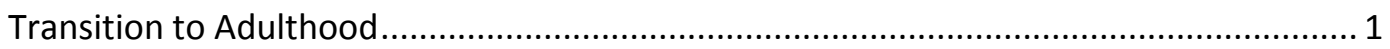

Transition to Adulthood for Youth in Foster Care ............................................................. 2

Youth in Foster Care Who Experience Disabilities............................................................ 4

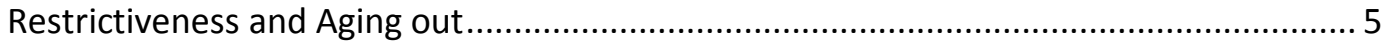

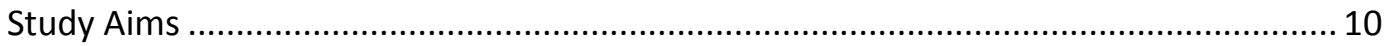

Chapter 2: Literature Review .................................................................................................12

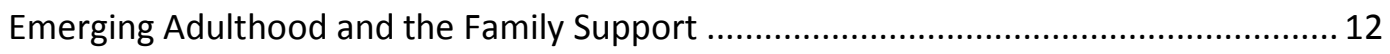

Transitioning to Adulthood from Foster Care ............................................................. 15

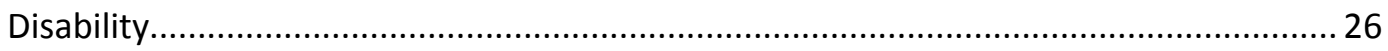

Important Additional Demographic Factors ............................................................... 32

Restrictiveness, Foster Care Placements, and Aging Out ............................................... 34

Important Additional Foster Care Experiences.............................................................. 41

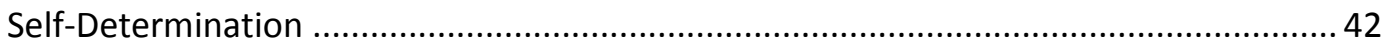

Chapter 3: Theoretical Perspectives.........................................................................45

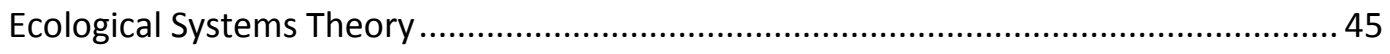

'Restrictive' Parenting and Adolescent Development ........................................................ 49

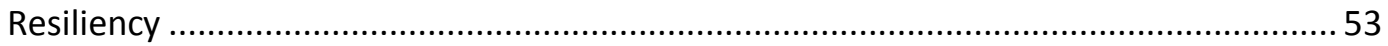

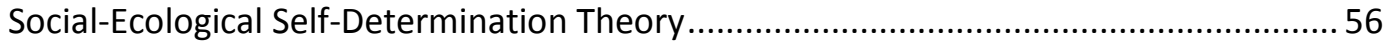

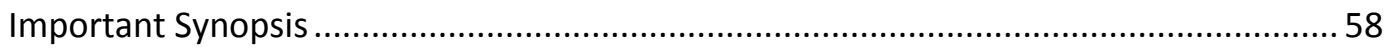

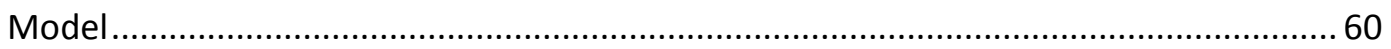

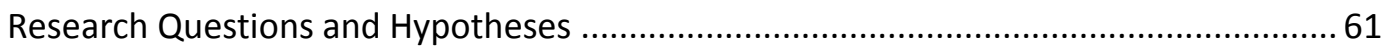


Chapter 4: Methods ................................................................................................................................63

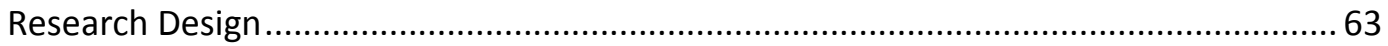

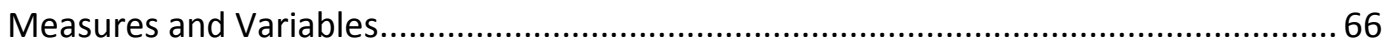

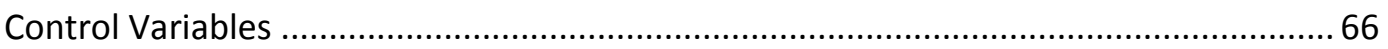

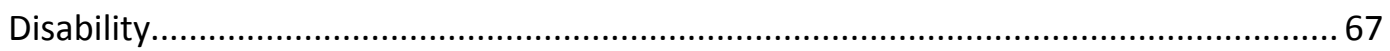

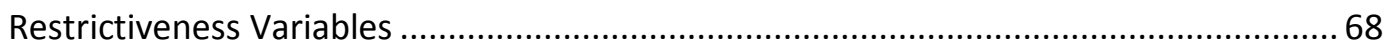

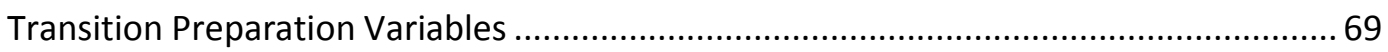

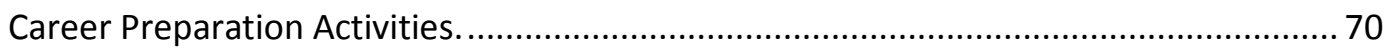

Preliminary Analysis and Analysis Plan ........................................................................ 73

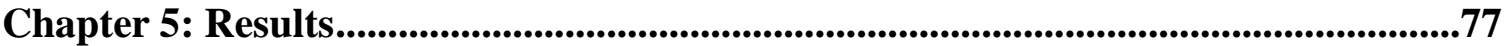

Associations among Independent Variables............................................................... 78

Disability and Restrictive Placement Type ..................................................................... 83

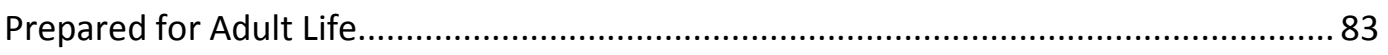

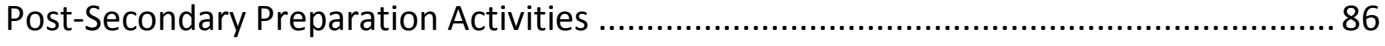

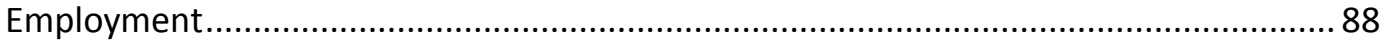

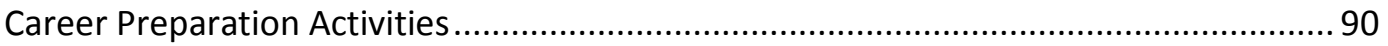

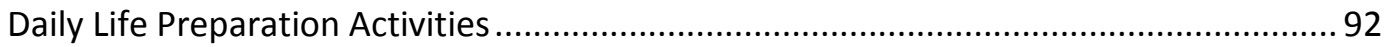

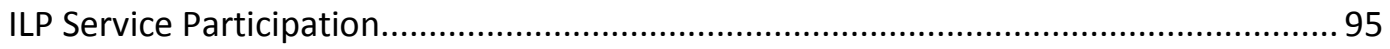

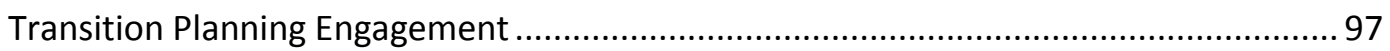

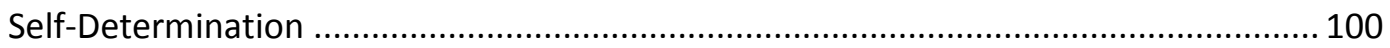

\section{Chapter 6: Discussion ......................................................................................................................103}

Question 1: Disability and Restrictive Placement Settings ............................................ 103

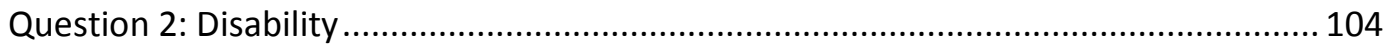

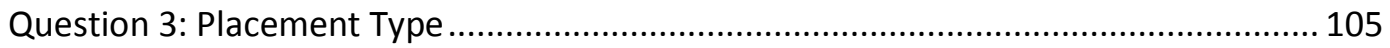

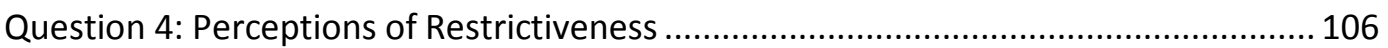

Findings Across Disability, Placement Type, and Youth Perceptions ........................... 107

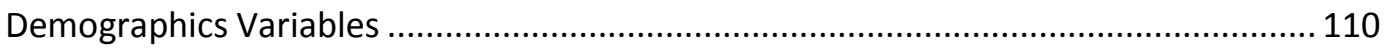

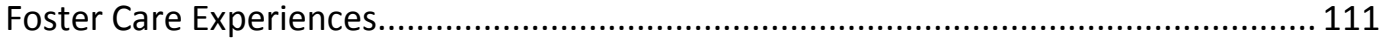

Social Work Policy and Practice Implications …......................................................... 113

Limitations of the Study and Future Research Implications ......................................... 123 


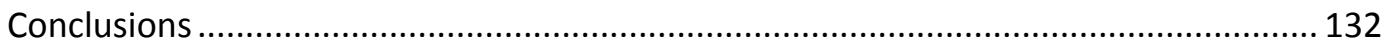

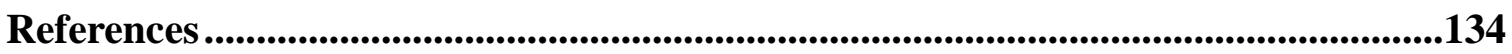




\section{List of Tables}

Table 1. Demographics................................................... 78

Table 2. Demographics by Placement Type.......................................79

Table 3. Means, Standard Deviations, and Percentages of Dependent Variables by Independent Variables.......................................... 80-81

Table 4. Prepared for Adult Life.......................................... 84

Table 5. Post-Secondary Preparation Activities.................................87

Table 6. Employment..................................................89

Table 7. Career Preparation Activities..........................................91

Table 8. Daily Life Preparation Activities........................................93

Table 9. ILP .......................................................... 96

Table 10. Transition Planning Engagement....................................... 99

Table 11. Self-Determination............................................... 101 


\section{List of Figures}

Figure 1: Association of experiencing disability with transition preparation for

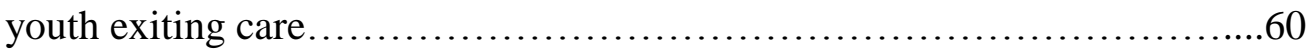

Figure 2. Association of restrictiveness (placement type and youth perceptions

of restrictive ness) with transition preparation for youth exiting care.........60 


\section{Chapter 1: Introduction}

"There's a lot of stuff that happens in group homes. When they put you in group homes or residentials, it's like jail. DSS [Child Welfare] does not put a lot of support behind it ... It's behind closed doors.... They can tell you one thing, but you would never know the truth. It's like dropping me off in a program and the program telling them what's going on with me. I'm the one that's there; I'm the one that should be telling you that." -male foster youth, 17 (Hyde \& Kammerer, 2009, p. 270)

\section{Transition to Adulthood}

In the $21^{\text {st }}$ century, transition to adulthood has been marked as a unique developmental period distinct from adolescence and early adulthood. Termed emerging adulthood, it is defined as occurring between the ages of 18 and 25. Emerging adulthood is a time when young adults are focused on exploring careers, romantic relationships and worldviews within a protective environment of partial independence. Generally emerging adults develop semi-autonomy during this period of moving away from home, entering into college or beginning full-time work. However, they still rely on adults such as parents, college administrators and other supportive adults for many types of support as they develop optimal levels of self-sufficiency and interdependence in the world (Arnett, 2000).

Most emerging adults are able to navigate the transition to adulthood successfully, particularly within the context of strong social networks and reliance on adults for support and assistance. In 2009, most emerging adults were transferring through the 
educational system fairly smoothly with $81 \%$ of young people aged $18-24$ having completed a high-school degree or it's equivalency and for those age 16-24, $66 \%$ of males and $74 \%$ of females successfully enrolled in college immediately after finishing high-school (U.S. Department of Education, 2013). While young people faced poverty at a higher rate than the overall population ( $21 \%$ vs. $15.3 \%)$, most young adults were employed in 2010 with $75 \%$ of young men and $66 \%$ of young women aged $20-24$ participating in the workforce (U.S. Department of Education, 2013). In addition, most young people aged 20-24 had stable housing with 3.6-6.8\% of the general population of young adults experiencing homelessness (Ammerman et al., 2004). These figures, however, are not representative of the experience of young adults exiting foster care, who face many barriers and obstacles in their transition to adulthood.

\section{Experience of transition to adulthood for youth in foster care}

Each year, nearly 23,000 youth age out of the foster care system, generally between the ages of 18 and 21, and enter into independence as young adults (AFCARS, U.S. Department of Health and Human Services, 2013). For youth aging out of foster care into independence, this developmental stage of life is generally a much different experience than for their same age peers and most are not afforded a period of semiautonomy to explore adult roles and responsibilities. In fact, there is not typically a period of emerging adulthood for youth aging out of care, as most young people in care must assume full responsibility for their own well-being when they exit the foster care system (Westat, 1991; Barth, 1990; Geenen \& Powers, 2007; Lee \& Berrick, 2014). Many youth aging out of care do not have the level of continuing supports available to their peers, 
whose biological families often provide financial and emotional support, dissemination of knowledge around skills necessary for independent living, and frequently a home to return to. These types of support allow young people to take on adult responsibilities gradually. While it is not uncommon for former foster youth to return to their biological families of origin when they age out, for those that do, these relationships are often complex due to early experiences that originally resulted in foster care. In the context of these barriers, it is not surprising then that youth aging out of the foster care system face bleak adult outcomes and are significantly different than their same-age peers in that they are more likely to experience low levels of high-school completion and participation in secondary education, and high levels of homelessness, unemployment, poverty, young parenthood, and mental health challenges (Pecora et. al, 2006; Courtney, Dworsky, Cusick, Havileck, Perez, \& Keller, 2007).

Another factor affecting developmental outcomes is that young people aging out of foster care often experience a higher level of restriction around opportunities to practice life skills and participate actively in their community during adolescence. For instance, few foster youth are supported in learning to drive in adolescence or are given the opportunity to spend the night in a place that isn't certified by the child welfare system or previously approved by a youth's caseworker. This restrictiveness is due in part to the licensing regulations of foster placements and an overall emphasis of the child welfare system on keeping youth safe and protected, which often sharply contrasts with the experiences adolescent development requires, including taking risks, exploring one's world, and developing self-reliance (Field, Hoffman, Posch, 1997; Schmidt et al, 2013). 
While services within the child welfare system, called Independent Living Programs (ILP), exist at the state level to prepare young people for their transition to adulthood, these services can vary greatly from state to state. Further, evaluations of these services have shown that many youth do not participate in ILP services and for those who do, not all receive the level of service intended by the Foster Care Independence Act of 1999 (FICA) (Courtney \& Heuring, 2005).

\section{Youth in Foster Care Who Experience Disabilities}

Children and youth who experience disabilities are overrepresented in the foster care system (Crosse, Kaye, \& Ratnofsky, 1992; Sullivan \& Knutson, 2000; Hill, 2012; Schmidt et al., 2013). While the U.S. Department of Education (2013) found that $13 \%$ of students aged 3-21 enrolled in public school received special education services, studies that examine the overall population of children and youth who experience disabilities within the foster care system have found prevalence rates ranging from $22 \%$ to $30 \%$ (Lightfoot, Hill, LaLiberte, 2011; Trout, Hagaman, Casey, Reid, \& Epistein, 2008; Goerge, Voorhis, Grant, \& Casey, 1992). When examining the population of older transition aged youth in care alone however, rate of experiencing a disability increases to approximately 47\% to 60\% (Westat, 1991; Hill, 2012; Hill, 2013; Schmidt et al, 2013). The impact of restrictiveness on transition preparation for youth is a particularly important issue as highly restrictive placement settings have been typically used to serve older youth, many who experience disabilities and who have behavioral, mental health and/or developmental needs (Schmidt et al, 2013; James, Leslie, Hurlburt, Slyman, Landsverk, \& Mathiesen, 2006; Wulczyn \& Brunner Hislop, 2001; Wulczyn, Smithgall, 
\& Chen, 2009; Courtney, Terao \& Bost, 2004). Thus, given the high prevalence rate of disability in this older population of transition-aged youth, the majority of youth aging out of foster care may also experience living in a restrictive setting during adolescence.

Youth who experience disabilities and reside in foster care face more barriers and challenges than their peers in foster care both while in Chile Welfare and after aging out of the system into adulthood (Westat, 1991; Slayter \& Springer, 2011; Smithgall, Gladden, Yang \& Goerge, 2005; Geenen \& Powers, 2006; Anctil, McCubbin, O'Brien, \& Pecora, 2007; Hill, 2012). One large scale study of youth exiting foster care compared the experience of aging out for youth with and without disabilities and found that youth with disabilities had significantly higher rates of unemployment and lower levels of social support, high-school completion, and overall self-sufficiency than those without disabilities (Westat, 1991). This trend was found to continue for young adults with physical and psychiatric disabilities formerly in foster care, with a mean age of 29 , who reported lower levels of education and self-esteem than their same age peers (Anctil et al., 2007). Further, youth in foster care receiving special education services for a label of emotional disturbance were found to have alarmingly high rates of school incompletion due to incarceration (18\%), particularly in comparison to the mere $16 \%$ of youth with this label who successfully graduated from high-school (Smithgall, Gladden, Yang \& Goerge, 2005). Therefore, it is those youth most at risk for a difficult transition out of care who face the additional limitations imposed by restrictive foster care placements.

\section{Restrictiveness and Aging out}

The Adoption Assistance and Child Welfare Act (1980) dictates that child welfare 
agencies place children and youth in the least restrictive placements necessary to meet young peoples' needs upon entry into foster care (Allen \& Bissel, 2004). Conversely, highly restrictive placements, such as group homes, residential treatment facilities, therapeutic foster homes, and developmental disability certified homes, are to be considered for children and youth with elevated emotional and behavioral needs that pose a safety risk when placed with kin or in typical foster homes (Barth, 2002). These child welfare policies were largely influenced by evidence from the movement for change within the children's mental health system during the 1960's and 1970's that called for least restrictive placement settings due to a variety of findings that indicated children and youth were being inappropriately placed in highly restrictive settings when their mental health needs did not indicate a need for such a placement (Behar, 1990; Keisler, 1993; Stroul \& Friedman, 1986). One study found that as many as $40 \%$ of children in an inpatient hospital setting did not have needs that necessitated this type of placement (Knitzer \& Olson, 1982). Similar findings were reported in the foster care system, even after the induction of the Adoption Assistance and Child Welfare Act policies. As many as one-third of youth were found to be inappropriately placed in residential treatment settings in a state-wide evaluation of youth being served in these types of settings in Illinois (Lyons, Libman-Mintzer, Kisiel, \& Shallcross, 1998). Additionally, James and colleagues (2006) found $25 \%$ of their sample of youth in care were placed in a restrictive placement at entry into the child welfare system, illuminating the fact that the least restrictive placement options are not always the first settings utilized in practice. Largely missing from the AAWCA policy are recommendations for ensuring least restrictive 
placements, such as offering services to children and foster families to minimize use of more restrictive placements or making use of accommodations and alternative supports to increase the effectiveness of least restrictive placements in meeting the needs of children and youth with disabilities.

The type of placement a youth resides in while in foster care could greatly impact the youth's experience of aging out of foster care. Highly restrictive foster care placements, such as group homes, Developmental Disability (DD) certified homes, and residential treatment facilities, could further amplify negative transition-related outcomes and the challenges youth face as they age out. For example, youth with no previous arrests who are then placed in restrictive placement settings have been shown to experience higher rates of arrest while in foster care than youth in other types of foster care placements controlling for salient demographic variables, key foster care experiences and problem behaviors associated with placement instability (Ryan, Marshall, Herz, and Herndandez, 2008). There is also some evidence that poor adult outcomes around education, well-being, social support, housing and economic stability may be correlated with restrictive placement type while in foster care (MacDonald, Allen, Westerfelt \& Piliavan, 1996).

Likewise, there is some evidence that less restrictive foster placement settings may act as a protective factor for youth aging out of foster care. Young adults who resided in less restrictive foster care placements were shown to be much more likely to be enrolled in post-secondary education than those in restrictive settings (Mech \& Fung, 1999). Further, there is some support that youth residing in kinship care, conceptualized 
as a less restrictive setting, may fair better than youth residing in other types of placement settings in regards to self-concept and resiliency, employment rates, and educational outcomes (Conger \& Rebeck, 2001; Metzger, 2008; Dworsky \& Courtney, 2001). Additionally, young people in kinship care were less likely to experience drug or alcohol abuse, to have run away from home, or to be truant from school (Franck, 2001). Moreover, residing independently in one's own apartment has been shown to be correlated with an increase in life-skills knowledge while youth in group care or institutional settings had the lowest levels of life skill knowledge (Mech, Ludy-Dobson \& Hulseman, 1994).

While there is some initial evidence that outcomes for young people in foster care differ by placement type, few studies have adequately controlled for demographic factors and foster care experiences to examine the impact that restrictive placement types may have on the experience of youth aging out of care. It is all too easy to focus this discussion on the high proportion of youth in restrictive settings who experience a disability (Schmidt et al, 2013; Franck, 2001; MacDonald et al., 1996) and the association of poor outcomes related to experiencing a disability for youth in care (Westat, 1991; Slayter \& Springer, 2011; Smithgall, Gladden, Yang \& Goerge, 2005; Geenen \& Powers, 2006; Anctil et al., 2007; Hill, 2012). However, this issue is critical to examine because the very group most likely to experience restriction is youth with disabilities and these restrictions can be particularly detrimental for this group of young people, for whom exposure to experiential skills, opportunities for self-determined behavior, and supports that maximize capacities for successful adult living is absolutely 
critical (Dennis, Williams, Giangreco, \& Cloninger, 1993; Halpern, 1994; King, Baldwin, Currie \& Evans, 2005; Stewart, Stavness, King, Antle, \& Law,2006).

There are multiple potential reasons that restrictive placements may negatively impact young people in care and compound the challenges of transition aged youth who experience disabilities as they exit care. For instance, restrictive placements have strict certifying standards in place to ensure the safety of youth with high-level needs and operate under protocols that are generally designed as 'one size fits all' methods despite the unique needs and behavior of youth in their care. These policies and protocols often restrict youth in foster care from participating in activities at home and in the community that are necessary for building responsibility, acquiring and practicing the skills necessary for independent living, and having adequate access to natural allies who could otherwise provide a support network to youth as they plan their exit from care. Additionally, youth in group care settings are generally cared for by young shift staff with high levels of turnover, making it difficult for youth to maintain meaningful relationships with adults that would support their transition to adulthood (Courtney, 2009). Further, due to the nature of policies that task restrictive placement settings with prioritizing care and safety first, staff generally do not place much emphasis on helping youth maintain contact with biological family members (Courtney, 2009). Finally, youth in restrictive placement may have less flexible service plans that are not tailored to the individual needs of the youth or utilize community-based services (Breland-Noble, Farmer, Dubs, Potter \& Burns, 2005) and report more dissatisfaction with their living situation more often than youth in other placement types (NSCAW, 2002). While there are many indicators in the literature that 
restrictive placement type may have an impact on youth preparing to exit care, this study will be the first to examine the direct impact of restrictiveness on the transition preparation of youth in foster care.

\section{Study Aims}

The transition to adulthood is a distinctly different experience for youth aging out of foster care and many of these youth face poor adult outcomes. Despite the large number of youth who experience disabilities within the population of transition-aged youth in foster care, much of the literature focused on outcomes for youth aging out of care has not addressed the differences youth with disabilities may experience compared with their peers. In fact, several large scale evaluations of the experience of youth aging out of foster care have excluded groups of young people who experience certain types of disabilities. Furthermore, little is known about the impact of residing in restrictive foster settings during adolescence or how aging out of a restrictive foster placement may impact adult outcomes after leaving care for youth with or without disabilities. Adolescence is a critical developmental period for developing skills and knowledge that will support one's transition to adulthood, and the context of ones' home and family life during this time has major implications for how well one is prepared for this transition.

The work in this dissertation will provide knowledge around the transition preparation that occurs, or lack thereof, for youth while in foster care particularly those with disabilities and those residing in restrictive foster care placements as they prepare to enter into adulthood. Specifically, this study will explore how youth with disabilities engage in transition preparation, including perception of readiness for adult life, post- 
secondary skill engagement, employment and career skill engagement, daily life skill engagement, ILP participation, transition planning engagement, and levels of selfdetermination. Further, this study will examine how restrictiveness in foster care, measured by foster care placement type and youth perceptions of restrictiveness, may further limit transition preparation activities and engagement for youth in care. Because the majority of youth who reside in restrictive foster care settings experience a disability, findings from this dissertation may have implications for a large percentage of youth with disabilities in foster care, who may be exponentially behind in preparing to enter adulthood because of the restrictions placed on them within the foster care system. 


\section{Chapter 2: Literature Review}

\section{Emerging Adulthood and the Family Support}

The modern day conceptualization of the developmental period of young adulthood has shifted from the age of 18 to begin now in one's mid-twenties and even early thirties (Arnett, 2000; Arnett, 2014). Two historical indicators of adulthood, marriage and parenthood, have shifted to occur later in life for many young people. The transition from high-school graduation to young adulthood is now a more gradual process and there is greater time for exploration and freedom from typical adult roles (Arnett, 1998; Rindfuss, 1991). Thus, a new developmental period has emerged in the transition to adulthood defined as emerging adulthood and representing young people ages 18-25 (Arnett, 2000).

Emerging adulthood is a developmental model proposed by Jeffery Jensen Arnett and is defined by five major components. The first component describes emerging adulthood as a time of great instability for young people. Subsequently, emerging adults are focused on exploring their identity, particularly as it relates to romantic relationships and one's career focus. Emerging adulthood is also a time of deep self-focus. Next, this period is a time when a young person may have feelings of being in-between, not yet an adult but no longer an adolescent. The final component of emerging adulthood is defined optimistically as being a time of endless possibilities for one's future (Arnett, 2000).

Emerging adulthood is a subjectively defined experience for young people. Rather than focus on the assumption of adulthood through typically defined adult roles such as completing schooling, getting married, or entering parenthood, young people today tend 
to identify as adults based on individual characteristics (Arnett, 1997; 1998; Greene, Wheatley, \& Aldava, 1992). The most salient characteristics are inherently individual and focus on the ability to make choices for one's self, to be responsible for one's self (Arnett, 1997; Greene et al, 1992) and to be financially capable of providing for one's self (Nelson, 2003). For most young Americans, these characteristics are achieved by the late twenties and once fulfilled, the developmental stage of adulthood has begun (Arnett, 2000).

Support from family is an important component to this transition (Furstenberg \& Hughes, 1995; Mortimer \& Larson, 2002). Parents often provide emerging adults financial and emotional support, help young people make connections for career and education advancement through networking, and model important tasks and roles necessary in adulthood (Zarrett \& Eccles, 2006). Nearly half of emerging adults in the United State in their late teens and twenties rely on their parents to provide them shelter by residing at home (Furstenberg, 2010). The relationship that young people have with their parents is correlated to overall well-being and self-esteem in young adulthood (Roberts \& Bengston, 1996). Additionally, parental support has been found to provide a protective capacity for young adults coping with stressful change (Hobfoll \& Spielberger, 1992; Holahan \& Moos, 1991) and help with the psychological adjustment to transitioning to adulthood (Holahan, Valentiner, \& Moos, 1994; Powers, Hauser \& Kliner, 1989; Rice, Cole \& Lapsley, 1990).

Because emerging adulthood is mostly constructed by larger social norms and values, this developmental period may be viewed quite differently in the context of 
different ethnic groups and cultural values. For example, studies examining views on individualism in the United States have found differences amongst African-Americans, Asians, and Latinos compared with Whites in terms of valuing collectivism rather than individualism (Fuligni, Tseng, and Lam, 1999; Phinney, Ong, and Madden, 2000; SuarezOrozco \& Suarez-Orozco, 1996). Examining the constructs of emerging adulthood with African-American, Latino, Asian, and White respondents aged 18-29, Arnett (2003) found some key ways in which cultural values differed for each ethnic group compared with the group of White respondents. All four groups had similar views around independence from parents and self-sufficiency as key tenements to achieving adult status. However, all three groups varied from White respondents in defining adulthood by prioritizing the capacity to care and support for a family and children, valuing compliance of social norms such as avoiding substance use and crime, and achieving certain adult milestones such as completing one's education, becoming married, buying a home, and being employed full-time. African-Americans and Latino respondents more consistently indicated that they perceived themselves to have reached adulthood while Asian and White respondents were more likely to respond more ambiguously to whether they felt they had reached adulthood with a response of "in some respects yes, in some respects no". African-American and Latino respondents were more likely to have families with lower socio-economic status and become parents during their twenties, thus likely altering the experience of responsibility attainment and emerging adulthood for these two groups. While there is a dominant culture view that differs from the experiences of youth aging out of care that will be discussed in depth below, even within this framework of 
emerging adulthood, there are different cultural contexts outside of the culture of foster care that also impact the transition to adulthood for different groups of young people.

\section{Transitioning to Adulthood from Foster Care}

The period of emerging adulthood for youth in foster care is often a much different process compared with the normative experience of emerging adulthood that assumes extended support from one's family. While $45 \%$ to $55 \%$ of young adults aged 18 to 24 in the general population go on to remain living at home with birth parents and receive on average $\$ 38,000$ in financial support from age 18 to 34 (Courtney et al., 2007), most youth who age out of foster care experience independence at age 18 (up to age 21 in some states) and face a drastic decline in the financial, relational, and social service services they had previously received while in care (Smith, 2011). Having a support network is an unquestionably large part of a young person's success in entering the adult world. For example, in a study of 18 year old college students, parental support was found to predict positive adjustment to college and overall psychological well-being 2 years later (Holahan, Valentiner, \& Moos, 1994). For youth in care, many relationships while in child welfare are professional in nature and thus do not typically endure during the youth's exit from the foster care system. For youth who are able to remain with caregivers after discharge from care, transition can be more successful. These youth face lower levels of unemployment one year after exiting care, are more often engaged in continued education or training opportunities, and have greater access to others in their support network (Wade, 2008; Ward, 2009). However, the number of youth who are afforded this opportunity is low. Courtney et al. (2001) found that only about one-third of 
youth were able to remain in their placement after being discharged from care and only about $10 \%$ of the sample of former foster youth at age 19 were residing with a former foster parent who was not biologically related to the youth (Courtney \& Dworsky, 2006).

A study comparing the perceptions of adolescents preparing to enter adulthood, both in foster care and not in foster care, found key differences in views of adulthood. Youth in foster care were more likely to worry about their future, more likely to be thinking about working full-time after exiting care (compared to after high-school for peers not in care), more likely to think they would not receive financial assistance from the family they were living with after high-school, and more likely to think that their source of financial stability would come from paid employment, as compared to their peers (Iglehart, 1995). Additionally, very few resources are allocated to preparing youth while in foster care with the experiences and skills necessary to successfully navigate the transition to adulthood (Courtney, 2009). This sudden shift to self-reliance at such an early age with limited transition preparation while in foster care leaves the process of becoming an adult fraught with challenges and barriers for young people exiting care. Therefore, outcomes such as education, employment, daily life domains such as housing, access to health care, and economic stability for adolescents while in care and subsequent young adult outcomes for youth who have aged out of foster care, are strikingly different compared with their same aged peers (Westat,1991; Pecora et al., 2003, 2006).

Education. Educational attainment is often a critical component of a successful transition into adulthood and affords young people more options for entering the work force and becoming financially secure. However, studies have repeatedly shown that 
youth exiting foster care have poor rates of educational participation and degree attainment. Children in foster care face a plethora of challenges that impact their ability to do well at school. A history of abuse or neglect, moving homes and schools, not attending school for periods at a time, delays in schools transferring school records to new schools, and challenges properly assessing children for special education services have been shown to be correlated with poor educational outcomes (Mech \& Fung, 1999; Zetlin, Weinberg, \& Kimm, 2003). Zetlin and colleagues (2003) found nearly 3 in 4 children in foster care, in both general education and special education, were performing below grade level expectations, and over half had been held back at least one year in school. An investigation of educational outcomes for older youth in foster care found over half had failed at least one class, most had experienced a physical altercation with peers or a verbal altercation with a teacher (occurred equally amongst males and females), and almost all of the youth had been suspended at least once (McMillen, Auslander, Elze, White, \& Thompson, 2003). For the Midwest sample of youth preparing to exit care at age 17 , just over half $(59.6 \%)$ reported they had received any educational support or services to prepare them for independent living and yet the majority aspired to go to college. Additionally, one-third of the sample had attended at least 5 schools or more while in care (Courtney, Terao, \& Bost, 2004).

Several studies examining education for former foster youth have shown these young people attend school for fewer years overall than their same-age peers (Zimmerman,1982; Jones and Moses, 1984). Accruing fewer years of education also has implications for opportunities to obtain a degree. In a recent study examining outcomes 
for youth who had exited foster care, it was found that $58 \%$ of youth who exited care had obtained a high-school degree by age 19 compared with $87 \%$ of 19 year olds in a nationally representative comparison group (Courtney, Dworsky, Ruth, Keller, Havilcek, $\&$ Bost,, 2005). A follow-up look at this group of former foster youth at age 24 showed that nearly a quarter had still not completed high-school, compared with $7 \%$ of their peers (Courtney, Dworsky, Lee, \& Raap, 2010). While Pecora et al. (2006) did find similar rates of degree obtainment for former foster youth and youth in the general population ages 18-29 in the Northwest evaluation of transition-aged outcomes, it was found that young adults formerly in foster care obtained a GED rather than high-school diploma at much higher rates than their peers $(28.5 \%$ versus $5 \%)$. This is particularly relevant for outcomes around post-secondary education participation, as those who receive a highschool diploma rather than a GED are twice as likely to attend college. Additionally those young adults with a GED generally earn less income overall than young adults with a high school diploma (Pecora et al., 2006). Finally, a study that examined placement in college prep courses while in high-school found that amongst students of similar aptitude, youth in foster care were placed in the courses at less than half the rate of their peers (Shin, 2002).

The trend of low-educational attainment continues when post-secondary educational participation and completion is examined. While $70-80 \%$ of youth in foster care state that they aspire to attend college (Courtney et al., 2010; McMillen et al., 2003; Tzawa-Hayden, 2004), only 20-34\% actually attend (McMillen et al., 2003; Wagner, Newman, Cameto, Levine \& Marter ,2007; Courtney, Piliavan, Grogan-Kaylor, \& 
Nesmith, 2001; Courtney et al., 2005; Wolanin, 2005; Pecora et al., 2003, 2006).

Furthermore, young adults in foster care are significantly more likely to drop-out during their $1^{\text {st }}$ year of college and do not graduate, compared with their peers (Day, Dworsky, Fogarty, \& Damashek, 2011). Courtney et al (2010) found that just $6 \%$ of those who aged out of foster care earned diplomas from either a two-year or four-year post-secondary institution compared with $29 \%$ of young people in the general population.

Employment. For the sample of 17 year olds preparing to exit care in the Midwest study, almost half $(47.7 \%)$ reported having ever worked compared with their non-foster care peers, with just one-third reporting they had ever worked and $35.1 \%$ of the youth in care reporting they were currently working. Additionally, a little over twothirds of the youth in care reported having received employment/vocation support (Courtney, Terao, \& Bost, 2004). Being employed while in care seems to have implications for adult employment after exiting care. Goerge et al. (2002) found that for youth in California, South Carolina, and Illinois, involved in an evaluation of youth aging out of care at age 18 , not working prior to exiting care at 18 decreased the chance of being employed after exiting care. Youth who did not work while in care had only a 50\% chance of securing employment after exiting.

Not surprisingly, young adults who age out of foster care face many obstacles participating in the workforce and providing for themselves financially. Former foster youth face higher unemployment rates (Cook, Fleischman, \& Grimes, 1991; Goerge, Bilavar, Lee, Needell, Brookhart, \& Jackman, 2002; Courtney et al., 2005; Pecora et al., 2006) and are more likely to receive less pay for their work than young adults in the 
general population (Barth, 1990; Courtney, 2001; Goerge et al., 2002; Courtney et al., 2005; Pecora et al, 2006). While it is not uncommon for young people to enter the workforce later in life due to pursuing educational goals, nearly 1 in 3 youth in the MidWest Evaluation at age 19 were neither working nor in school, compared with $12.3 \%$ of youth in the general population (Courtney \& Dworsky, 2006).

In a study examining outcomes for youth exiting care at 18 , it was found that only $38 \%$ of young adults formerly in foster care who were able to secure employment at the time of exit were able to maintain this job one year later (Henig, 2009). For the youth involved in the Midwest evaluation at age 23-24, less than half were employed (48\%) and for those that were employed, the majority (85\%) received an income of $\$ 25,000$ or less a year (Courtney et al., 2010). At age 25-27, the $48 \%$ rate of employment persisted, in contrast to the $79 \%$ employment rate of young adults in the general population, and young adults who had aged out of foster care were making significantly less income than the median income of those in this age bracket who did not experience foster care (\$18,000 less) (Courtney, Dworsky, Brown, Cary, Love, \& Vorheis, 2011).

Daily Life. During the survey of youth preparing to exit care in the Midwest study, youth were asked if they had received services or training in various areas of daily life such as money management, food preparation, personal health and hygiene, and finding housing and transportation. Between one-third and one-half of youth had not received any support in any given service domain with the highest level of service receipt in health education services (68.9\%), followed by budgeting and financial support (56.2\%), housing services $(51.7 \%)$ and youth development services such as mentoring or 
leadership activities (46.1\%). Similarly, Pecora et al (2005) found that while over half of the young adults exiting care $(56.5 \%)$ reported they were very prepared or somewhat prepared for adult living, only about one-third had resources like a driver's license, \$250 in cash, or pots and pans, and less than half (47.4\%) had access to health insurance.

With the high number of youth exiting care having not received support in these critical areas, it is no surprise that these young adults fall behind in daily life domains as well. Young adults who exit foster care access public assistance at about 5 times the rate of their same-age peers (Barth, 1990; Cook et al., 1991; Courtney et al., 2001, 2005; Pecora et al., 2005, 2006). In several studies examining adult outcomes of former foster youth, $25-30 \%$ of these young adults received at least one type of need-based assistance from the government (Cook et al., 1991; Pecora et al., 2005). Youth who have just exited care are particularly vulnerable to experiencing poverty. Courtney (2001) and Goerge et al (2002) found that young adults who had aged out of foster care experienced especially high rates of poverty up to 2 years after leaving foster care. Nineteen year old youth formerly in foster care in the Midwest Evaluation reported that they were up to 2 times more likely to have difficulty paying their rent, mortgage, or utility bills, and/or have their telephone service disconnected, in contrast to with their peers in the comparison group (Courtney et al., 2005). Similarly, one-third of young adults who exited care reported not having health insurance (Pecora et al., 2006).

While housing instability in young adulthood is common, former foster youth experience particularly high rates of instability. Courtney et al. (2001) found that nearly one quarter of youth exiting care resided in 4 or more locations within $1 \frac{1}{2}$ years of 
leaving foster care. An early study that examined former foster youth 2.5-4 years post care found that $32 \%$ of these young adults had resided in at least 6 locations since exiting care (Cook et al., 1991). Rates of homelessness for this population are also quite high. Pecora et al. (2006) found that up to $20 \%$ of youth were homeless for at least one night within the year after aging out of foster care. Research that examines young adults who experience homelessness has found that young people with a history of foster care outnumber young people without a history of foster care in the overall population of young adults who experience homelessness (Susser, Liii, Conover, \& Struening, 1991; Sosin Piliavin, \& Westerfelt, 1990).

Transition Planning. Taken together, the poor adolescent outcomes for youth in foster care and later young adult outcomes after leaving foster care, suggest a transition process that is not sufficient to meet the needs of these young people as they enter adulthood. In focus groups addressing transition planning for youth, young people, both in care and those who had exited care, and foster parents identified an overall lack of individualized planning and support for youth, and a lack of youth involvement in decision making. Additionally, these participants noted a lack of overall collaboration between parties including youth, school staff, caseworkers, foster parents, and other service providers. Youth explicitly stated wanting more control in the process of making decisions about their life and articulated needs that were unmet (i.e., access to transportation, lack of knowledge about housing, lack of identified supports after leaving care etc.) as they prepared to exit care (Scannapieco, Connell-Carrick, \& Painter, 2007). Multiple additional authors cite the need for youth voice in the transition planning 
process and the involvement of youth in decision making as critical components of preparing youth for exiting care that have been largely missing (Mech, Ludy-Dobson \& Hulseman, 1994; Massinga \& Pecora, 2004; Frey, Greenblatt, \& Brown, 2005).

Independent Living Program Services. As part of the Title-IV-E funds through the Social Security Act of 1985 (PL 99-272) and Foster Care Independence Act of 1999 (FICA), Independent Living Programs (ILP) were created to address the abysmal outcomes young adults were facing aging out of the foster care system. These services were designed for adolescents in care who had a permanent plan of long term foster care and thus would exit foster care as young adults. ILPs traditionally provide access to financial support as well as skill-based training in an effort to better prepare youth for young adulthood. The programs are administered at the state and county level through a combination of federal, state, local and private funding (U.S. General Accounting Office, Health, Education and Human Services Division, 1999). While there is vast variance across programs, most teach skill training in a classroom around pertinent areas of independent living including housing, employment, money management, accessing resources, and making decisions and provide some individualized support around accessing transition resources (Georgiades, 2005). Additionally, the 2008 Fostering Connections Act calls for each youth exiting care to have a written transition plan in place detailing services and arrangements that will facilitate this transition.

In general, there are vast differences in the literature of ILP evaluations in terms of measurement, methodology, and youth participants, and thus few conclusions can be drawn across studies that would lend evidence to the true impact that ILP plays in 
addressing poor outcomes for youth exiting care (Courtney \& Heuring, 2005;

Montgomery, Donkoh, \& Underhill, 2006; Naccarato \& DeLorenzo, 2008; Smith, 2011; Courtney, Zinn, Koraleck \& Bess, 2011; Courtney et al., 2008). However, a more recent evaluation of ILP services at 3 sites (LA County, California, Kern County, California, and Massachusetts) utilized a randomized controlled trial design to evaluate outcomes across different domains including education, employment, housing, delinquency, economic well-being, and perception of preparedness for adult life. The two California sites did not find any significant differences between the ILP participants and control youth (Courtney, Zinn, Koraleck \& Bess, 2011; Courtney, Zinn, Zielwski, Bess \& Malm, 2011). The Massachusetts youth did report significantly higher service utilization in domains identified as useful for transitioning to adulthood at follow-up; however, the study included help received by ILP caseworkers to measure this outcome. ILP youth were also significantly more likely to have their birth certificate, get their driver's license, and enroll in college. However, the ILP group was found to remain in care past 18 at higher rates than the control group and once this factor was controlled for, the group differences no longer remained significant. In Massachusetts, it is required that youth be enrolled in school or vocational training to remain in care past the age of 18 (Courtney, Zinn, Johnson \& Malcom, 2011). Taken together, ILP may be helpful in supporting youth to stay in care longer and thus receive a longer period of support for transition aged youth but there have not been any findings that suggest ILP services address the poor outcomes youth face exiting care.

Nevertheless, ILPs remain the primary mode of independent living support and 
skill development for youth exiting care. However, rates of youth participation show that $40 \%$ of youth exiting care do not receive ILP services and that it is probable that the remaining $60 \%$ do not receive services in full as outlined in the Chafee Foster Care Independent Living Program in the FICA (1999) (Courtney \& Heuring, 2005). Low rates of participation in these services and the ILPs' inability to offer supports in line with the intent of the original legislation illustrates that the complete reliance upon this program to address gaps in the child welfare system in preparing young people for adulthood is unwarranted, and additional changes in policy should be considered to better address needs around the transition to adulthood.

There have not been any studies that have specifically examined ILP participation for youth in care with disabilities, and few that describe how participation differs by placement type. Lemon, Hines and Merdinger (2005) found that for college students formerly in care, those who had participated in ILP were more likely to have moved often and been placed in a non-relative foster placement or group care compared with the nonILP group who was more likely to have been placed with a relative. Thus, placement instability and restrictive placement types may in fact promote the inclusion of youth participate in these services. However, the fragmented service coordination between the child welfare system and the special education system in providing transition services to youth involved in both systems has been documented in the literature (Geenen and Powers, 2006). In addition, ILP services have historically lacked the ability to offer accommodations to youth and the reliance on caseworker referrals for participation leaves room for biases around ability and relevance of independent living for youth with 
disabilities, further impacting who participates.

\section{Disability}

Much like the absence of the examination of disability on ILP participation, most of the research evaluating outcomes for youth aging out of care does not include youth who experience disabilities nor does it distinguish outcomes for youth who experience disabilities from youth without disabilities. In fact, the two most notable evaluations of youth aging out of care excluded young people who experienced certain types of disabilities. Courtney et al. (2005) excluded youth who experienced a developmental disability, a severe mental health disability, or youth who were residing in a psychiatric hospital, while Pecora et al. (2005) excluded youth with major physical or developmental disabilities.

This exclusion of youth who experience disabilities is an important issue because there is evidence to suggest that a large percentage of transition aged youth in foster care experience a disability. Several studies have found that approximately $60 \%$ of populationbased samples of transition aged foster youth include youth receiving special education services and about $25 \%$ of receive developmental disability services (Schmidt et al., 2013; Hill, 2012; Hill, 2013). In contrast, only 5.2\% \% of young people in the general population aged 5-17 and 10\% of adults ages 18-64 were reported to experience a disability in the 2010 American Community Survey (Brault, 2011) while the National Center on Educational Statistics reported that $13.2 \%$ of school-aged young people receive special education services (US Department of Education, 2015). It has been well established that young adults who have exited care experience psychiatric disabilities at 
high rates (Jones and Moses, 1984; Courtney et al., 2005; Percora et al. 2005). Festinger (1983) found that nearly half of young adults who exited foster care residing in New York had sought mental health services from a professional after exiting care. More recently, the Midwest Evaluation and Northwest Evaluation of youth exiting care replicated these findings and young adults who had been in care as teenagers sought mental health support twice as often as their peers in the general population (Pecora et al., 2005; Courtney et al., 2005). Most commonly, these young adults report experiencing PTSD (Pecora et al., 2010). In fact, youth exiting care experience higher rates of PTSD than war veterans returning home from war zones in this country (Hoge, Castro, Messer, McGurk, Cotting, \& Koffman, 2004). The most recent look at outcomes for the Midwest sample found that $33 \%$ experienced social anxiety, $25 \%$ experienced depression, $60 \%$ experienced PTSD, and $14.5 \%$ of the sample was taking psychotropic medications (Courtney et al., 2011). This high level of disability for youth in foster care is likely a complex interaction between marginalizing social conditions, poverty, low educational opportunities, exposure to trauma, instability of living situations, minimal exposure to resources that support well-being over time, and an overall lack of reliable, consistent support from adults. Often, these youth must manage multiple service systems such as special education, child welfare, mental health, juvenile justice, and developmental disability agencies (Zetlin, Weinberg, \& Kimm, 2003). Further, exposure to systems that focus on diagnosis may increase the likelihood of receiving a disability label. Zetlin and colleagues (2010) found that some foster children who were labeled as experiencing learning disabilities and were subsequently referred to special education services were 
likely experiencing problems related to emotional trauma and frequent movement from home and school rather than meeting the criteria for a learning disability. Thus, disability is disproportionately represented within young people involved in foster care and yet this issue has been over-looked in the research for some time.

Outcomes for Youth with Disabilities Exiting Foster Care. While there are certainly gaps in the literature regarding transition outcomes for youth with disabilities aging out of care, there have been some studies that have examined what is happening as this group ages out of care. The only comparative study to examine transition outcomes for youth in care experiencing disabilities compared with youth without disabilities, the National Evaluation of Title IV-E Independent Living Programs, found that youth with disabilities were less likely than their counterparts to be employed, graduate from high school, have social support, and be self-sufficient (Westat, 1991). More recently, Smithgall et al. (2005) found that for youth in care with an emotional disturbance disability code (ED), more youth left high school because of incarceration (18\%) than graduated from school (16\%). Geenen and Powers (2006a) examined academic achievement of youth in special education and foster care compared with youth in general education and foster care and youth in special education only. The youth in foster care and special education were behind academically compared with both the youth in general education and foster care and the special education only group. Additionally, despite the legislation (Individuals with Disabilities Education Act (IDEA), amended 2004) that mandates transition planning for youth receiving special education services at 16, students in foster care and special education receive poorer transition planning services 
compared to students in special education alone. Students in care had significantly fewer post-secondary and independent living skill goals and had fewer overall transition goals listed than students not in foster care. Many goals did not explicitly list an attainable action plan for achieving the goals listed. Finally, youth in care are less likely to attend their IEP/Transition Planning meeting, less likely to have an advocate attend, and a child welfare caseworker was present at only one-third of the transition planning meetings. Taken together, these factors illustrate poor collaboration between child welfare and educational transition planning activities (Geenen \& Powers, 2006b).

Youth with disabilities also experience disproportionate placement instability compared with their peers in foster care. Slayter and Springer (2011) found that youth with intellectual disabilities moved more often than their peers, were less likely to be placed in kinship placements, and were more likely to be placed out of state than their peers in foster care. Similarly, Hill (2012) found older youth with disabilities were more likely to move foster placements during adolescence and less likely to reside with biological family members as a plan of permanency than youth in care without disabilities. Finally, one study that examined adults with experience in foster care (mean age 29 years old) found that compared, with young adults who had exited foster care without disabilities, those with psychiatric disabilities reported lower levels of selfesteem, overall physical health, and less educational completion (Anctil, McCubbin, O'Brien, Pecora \& Anderson-Harumi, 2007).

Studies that have examined an intervention to enhance the self-determination of transition-aged youth in foster care who experience disabilities highlight some key 
variables that, taken together, create a composite of characteristics that indicate a trajectory towards improved transition outcomes (Powers et al, 2012; Geenen et al, 2013). The first preliminary evaluation study for the My Life self-determination and transition to adulthood intervention, which preceded the full-scale My Life intervention evaluation study, and which provides the sample of youth represented in this study, included 67 youth with disabilities in foster care aged 16.5-17.5 randomized into an intervention and control group. Youth in the intervention group had trend level increases in high school completion, employment, and independent living skill engagement from baseline to post-intervention. At follow-up 1 year later, youth in the intervention group continued to be engaged in independent living skills at a significantly higher rate than those in the comparison group. Furthermore, at follow along, $72 \%$ of the treatment group had completed high-school compared with $50 \%$ of the control group and $45 \%$ were employed compared with $28 \%$ in the control group. The intervention group also had significantly higher levels of use of community transition services as well as quality of life and self-determination between assessment time points. Self-determination was also found to be a partial mediator for quality of life scores (Powers et al, 2012). A similar intervention that included 133 high-school students in care who were in special education and focused on self-determination enhancement, called Project Success, found that students in the intervention group experienced increased self-determination, engagement in school planning, academic performance including catching-up on credits, and a reduction in anxiety and depression scores from baseline to follow along. At the 18 month follow-along assessment, $60 \%$ of the intervention group was employed compared 
with $37 \%$ of the control group (Geenen et al, 2013).

Other Studies Examining Youth with Disabilities. While the literature examining youth with disabilities exiting foster care is sparse, there is existing research around the transition to adulthood for youth with disabilities not in foster care, which is useful to examine. This literature indicates that youth who experience disabilities, foster care notwithstanding, do not fare as well as their same age peers in the transition to adulthood. The National Longitudinal Transition Study-2 (NLTS2) which examined youth with disabilities, including psychiatric disabilities, found that two years post highschool participation, $28 \%$ of the sample had dropped out and nearly half (44\%) of youth with an ED code had dropped out of school. Youth in the general population were almost twice as likely to go on to college and 4-and-a-half times more likely to attend a four year university than the sample of NLTS2 youth with disabilities despite the majority of youth in the NLTS2 sample reporting aspirations of attending college. While youth with disabilities had similar rates of residing at home with biological parents (75\%) as did youth in the general population, for the $12 \%$ of youth with disabilities residing with a spouse or roommate, two in three reported an annual income of $\$ 5000$ or less, well below the federal poverty rate. This is particularly important as this indicates that youth with disabilities not residing with biological parents, often the case with youth aging out of care, are at an elevated risk for experiencing poverty in adulthood. Further, youth with disabilities were approximately 1.5 times less likely to be employed than youth without disabilities (Wagner, Newman, Cameto, Garza, \& Levine, 2005). Six years later, 8 years post high-school completion, Newman et al (2011) found young adults with disabilities 
were still less likely than their peers in the general population to attend post-secondary school, though the gap between the two groups was closing, and were less likely to complete post-secondary school once enrolled. Young adults without disabilities also earned more money per hour and were more likely to live independently than young adults with disabilities (59\% vs. 45\%). Additionally, a history of experiencing a psychiatric disability is correlated with high rates of unemployment (Cronce \& Corbin, 2010).

\section{Additional Important Demographic Factors}

Race. Race has important implications for findings around education, employment, and self-sufficiency amongst youth aging out of care. African-American and Latino youth are disproportionality represented in the population of youth in care and youth aging out of the foster care system (Goerge \& Lee, 2000; Smith, 2011). AfricanAmerican children are more likely to stay in foster care for longer periods of time, have more foster care placements, receive poorer quality of services while in care, and are less likely to be reunified with parents or adopted (Roberts, 2002). Along with disproportionate negative experiences with foster care, youth of color also face oppression and systemic racism that create additional barriers in the transition into adulthood. Harris, Jackson, O'Brien, and Pecora (2009) found that amongst young adults who had exited foster care, African-Americans were more likely to experience poverty and less likely to own their own home or apartment than their White peers who had exited foster care. Goerge et al. (2002) found that African-American youth in care were less likely to be employed while in foster care and after aging out of foster care than their 
peers. A study examining perceived stress and life-satisfaction of transition-aged youth in foster care at 18 years of age found that youth of color reported higher levels of perceived stress and lower levels of life satisfaction (Munson \& McMillen, 2009).

While youth of color in foster care face many additional risks and barriers compared with their White peers, White youth aging out of foster have been shown to experience higher rates of alcohol and substance use than youth of color in care (Substance Abuse and Mental Health Services Administration [SAMHSA], 2005). Raghavan and McMillan (2008) also found that White youth were significantly more likely to be prescribed psychotropic medication while in foster care than youth of color. Finally, examining rates of delinquency amongst youth aging out of care, Ryan, Hernandez, and Herz (2007) found no differences in race amongst African-American, Hispanic, and White youth exiting foster care and arrest rates.

Gender. Several studies examining outcomes for transition-aged youth have found an over representation of females in this group (Courtney \& Barth, 1996; Goerge et al., 2002; Daining \& DePanfilis, 2007) while other studies such as the Midwest evaluation of youth exiting care found equal proportions of males and females exiting foster care (Courtney, Terao \& Bost, 2004). Goerge and colleagues' (2002) examination of employment outcomes for youth exiting care showed that females were more likely to be employed than males prior to exiting foster care and after exiting care. A study of lifestressors and resiliency one-year after exiting care found that females reported higher levels of resiliency than did males (Daining \& DePanfilis, 2007). Transition-aged males 
in foster care have also been shown to have more contact with the juvenile justice system than females, and nearly one-half of the 17 and 18 year old males in the Midwest evaluation reported having been a victim of violence in the past 12 months compared with one-third of the female respondents (Courtney, Terao \& Bost, 2004). Females in foster care, however, may be more likely to experience depression at age 18 than males, as was found in Munson and McMillan's (2009) study examining life satisfaction.

\section{Restrictiveness, Foster Care Placements, and Aging Out}

As already established, almost 2 in 3 transition-aged youth in care experience a disability (Hill, 2013; Schmidt et al., 2013) and as a group, are at an elevated risk for poor transition-related outcomes after exiting care, a process which is undeniably challenging for all youth exiting foster care. Experiencing a disability, particularly a behavior health need, psychiatric disability, or developmental disability, is also associated with being placed in restrictive placements (James et al., 2004; James et al, 2006). In fact, the majority of youth in restrictive placements may in fact experience a disability. For instance, Schmidt et al (2013) found that the vast majority of transition-aged youth residing in restrictive placement settings received special education services associated with experiencing a disability. And yet, little attention has been given to the role that restrictive placement types may play in the compounded disadvantage that youth with disabilities face while exiting foster care. Due to the high percentage of youth with disabilities in the population of young people exiting care and the child welfare system's reliance on restrictive placement types for this group, it is imperative that this relationship be further examined. 
There exists some evidence that these placement types may in fact present barriers for youth aging out of foster care. For example, MacDonald et al. (1996) reviewed the literature on youth in foster care who had resided in group homes, a type of highly restrictive placement, and found that these youth had poorer outcomes as young adults than did their peers in other types of foster placements. For instance, compared with young adults who spent the majority of time in care in group settings, young adults who spent most of their time in typical family-like foster settings were less likely to have been arrested or convicted of a crime (Festinger, 1983; Jones \& Moses, 1984), more likely to have progressed educationally, reported higher levels of satisfaction with the contact they have with their birth siblings (Festinger, 1983), were more likely to report stronger social support networks (Jones \& Moses, 1984), were less likely to move often in adulthood, be divorced, live alone, or be a single parent, reported higher levels of satisfaction with their income and had high levels of optimism regarding their economic futures (Festinger, 1983), and were more likely to be self-assessed and assessed by interviewers as satisfied with their lives overall (Festinger, 1983; Jones \& Moses, 1984). However, the authors noted that they did not control for the nature of problems children had when they entered foster care or for experiencing emotional, physical, or cognitive disabilities which may have accounted for these findings.

Residing with youth who are exhibiting high levels of externalizing behaviors in placements such as group homes and residential treatment centers can lead to an increase in externalizing behaviors of other youth in those placements (Lee \& Thompson, 2008). Ryan, Marshall, Hertz and Hernandez (2008) examined a sample of youth with no prior 
arrests to investigate the effects of group care versus other types of foster care placements utilizing propensity score matching on the following characteristics: age at first placement, race, gender, total placement changes, placement changes related to running away, placement changes related to child behavioral problems, and physical abuse as the primary reason for placement. It was found that youth in group homes experienced a significantly higher rate of arrest during their stay in foster care than those in other foster care settings. The authors hypothesize that these differences may be likely due to peer contagion in group care and that group care staff may have a lower threshold for behavioral noncompliance than foster parents or kin caregivers that may increase communication with law enforcement. Additionally, youth and children residing in group care as a foster care placement and who participated in the National Survey of Children and Adolescent Well-being (NSCAW, 2002) reported significantly higher dislike for the people with whom they were living compared with youth in kinship or non-relative foster placements. Youth in group care have also been found to be more likely to have visits with others cancelled more often (Chapman, Wall, \& Barth, 2004) and were less likely to visit with their birth family than youth in other types of foster settings, a finding that is particularly disturbing due to the known protective capacities that birth family visitation has for the adjustment of young people while in foster care (Berrick, Courtney \& Barth; 1993; Dubowitz, 1990).

There is also evidence that restrictive settings further limit youth in foster care educationally. In a sample of younger children in foster care aged 6-12, those residing in group care were 3 times more likely to repeat a grade in school than children in kin care 
or non-relative foster care (Zima, Bussing, Freeman, Yang, Belin \& Forness, 2000). Similarly, school aged children in group care have been shown to have lower school attendance than youth in other placement settings (Conger \& Rebeck, 2001). Residing in a psychiatric institution and having a lack of progress in treatment or receiving poor services has been also associated with failing in school (Fanshel et al., 1990; McMillen \& Tucker, 1999). Smith (2011) suggests that youth in restrictive settings face poorer educational outcomes due to insufficient educational services, and that low attendance rates combined with psychiatric disabilities may make learning difficult.

Alternatively, Metzger (2008) found that youth and children in kinship care, a placement type which is theorized as one of the least restrictive types of placements in foster care, exhibited higher levels of self-concept and other attributes that can be linked with resiliency when compared with youth residing in non-relative foster care. Dworsky and Courtney (2001) also found a positive association with kinship care and employment rates for young adults after exiting care compared with other placement types. Additionally, youth in non-relative foster care placements were more likely to be employed after exiting care than youth in group homes or institutions. Mech \& Fung (1999) found that among emancipated youth, those who had resided in least restrictive placement types were twice as likely to enroll in secondary education as compared to peers who had resided in highly restrictive placements. Conger and Rebeck (2001) also found a link between educational outcomes and kinship care for school aged children in foster care. Youth in kinship placements had higher rates of attendance than other placement types, a factor that was associated with stronger math and reading test 
performance.

Nevertheless, there is some mixed evidence in the literature around the benefit of least restrictive placement settings for transition-aged youth. Research that included older youth in care found non-relative foster care and kinship care placements to be similar for youth in terms of their perceptions of their independent living skill level and readiness for independent living, as well as their employment rates (Iglehart, 1995). Research on young adult outcomes for youth who have exited care also found no differences for youth who resided in kin placements or non-relative care in education, employment, physical and mental health, risk-taking behaviors, and life stressors and supports (Benedict, Zuravin \& Stallings, 1996). It is important to note that both studies examining transitionrelated outcomes excluded youth in group care or residential treatment thus little is known how youth outcomes in these studies might differ for this group in restrictive placement settings. Additionally, surveys of youth revealed that living in one's own apartment, the least restrictive of settings, was related to increased life skills-knowledge (Mech, Ludy-Dobson, \& Hulseman, 1994). Nevertheless, some risk remains for youth residing in a foster placement without a caregiver and it has been found that youth in foster care residing independently have an elevated risk of substance-use compared with youth in other placement types (Vaughn, Ollie, McMillen, Scott, \& Munson, 2007; Keller, Blakeslee, Lemon and Courtney (2010). Further, the literature that links restrictive placement types with outcomes for young people not in child welfare foster care but in out of home-care for the purposes of receiving mental health services also points to mixed evidence in terms of positive and negative outcomes (Fields \& Ogle, 2002; 
Peterson, Zabel, Smith \& White, 1983; Hundert, Cassie, Johnson, 1988; Dore, Wilkinson \& Sonis, 1992; Friman, Evans, Larzelere, Williams, \& Daly 1993; Friman, Soper, Thompson, \& Daly,1993; Zimet, Farley, \& Zimet, 1994; Handwerk, Friman, Mott, \& Stairs, 1998).

Demographic factors related to placement restrictiveness. Older age of youth in care is a strong predictor of placement within a restrictive setting. National statistics show that for youth who enter care under the age of $12,75 \%$ are placed with kin caregivers or non-relative foster families. However, for children who enter care at 12 years of age and older, restrictive placement types become more dominantly utilized. For youth who enter care at age $16,42 \%$ resided in group care while only $12 \%$ resided in a kinship placement setting (Wulczyn \& Brunner Hislop, 2001). The Midwest evaluation of youth exiting care found that nearly two-thirds of their sample had resided in a group home or institutional setting at least once during their time in foster care (Courtney, Terao, \& Bost, 2004). Further, Lyons and colleagues (1998) findings around the prevalent use of residential treatment for young people who did not exhibit the level of need necessary to warrant residing in a restrictive setting showed that older youth in particular had an elevated risk of being inappropriately placed in restrictive settings absent of any behaviors present that would indicate a need for this setting. Interestingly, there is evidence that an association exists between older age, being a youth of color and not experiencing a disability, and an increased likelihood of a kinship placement (Beeman, Kim \& Bullerdick, 2000; Slayter \& Springer, 2011; Schmidt et. al, 2013). AfricanAmerican children in particular are two times more likely to be placed in a kinship 
placement than White youth (Hill, 2004; Harris \& Skyles, 2008).

Sex is also an important demographic to examine when exploring restrictive placement settings. James et al (2006) found that males are more likely than females to be placed in restrictive settings. Males are also more likely to experience a disability than females (Oswald et al, 2003; Valdes, Williamson \& Wagner, 1990) and are overrepresented in the special education system (Coutinho \& Oswald, 2005). Schmidt et al. (2013) found that White males who were in special education, compared with females, youth of color and youth not in special education, were most at risk for residing in specialized restrictive care placements and reported higher levels of perceptions of restricted access to movement around their home, access to the community, and access to the telephone and internet. Receiving developmental disability services (DD) was an even stronger predictor of restrictive placement settings and perceptions of high levels of restrictiveness than just receiving special education services alone. Additionally, youth in DD certified homes reported significantly higher levels of restricted access to the community than youth in other types of restrictive care such as group homes, residential treatment, and therapeutic foster care (Schmidt et al., 2013).

While being a youth of color may provide some protection around being placed in kinship placements more often and restrictive placements less often, African-American children in particular still face some additional barriers while in the system which make placement a complex issue. African-American children are more likely to stay in care longer (Barth, 2005) and are less likely to be reunified with their biological family than White children involved with the child welfare system (Hill, 2005). Because older age is 
a predictor of residing in restrictive placements, longer length of time in care elevates the risk of African-American children residing in these types of placements as they become older (James et al., 2006). Additionally, African-American youth are disproportionally represented in special education within disability eligibility categories of intellectual disabilities (Losen \& Orfield, 2002) and emotional/behavioral disorders (Fierros \& Conroy, 2002). As previously discussed, having a psychiatric disability, behavioral health need, or developmental disability also elevates the risk of being placed in a restrictive placement setting (James et al., 2004; James et al., 2006). Finally, while the majority of youth residing in restrictive placement settings are White (Schmidt et al, 2013; Curtis, Alexander, \& Lunghofer, 2001), several studies have found that youth of color are disproportionately represented in these placement types compared with the general population (Ryan et al., 2008; Berrick, Courtney, \& Barth, 1993).

\section{Important Additional Foster Care Experiences}

Length of Time in Care. The length of time one spends in foster care may have important implications for one's adult outcomes after exiting care, yet little research exists that examines length of time in care in association with youth or young adult outcomes. Wulczyn and Brunner Hislop (2001) analyzed the discharge pathways longitudinally for foster youth beginning at age 16 in 12 different states $(n=119,011)$. They found that only $10 \%$ of older youth in care had entered foster care at or before the age of 12 and that the majority had entered foster care since turning 15 . Thus, the majority of youth aging out of care did not spend their entire childhood in foster care. Courtney (2009) surmises that because many older youth exiting care have spent more of 
their childhood facing abuse and neglect before coming into foster care, the difficulties that these young people face entering adulthood may be largely associated with having lived longer with child abuse and neglect prior to the child welfare system intervening; however little exists in the literature to support this hypothesis. For instance, Reilly (2001, 2003) found different findings when surveying 100 young adults who had exited care in Nevada. The participants in this sample had a mean age of 9.3 at time of entrance into care and a mean length of time in care of 8.3 years.

Placement Instability. Placement instability has long been associated with negative outcomes for youth (Pecora et al, 2005; Taussig, Clyman, \& Landsverk, 2001; Johnson-Reed \& Barth, 2000) and is a common experience for youth with emotional and behavioral disabilities (James, Lansverk \& Slymen, 2004). Half of the young people involved in the Nevada study reported having moved at least 5 times while in care with responses ranging up to 50 placements while in care, indicating placement instability occurred commonly for many of these young adults while they were in care (Reilly, 2001). Thus, more exploration is needed around the association of foster care experiences, such as length of time in care and its relationship to placement instability, with outcomes for transition aged youth exiting care before conclusion are drawn about any protective capacity foster care may provide for youth in terms of young adult outcomes.

\section{Self-Determination}

An evaluation of an intervention designed to enhance the self-determination of youth with disabilities in foster care found significantly higher quality of life, transition 
planning engagement, and utilization of community transition services and higher education completion, employment rates, and engagement in independent living activities compared with the control group (Powers et al, 2012). Further, there is some evidence to support self-determination as a mediator of key outcomes for transition-aged youth who experience disabilities in foster care (Powers et al, 2012; Geenen et al, 2013).

Studies that examine outcomes for adolescents who experience disabilities have shown that increased self-determination is positively associated with improved quality of life (Wehmeyer \& Schwartz, 1998), improved employment outcomes and greater independence (Wehmeyer \& Palmer, 2003; Wehmeyer \& Schwartz, 1997). Enhanced self-determination has also been associated with improved quality of life (Lachapelle et al., 2005; Nota, Ferrari, Soresi, \& Wehmeyer, 2007), employment (Fornes, Rocco, \& Rosenberg, 2008; Wehmeyer \& Palmer, 2003), and independence (Wehmeyer \& Palmer, 2003) for adults who experience disabilities, as well as an increase in overall physical and psychological health and well-being (Johnson \& Krueger, 2005). This research also points to the association of one's home environment with expressions of selfdetermination. Studies have shown decreased expressions of self-determination for adults with intellectual and developmental disabilities who reside in congregate care or group homes where rules may restrict the choices adults are given (Heller, Miller \& Hsieh, 2002). Conversely, adults who experience intellectual and developmental disabilities and are living semi-independently have shown greater expressions of self-determination (Stancliffe, Abery, \& Smith, 2000).

Important Synopsis. Taken together, the literature presented here illustrates the 
difficulties that many youth face aging out of the child welfare system into adulthood. While literature has established that youth with disabilities face many barriers entering adulthood, only a few studies exist that provide evidence that youth in foster care who experience disabilities face exponential risk entering adulthood after being in the foster care system. Further, little is known about how experiences in foster care, such as placement setting, length of time in care, or placement instability while in foster care, may impact youth as they age out of the system. While some literature has begun to address outcomes comparing youth in non-relative care and kinship placements, no literature exists that describes how youth in restrictive placement settings may differ on transition preparation, such as education, employment, daily life skills engagement, transition planning, participation in ILP, and self-determination compared with youth in other placement types. Finally, it is has been established that restrictive placement settings may limit opportunities for developing independent living skills, access to engaging in one's community, and building strong support networks, all of which are pertinent for a successful transition to adulthood. With the high propensity of older youth, particularly those who experience disabilities, to reside in restrictive placement settings in adolescence, it is particularly important that we begin to understand the ways in which placement settings and the perceptions of youth around restrictiveness in their lives may in fact influence the poor transition outcomes found for youth aging out of care. 


\section{Chapter 3: Theoretical Perspectives}

\section{Ecological Systems Theory}

To understand the impact of environmental variables on the trajectory of independent living for youth aging out of foster care, Bronfenbrenner's Ecological Systems Theory (1974) is a beneficial perspective to examine. As a youth prepares for independent living, there are multiple levels of interconnected factors that influence the development of that young person within the context of residing in foster care. According to Bronfenbrenner, there are five levels of environmental factors nested within one another: 1) the first level (micro) encompass the youth's immediate environment, such as the home they reside in, 2) the second level (meso) represents the interaction of any two micro systems, 3) the third level (exo) are factors that affect the youth indirectly by affecting the micro systems of the youth, 4) the fourth level (macro) includes broader cultural and societal factors that the youth may not have direct contact with that nonetheless impact the youth, such as policy and 5) the last level (chrono), relates to the degree of stability or change one experiences over their life span and major life transitions that occur.

Microsystem. The most salient microsystem to examine in the context of this research is one's type of foster home and relationship with one's caregiver(s), the context that most directly impacts a youth's development. By examining categories of placement type, this work allows an examination of the different experiences youth may have within the context of residing in foster care. Different types of placements may allow for different structures, roles, and relationship bonds with caregivers. A kinship placement 
may provide more stability over one's lifetime, a closer bond to a caregiver, more access to one's community and support network. Conversely, youth in restrictive placement types may move frequently, have less security about housing when they have aged out of care, may have a difficult time developing secure bonds with numerous staff people with high rates of turnover in facilities such as group homes or institutional settings, and have less access to one's community and communication technology such as internet and telephone.

Mesosystem. Interactions amongst microsystems comprise the mesosytem in Ecological Systems Theory. For youth aging out of foster care, the primary microsystems of importance in this study, placement type and relationship with caregiver(s), interact with nearly all other systems involved in the youth's life, including school, peer groups, neighborhood or community involvement. Thus, a youth in a less restrictive placement setting may experience attending school in a community setting, a caring adult who serves as an academic advocate, participation in after-school events and clubs with peers, greater access to phone and internet use to stay in touch with peers and those in one's support network, greater access to engage in one's neighborhood thus creating more opportunities for networking and enhanced proficiency navigating one's community, and be allowed to be in the community independently to obtain employment and practice life skills. Those youth in more restrictive placement settings may have few opportunities for interactions amongst microsystems that allow for self-determined action, independent skill engagement, and access to the community and social support due to the structures and relationship prescribed by these environments. 
Exosystem. The exosystem involves a link between a setting that does not directly impact the youth and the youth's immediate environment. Perhaps most salient in this context is the mandate of local child welfare agencies that license foster homes and institutions and provide the policies and rules that dictate what a foster caregiver is permitted to allow of a youth in their care. Licensing standards for more restrictive placement settings provide a great deal of structure and restriction around the freedom a youth may experience to interact in the community, take self-determined action, and build networks of support in the name of providing a safe environment for youth who have been deemed to have a greater level of need than youth in kinship and non-relative placements. Additionally, agency practices that defer equitable financial support to kinship caregivers and lack the training and support to promote kinship care for youth with disabilities and mental health conditions also impact the restrictiveness a youth faces because lower levels of care are not adequately supported to provide for the needs of these youth.

Macrosystem. The macrosytem brings into context cultural beliefs and ideologies within the larger environmental context. The child welfare system as a structure of broader society was not intended as a mechanism to successfully raise children into adulthood. While federal policy and child welfare practice have created long-term foster care as a plan of permanency for young people reaching the age of transitioning, licensing standards and regulations do not change to accommodate the needs of older youth over longer periods of time. Without a shift in the larger child welfare policy, agencies are left to operate with mandates created for young children and intended for 
short periods of a child's life. These inconsistencies do not match society's expectations for age-appropriate experiences for adolescents and young-adults to develop skills for self-sufficiency and enter adulthood incrementally with a great deal of social support. This is especially true for young people with disabilities, who are most often placed in restrictive placement and will need more opportunities to practice these skills and greater levels of social support to prepare for the additional challenges related to experiencing a disability that lay ahead in adulthood.

Chronosystem. The chronosystem reflects the major life transitions or sociohistorical contexts of the system. For youth aging out of care, the move out of foster care and into adulthood is that defining life transition. For many youth aging out of care, particularly those not in kinship placements, the young person's environment shifts to necessitate true self-sufficiency with a limited network of support. For youth aging out of restrictive placements, this shift from highly controlled adolescence to full independence and self-reliance as a young adult may be the most drastic life transition they may experience. With this transition, many of the different levels of systems that youth interacted with or were impacted by no longer act as a part of the young person's environment. Leaving foster care generally signifies a shift in housing and the loss of a multitude of paid professionals and agencies in that person's life who may have provided support or guidance. Young adults may also be leaving the school system, their neighborhoods, the family they have most recently resided with and all of the rules, regulations, and services, supportive or prohibitive that come with being involved with the child welfare system. 


\section{'Restrictive' Parenting and Adolescent Development}

While there are multiple levels of environmental factors that contribute to a youth's success or present as barriers, research on parenting styles emphasize the importance of the microsystem, more specifically one's home life and connection to one's caregiver, in shaping the trajectory of adolescent behavior and development. One's home life as a young person and the caregiver relationship are critical influences on the developmental process of a young person in that these relationships affect the young person in their daily life and shape their interactions with other systems. Research has shown that overall life satisfaction for adolescents is more strongly tied to positive relationships with caregivers than peer relationships or the impact of one's educational setting (Dew \& Huebner, 1994; Leung \& Leung, 1992; Leung \& Zhang, 2000). Much like the three categorizations of foster care placement types represented in this work which conceptually offer a continuum of levels of support, autonomy, and opportunities for self-direction for young people, the field of child development offers three important categorizations of parenting styles most commonly observed in interactions with caregivers and their children on a similar continuum: authoritative, authoritarian and permissive parenting styles (Baumrind, 1967).

Authoritarian parenting describes a process whereby caregivers control and evaluate children's behavior within a rigid, absolute standard usually based on the needs of the adult caregiver. This style focuses on the caregiver as the authority figure with little give and take between the child and caregiver. This type of parenting focuses on firm enforcement of rules and standards, utilization of both psychological and behavioral 
control, and low levels of responsiveness to the individual needs of the child. Permissive parenting, on the other end of the spectrum, offers warm, responsive parenting with high levels of autonomy granted to children. These parents consult with their children and do not utilize overt power over the child, punishment, or attempt to regulate the behavior of their children. Authoritative parenting, falling in the middle of the continuum of parenting styles, offers both opportunities for parental structure and autonomy of the child. These parents are consistently supportive and loving, have give and take between the parent and child, and yet also impose expectations and set standards. These parents may set firm rules but are aware not to over restrict a child's behavior (Baumrind, 1991).

There is much research to support that authoritative parenting is the optimal parenting style for positive outcomes in adolescent development across a variety of domains including academic engagement and success (Steinberg, Lamborn, Dornbusch, and Darling, 1992), low levels of substance use (Baumrind, 1991), low levels of depression (Simons \& Conger, 2007), high levels of self-esteem and life-satisfaction (Suldo \& Huebner, 2004; Milevsky, Schlechter, Klem, and Kehl, 2008), high levels of competence, achievement, and social development (Maccoby \& Martin, 1983), and high levels of overall quality of life (Petito \& Cummins, 2000). Increased psychological autonomy granted by parents' decreases internalizing difficulties while increasing selfreliance and self-esteem in adolescents (Gary \& Steinberg, 1999). Additionally, parental warmth and nurturing serves as a strong protective factor for adolescents who face adversity (Roche, Ensminger, and Cherlin, 2007). Parental warmth has been correlated with higher levels of self-esteem, a reduction in externalizing behaviors over time, and a 
significantly reduced use of alcohol and substance use (Barnes, Hoffman, Welte, Farell, and Dintcheff, 2006; Barnow, Schuckit, Lucht, John and Freyberger, 2002).

Conversely, there is research to support the harmful effects of power-assertive, restrictive parenting found in the authoritarian style of parenting. For example, adolescents in White authoritarian families have been found to experience high levels of depression, low levels of social skills, and low self-esteem (Milevsky, Schlechter, Netter, and Keehn, 2007). Dornbusch, Ritter, Leiderman, Roberts, and Fraleigh (1987) found a negative association with adolescent school performance and authoritarian parenting, while Curtner-Smith and MacKinnon-Lewis (1994) found that adolescents with authoritarian mothers had higher levels of susceptibility to antisocial peer pressure. However, there is a limitation to this research's applicability to this study as previous studies have shown that being a person of color may serve as a protective factor when faced with authoritarian parenting styles and the negative outcomes associated with this type of parenting (Murry, Bynum, Brody \& Willert, 2001; Simons, Simons, \& Wallace, 2004; Parke and Buriel, 2006; Mason, Walker-Barnes, Tu, Simons, \& Martinez-Arrue, 2004). Nevertheless, this research is applicable due to White males with disabilities facing the highest level of restrictive placement settings and reporting the highest rate of perceived restriction in this sample (Schmidt et al, 2013).

The authoritarian type of parenting style can be most closely tied to the types of experiences youth in restrictive placements have with caregivers and rules in their placements. While there may certainly be a range of parenting styles found within each individual placement, the rules and licensing regulations of restrictive placement settings 
often impose authoritarian style rules and regulations on the young people living in these homes and ask the caregivers in charge to align their practices around these rules and regulations. For example, there is often little individuation on rules and regulations in restrictive settings that allow for adapting to the individual youth's needs. Rules are often set as an absolute authority by licensing agencies and are often enforced by strict behavioral and psychological enforcement such as the use of behavior charts to earn one's privileges or the loss of rights such as visitation with a family member or mentor or access to going out in the community. Further, agencies and licensing standards may impact the closeness and warmth that a youth feels with their caregiver. For instance, group home and other institutional placements often have a great deal of different staff caring for youth over the course of their week with high turnover rates. Staff are often given expectations to maintain strict boundaries around the relationship they hold with the youth. This expectation can also been seen in more family-like restrictive settings like DD homes and therapeutic foster homes where agencies emphasize foster parents in the role of service provider rather than parental figure. The stress foster parents and staff feel enforcing such strict rules may also further impact their ability to connect with a young person and provide warmth. Pecora et al. (2005) surveyed former foster youth around parenting styles of their former foster parents and found only $27.4 \%$ reported having authoritative parenting styles while the remaining reported styles included authoritarian, disengaged, permissive or 'other' parenting styles; however, the researchers did not examine these findings in context with type of placement the young person had been residing. 
Baumraund's parenting styles framework has also been found to be useful for examining the relationship students have with teachers in educational settings. In a study examining the paramount characteristics of authoritative parenting style with middle school teachers and students, Wentzel (2002) found that high expectations from teachers was a positive predictor of student's goals and interests while lack of nurturance or negative feedback from teachers predicted poor social behavior and low academic achievement. There were no significant differences between males and female students or African-American or White students.

\section{Resiliency}

The large body of research that has been conducted around the development of resilience in young people extends the discussion of authoritarian parenting as a risk factor and authoritative parenting as a protective factor for adolescent development. Research across a diverse body of samples of children and adolescents experiencing high levels of risk factors and exposure to adverse environments has shown that many young people will go on to become resilient, healthy, well-functioning adults (Rutter, 1985; Rutter, 2006; McGloin \& Widom, 2001; Werner \& Smith, 2001; Yates \& Grey, 2012). Benard (1991) proposes a synthesized model of this research on the development of resilience in children and youth that is rooted in Bronfenbrenner's Ecological System's Theory (1974). Benrad's model proposes characteristics of resilience across multiple systems level that have been commonly found across studies on the development of resiliency in children and adolescents. These common protective characteristics and factors are found at the individual level of the young person, within the family system, 
within the educational setting, and finally, at the community level.

At the individual level, Bernad identified four common protective factors that create the profile of resilient children: social competence, problem-solving skills, autonomy, and a sense of purpose and future. Social competence describes characteristics such as being flexible, having empathy for others, strong prosocial skills, a sense of humor, and strong communication skills. Problem-solving skills are a constellation of skills including thinking abstractly, being reflective about oneself and environment, and being able to apply multiple solutions to a given problem. Autonomy, is defined as believing in one's own sense of power or having an inherent sense of independence, and self-efficacy or self-determination. Finally, a sense of purpose and future is comprised of having expectations for oneself, being goal-directed, having hope and persistence, and a sense of a bright future.

Much like the characteristics of authoritative parenting, a family that provides protective factors to a young person provides a caregiver or at least one adult figure who is caring, warm, and supportive. Feldman, Stiffman, and Jung (1987) found that the relationship a child has with their caregiver is the best predictor of their overall outcomes and having at least one warm and affectionate parent is correlated with adult outcomes around social accomplishments and overall contentment (Franz, McClelland, and Weinberger, 1991). Families of resilient young people also provide high expectations for their children, maintaining an attitude of potential and growth for their child and believing that the child is capable of achieving success. Simultaneously, the family offers opportunities for the autonomous action of the young person, values the young person as 
an individual able to fully participate in family life, and invites him or her to contribute to the family and home in meaningful ways.

Like the familial characteristics of resilient young people, both the school setting and broader community also provide opportunities for acting as salient protective factors (Bernard, 1991; Gilligan, 2000; Bond, Toumbourou, Thomas, Catalano, \& Patton, 2005). School environments that promote resiliency provide a caring and supportive adult, provide high expectations for all young people and the necessary supports needed to reach those expectations, and provide opportunities for youth involvement, promotion of responsibility, and the assertion of power and control over one's own life. Likewise, protective communities promote opportunities for building strong support networks of both peers and intergenerational relationships, place value on youth as strong contributors to the community, and create opportunities for young people to participate in the community in meaningful ways.

Young people in restrictive foster placements may experience greater barriers around access to protective factors at all levels compared with youth in other settings. As outlined in the discussion of important parenting factors, the systems that create licensing standards emphasize safety over autonomy development and professional boundaries in relationships with those in caregiver roles. This restricts many of the opportunities for protective capacity building that family life may afford young people in foster care. Additionally, youth in restrictive foster placement settings experience a high rate of disability and many receive special education services at school. For many of these youth, being placed in restrictive educational settings also limits the opportunities for 
autonomy, youth direction, and meaningful participation in school settings. Finally, youth in restrictive foster placements report experiencing greater restriction to the phone and internet, forms of technology critical to staying in touch with allies and building connections with others to form support networks, and more restriction around access to the community (Schmidt et al., 2013). While resilience research offers hope for a trajectory of success despite life obstacles, the placement types these youth experience may provide barriers to many of the protective factors found in the research on resiliency. Macro level changes to policy and practice in child welfare as previously described are necessary to create a shift for youth in restrictive foster placements towards promoting the experience of higher levels of protective factors within these young people's environments.

\section{Social-Ecological Self-Determination Theory}

Self-determination is an important construct to examine in the context of aging out of foster care. Self-determination, as defined by Abery and Stancliffe (1996) is "a complex process, the ultimate goal of which is to achieve the level of personal control over one's life that an individual desires within those areas the individual perceives as important" (p. 27). This definition of self-determination aligns closely with the way independent living, self-sufficiency, and adulthood are defined in our culture in the United States. To be recognized as a self-sufficient adult, one must be able to independently define what he or she wants his or her life to look like and how much support he or she desires in achieving goals that are most important to him or her. Selfdetermination is a key facilitator of the development of autonomy and is interwoven with 
self-identity, the way others view you, and overall quality of life of an individual (Abery, 1994). While the expression of self-determination is focused on the individual, the development of this process is deeply rooted in a systems perspective.

One of the strongest predictors of high levels of self-determination is being provided opportunities to take control of one's own life (Abery, 2001; Abery, McGrew \& Smith, 1994), a process that is often fraught with barriers for youth in foster care and particularly for those residing in restrictive placement settings. At the micro-level, the family, school environment and peer group are the most integral facilitators of these opportunities. Additional factors that may contribute or become barriers to selfdetermination at the micro level are the fulfillment of ones' basic needs, respect and acceptance, positive reinforcement for exercising self-determination, participation and inclusion, availability of role models, and individualized services and supports. Recent findings from an evaluation of group home staff interactions with young people in care found a higher percentage of overall interactions with young people were negative than positive calling into question the access young people have in restrictive placements to these self-determination promoting opportunities. These negative interactions included staff questioning, arguing, using sarcasm, force, threats, criticism, despair, logic, telling on them to others, taking away privileges, items, allowances, one-upsmanship, and silent treatment or otherwise causing harm to the child (Crosland et al., 2008).

At the meso-level, self-determination can be bolstered or hindered by the level of interconnectedness of the family system with other agencies supporting young people, the collaboration of service providers within an agency, and the collaboration of different 
agencies providing services to young people. Within the exo-system, agencies that provide services to young people must also practice inclusion and participation of young people in service conceptualization and provide training opportunities to staff to promote self-determination of young people and support attitudinal changes held by staff around the importance of promoting such self-determined behavior (Abery \& Stancliffe, 2003). Certainly the documented lack of coordination around transition planning for youth with disabilities in care (Geenen \& Powers, 2006) and the overall lack of inclusion of voices from young people in child welfare proceedings (Krinsky \& Rodriguez, 2005) point to additional barriers at the meso and exo system levels in the promotion of selfdetermination of youth in foster care.

\section{Important Synopsis}

This dissertation will begin to explore how the transition preparation of youth with disabilities in foster care about to age out into adulthood may differ from their peers in foster care including perceptions of readiness for adulthood, education and postsecondary skill engagement, employment and career development skill engagement, daily life skill engagement, transition planning engagement, ILP participation, and selfdetermination. Additionally, this work will examine how placement type and restrictiveness may further impact the engagement of transition preparation for young people in foster care. Since youth with disabilities are often placed in restrictive placement settings because of the disability-related challenges they experience, it is integral to understand how these settings that aim to meet the safety needs of these youth may in fact be denying youth the experiences and opportunities they need to successfully 
enter adulthood. Further, it is known that having a disability adds additional challenges to the transition to adulthood. Thus, it is this very group of youth who need more opportunities for developing independence and building support networks compared with youth without disabilities exiting care, and yet the child welfare system is currently designed in a way that oppresses the very group most at risk during this transition. Therefore, this work will provide a much needed exploration of the experiences of transition-aged youth in care and the implications of restrictiveness. This work will also help shed light on whether restrictiveness may impede youth in the preparation for the transition to adulthood and thus account for some of the negative outcomes young adults experience after leaving care.

The proposed model below explores the impact of disability and restrictiveness, defined as a) placement setting and b) youth perceptions of restrictiveness on transition preparation engagement in the following domains: 1) perception of preparedness for adult life, 2) employment and career preparation activities, 3) post-secondary preparation activities, 4) daily life preparation activities, 5) transition planning engagement, 6) ILP participation, and 7) self-determination. While not explored in this dissertation, the model theorizes transition preparation engagement while in foster care will directly predict young adult outcomes once youth exit care. 


\section{Model}

Figure 1: Association of experiencing disability with transition preparation for youth exiting care.

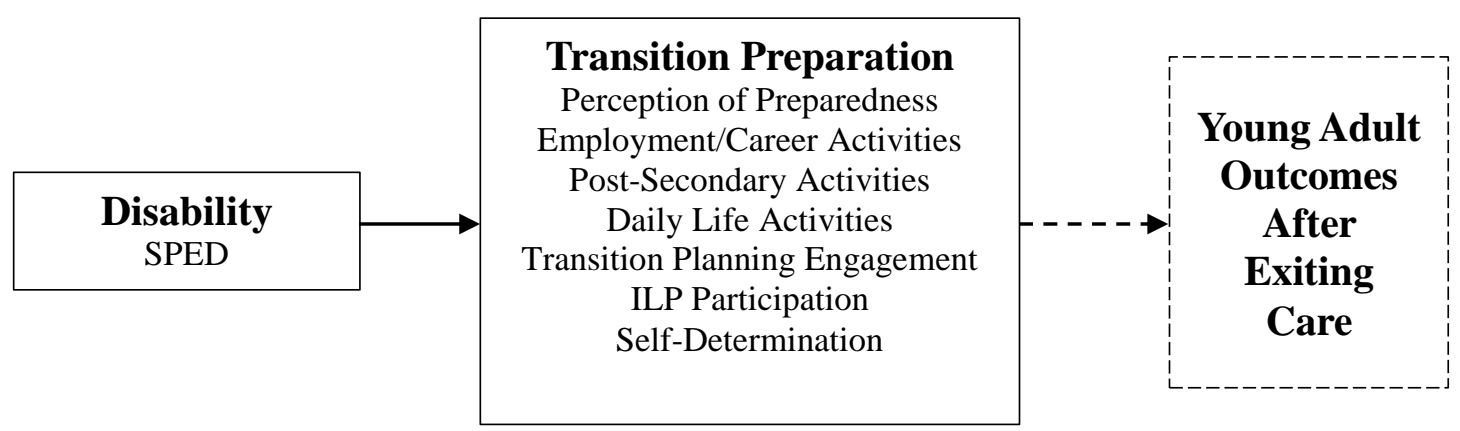

Figure 2: Association of restrictiveness (placement type and youth perceptions of restrictiveness) with transition preparation for youth exiting care.

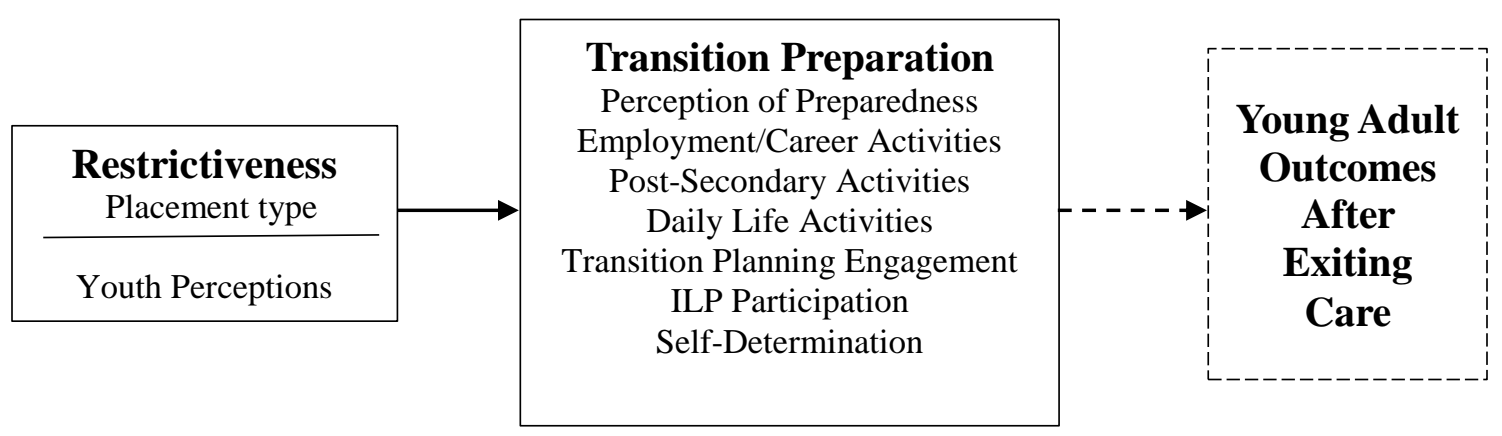




\section{Research Questions and Hypotheses}

Question 1: Are youth in restrictive placement settings more likely to experience a disability than youth in kinship or non-relative foster care settings?

$\mathrm{H}_{1}$ : Youth who live in a restrictive placement setting will be more likely to experience a disability than youth in other placement settings.

Question 2: Do transition-aged youth with and without disabilities differ in transition preparation engagement for adulthood as defined by: 1) perceptions of readiness for adulthood, 2) post-secondary activity engagement and employment, 3) career preparation activity engagement, 4) daily life activity engagement, 5) transition planning engagement, 6) ILP participation, and 7) self-determination?

$\mathrm{H}_{1}$ : Youth with disabilities will report lower levels of readiness for adulthood, be engaged in fewer post-secondary activities, be employed less often, be engaged in fewer career development activities, be engaged in fewer daily life preparation activities, participate in Independent Living Program services less often, have lower levels of transition planning engagement, and lower levels of self-determination than youth without disabilities.

Question 3: Does restrictiveness, as defined by placement in a restrictive setting, have a negative association with youths' transition preparation? 
$\mathrm{H}_{1}$ : Residing in a restrictive placement will have a significant negative association with youths' transition preparation.

Question 4: Does restrictiveness, as defined by youth self-report of restrictiveness, have a negative association with youths' transition preparation?

$\mathrm{H}_{1}$ : Reporting higher levels of youth perceptions of restrictiveness will have a significant negative association with youths' transition preparation. 


\section{Chapter 4: Methods}

\section{Research Design}

This dissertation study is a secondary cross-sectional analysis that utilized baseline data from an experimental longitudinal evaluation of the My Life intervention. The My Life project is a full-scale randomized controlled trial (RCT) conducted to evaluate the efficacy of a coaching intervention designed to enhance self-determination for youth aging out of foster care. It is hypothesized in the My Life project that selfdetermination is a significant mediator of young adult outcomes for youth exiting care including but not limited to career success, education attainment, housing stability, selfsufficiency, and access to social support and resources. The study is being conducted at Portland State University at the Regional Research Institute. While the My Life evaluation employs a longitudinal design, the cross-sectional analysis utilized in this study examined baseline data around transition preparation for youth with disabilities, for youth residing in restrictive placement settings, and for youth who reported high levels of perceived restrictiveness. Disability status (defined as receiving special education services, SPED), placement type and youth perceptions of restrictiveness will be used to predict engagement in transition preparation engagement along 7 domains: 1) perceptions of readiness for adulthood, 2) post-secondary preparation activities, 3) employment and career preparation activities, 4) daily life preparation activities, 5) transition planning engagement, 6) ILP participation, and 7) self-determination. Control variables in the analysis will include key demographics and foster care experiences. Demographic variables will include age, gender, and race. Additionally, key foster care experiences will 
include the length of time in care and placement instability, as represented by number of foster placements during their last episode in care.

Although this dissertation focuses on exploring baseline data only, the overall model proposes that the transition preparation engagement indicators included in this study will predict key young adult outcomes after youth have exited care, for example, education, employment, housing, economic sustainability, and overall well-being. Phase two in validating the model's ability to predict young adult outcomes will be completed in a separate study once all follow-along data has been collected for the My Life participants.

Sample. The participants are from a population-based sample of youth in foster care who were recruited as a part of the evaluation of the My Life intervention. All recruited youth were between the ages of 16.5 and 18.5 and under the guardianship of child welfare for at least 90 days, and were within the Portland, Oregon Metro area. Youth who were adopted, had a voluntary case with DHS, or were under the guardianship of a caregiver rather than the child welfare agency were not included in this study. All youth who fit the criteria for age, guardianship under the child welfare system and within the identified geographic location were invited to participate. If a caseworker, caregiver, or staff person informed the researchers that a youth was not permitted to leave their residence under the supervision of a My Life coach, generally due to a high level of restricted access to the community for some youth in restrictive placement settings, they were also not included in the sample of My Life participants. This exclusion was in place because these youth would have been unable to partake in key experiential activities in 
the community that were part of the intervention curriculum. In restrictive placement settings, there is generally a range of restrictions that vary by individual youth within any given setting. While this exclusion criterion did effect the specific population of youth who are the main focus of this study, youth in restrictive placement settings, this exclusion was rare and one-third of the final sample includes youth in restrictive placement settings. Approximately ten youth who were approached to participate were excluded for this reason. Thus, rather than eliminating all youth placed in restrictive settings, this criteria excluded only a very small sub-sample of youth in restrictive placement settings.

Frequencies were run to determine the total $\mathrm{N}$ for all the independent and dependent variables being utilized in this study. For the purposes of this study, two youth who participated in My Life and were listed as on the run and not residing in an identified foster placement at baseline were excluded from this study. In addition, 13 youth who were missing an independent variable or missing three or more dependent variables were excluded from the sample. A total of 15 youth, or $4.8 \%$ of the My Life participants, were excluded from this study. Four youth did not list a race/ethnicity at baseline but rather than excluding them from the study, their race/ethnicity data was taken from time two assessments as all four youth responded to this item at time two. The final sample size for this dissertation is 294 youth.

Procedures. The local child welfare agency provided a list of youth who fit the above recruitment criteria including age, time in care, and geographical location. Youth and foster parents met in person with a child welfare representative to learn about the 
study, including possible benefits and risks, and signed assent was obtained from youth who chose to participate; $90 \%$ of the approximately 340 youth invited to the study assented to participate. Official consent was given by child welfare caseworkers in the role of guardian. The local school districts also provided information about youth involvement in special education services and the local Developmental Disability (DD) agency confirmed which youth participants also received DD services.

Youth were administered in-person assessments at baseline by trained assessors who were M.S.W., B.S.W., or Ph.D. students or were paid professionals. As part of their training, assessors received in-depth training around procedures for data collection by the Project Manager, observed an assessment being completed by a fully-trained assessor, and then were observed completing an assessment. Youth assessments were scheduled at the time of the in-person meeting when youth assented to be in the project. Each assessment took between 2 to 3 hours and was conducted in locations chosen by the youth participants based on where they felt most comfortable. Each survey instrument was reviewed by a trained staff person upon completion by the youth to ensure no items were unintentionally skipped and to review any answers that were unclear (ie: youth gave 2 responses for a question that directed the youth to choose one answer or handwriting was unclear for a qualitative response). Data was then entered into SPSS and cleaned by staff and interns trained and supervised by the Project Manager.

\section{Measures and Variables}

\section{Control Variables}

Age, Race and Gender. Information collected on gender and race was based on 
youth self-report collected at baseline during in-person structured interviews. Gender was defined as male or female. Three youth chose 'other' for gender but unfortunately, due to the low $\mathrm{N}$ for this category, were excluded from the overall sample. Race was recoded into White or Youth of color (Asian, Pacific Islander, bi-racial, African-American, Native-American, or Hispanic). Age was determined by confirming the youths' date of birth with official child welfare records.

Other Foster Care Factors. Length of time in care since one's most recent episode in foster care and placement instability as represented by number of placements while in care during one's most recent episode, were collected from official DHS records utilizing data that corresponded with the date youth completed their baseline assessment. Length of time in care was recorded in days from the last episode in foster care as a continuous variable. Placement instability was represented by the number of placements one had resided in since their last episode in care. The data collected by DHS for number of placement was recorded categorically: 1-2 placements, 3-4 placements, 5-7 placements, and 8 or more placements.

\section{Disability}

For the purposes of this study, disability was indicated by receipt of special education services (SPED). Official school records were gathered from the local school district. When a youth was identified as receiving SPED services, an IEP was requested from the school to gather the official disability code(s). All youth who were coded as receiving developmental disability (DD) services also received SPED services and as such, receiving SPED services is the proxy for experiencing a disability in this study. 


\section{Restrictiveness Variables}

Placement Type. Type of foster care placement was obtained through the local child welfare agency. Placement type was recoded into 3 categories: kinship care (which included trial reunification with parents), non-relative foster care, and restrictive placement setting (DD certified home, BRS mental health home, group home, residential treatment, independent living in a mental health licensed facility, or therapeutic foster care). Restrictive foster care included all placement types that require a specialized level of certification, offer more intensive levels of care, and are compensated at higher rates than ordinary. As previously noted, youth who were adopted, on the run, or were living independently at baseline are not represented in this study.

Youth Perceptions of Placement Restrictiveness. Indicators of youth perceptions of restrictiveness were drawn from Rautkis and colleagues' (2009) measure of restrictiveness. Five total items from the Restrictiveness Evaluation Measure for Youth (REM-Y; Rautkis, Huefner, O'Brien, Pecora, Doucette, \& Thompson, 2009) were selected as indicators of restrictiveness in the categories of communication with others, ability to move freely in the home, community participation, ability to visit with birth family, and access to employment. Rautkis et al (2009) reported strong reliability for the original 21-item REM-Y measure with an alpha value of .92. Hwang and Lee (2013) surveyed 40 youth and 37 caregivers and found strong agreement between youth and caregivers in rating the restrictiveness of the youth's environment. The five items were rated on a 5-point scale:1=I have no limits, $2=\mathrm{I}$ have a few rules, $3=\mathrm{I}$ have some rules, 4=I have very limited access, $5=\mathrm{I}$ am usually not allowed. These items were, "What best 
describes how much you are allowed to use the telephone or internet to communicate with others?"; "What best describes how much you are allowed to move around where you live?" "What best describes how much you are allowed to go out into the community?", "Are there restrictions on you seeing members of your birth family?" and “How much are you allowed to work?". A sum score was calculated for the 5 items above with a total possible range of $0-20$. For instances when a youth did not answer one of the five items, a mean score was calculated for the 4 items answered and a sum score was then calculated using the mean score in place of the $5^{\text {th }}$ item and adding it to the 4 given responses.

\section{Transition Preparation Variables}

Perceptions of Preparedness for Adult Life. Youth were asked to report their preparedness for adult life based on a 4-point scale. The single item asked, "How prepared do you feel for life as an adult? (Very prepared, somewhat prepared, somewhat unprepared, or very unprepared)".

Post-secondary Preparation Activities. The Postsecondary Preparation Questionnaire (Geenen et al., 2013) was developed for an earlier project, Project Success, and has been sensitive enough to indicate significant group differences for intervention and control youth in previous studies. Youth were asked to report on 11 post-secondary preparation activities (including the option to fill in 'other preparation activity for the last item) they have completed over the last 12 months including, "looked up information on colleges or vocational schools", "visited a college or vocational school", and "talked to a family member about going to college or vocational school". Alphas were run for this 
study on the 11 items and the measure was found to have high reliability $(\alpha=.818)$.

Employment. Current level of employment is represented by two items including: Are you currently working? (Yes, no)”. Youth also indicated their hourly wage if they responded 'yes' to working. For five youth who reported earning well below minimum wage (those in sheltered workshops for people with disabilities or in SPED transition programs) youth were recorded as not working to capture employment as those working in competitive wage earning positions. As will be discussed further in the discussion chapter, youth with disabilities are often given fewer opportunities to pursue opportunities related to work experiences related to their career interests or that would contribute to a young person's economic stability. Earning below minimum wage was conceptualized as a learning experience or paid internship rather than competitive employment.

Career Preparation Activities. The Career Development Preparation Questionnaire (Powers et al., 2012) asked youth to identify the activities they have engaged in within the last 12 months around career development. The measure includes 12 items, including an option to enter 'other career planning activity, describe' on the last item. Examples of activities asked are as follows: "talked to someone in a career that interests me", "filled out a job application", and "had a job interview". Youth checked all items that they had completed during the last 12 months only, indicating a 'yes' to the corresponding activity. This measure was developed for the My Life pilot and alphas were run for this study, indicating strong reliability $(\alpha=.718)$.

Daily Life Preparation Activities. The Independent Living Skills Questionnaire 
(Geenen et al., 2013) developed for Project Success, showed significant group differences between intervention and control youth. This measure includes 20 items and like the above questionnaires, allows for filling 'other' on the last item. The remaining 19 items include for example, "got my state I.D.”, “arranged for people to bring me housing references", "applied for health insurance", and "took public transportation". Youth answered 'yes' if they had completed an activity within the last 12 months. Alphas were also run for this measure for the purposes of this study and also indicated high reliability $(\alpha=.770)$.

Independent Living Program (ILP) Services. Involvement of youth in ILP was based upon youth self-report at baseline. Youth were asked whether they were currently enrolled in ILP services. Youth who had visited with an ILP caseworker or attended ILP classes within the last 90 days were coded as receiving ILP services.

Transition Planning Engagement. A modified version of The Transition Planning Assessment (Powers, Turner, Westwood, Matuszewski, Wilson, \& Phillips 2001) was used to measure youth engagement around transition planning within the child welfare system and the education system. The original measure included 14 items with a Likert scale set of responses. Examples of items include the following: "People ask about my opinions and ideas at meetings", "I help run my transition planning meetings" and "I understand everything decided at the meeting". This measure has been utilized in several studies evaluating the efficacy of the Take Charge curriculum utilized with similar populations (Powers et al., 2001; Powers et al., 2012). Utilizing exploratory factor analysis, a previouss study found two factors in the measure, youth understanding of 
transition planning (.83) and the actions of youth and others (.88) (Powers et al., 2012). Additionally, standardized item alpha coefficients for this measure range from .84-.91 (Powers et al., 2001). This measure added some additional questions focusing on transition planning that happens with child welfare staff and youth. For instance, "I understand how DHS can help me plan for the future" and "my plans for life after leaving foster care are clear to me".

Self-determination. The Arc Self-determination Scale (Wehmeyer, 1996; Wehmeyer \& Kelchner, 1995) is a 72-item self-report measure that provides data on an overall self-determination score as well as four sub-scales of self-determination: autonomy, self-regulation, psychological empowerment, and self-realization. This measure has been well established with samples of youth with and without disabilities. The measure's validity, including construct validity, and reliability have been determined to be adequate in previous studies. Analyses of variance by age and disability type were conducted utilizing the ARC and confirmed the measure's strong discriminative and construct validity. The ARC's criterion-related validity was established by examining correlations with instruments measuring similar constructs. Item consistency was found to range from .91 to .98 and reliability utilizing split-half evaluation techniques produced a correlation of .95 . Additionally, test-retest correlations within 3 month time periods was established at .74 and overall internal consistency reliability was .90 (Wolman, Campeau, Dubois, Mithaug, and Stolarski, 1994). The measure has been utilized in several youthfocused studies including an evaluation of an intervention to enhance self-determination for students (Wehmeyer, Palmer, Agran, Mithaug, \& Martin, 2000) and several studies 
that have investigated the participation of students in transition planning activities (Cross, Cooke, Wood \& Test, 1999; Sands, Spencer, Gilner \& Swaim, 1999; Zhang, 2001).

\section{Analysis Plan}

\section{Preliminary Analysis}

Following the outline of data preparation by Tabachnick and Fidell (2007), the data was first examined for errors in entry. Frequencies were run on each measure at the item level to determine whether youth had completed at least $80 \%$ of the questions for measures utilizing a scale. For entries with fewer than required answered questions, the hard copies of files were pulled and examined to determine whether there was a data entry error or whether the youth had not answered all of the questions due to choosing not to answer or some other error in data collection. Those entries with data entry errors were re-entered. Scores were then calculated using weighted means for each youth with at least $80 \%$ of the questions completed. One exception to this process included 17 youth who had utilized an older version of the Transition Planning Engagement measure and were only asked 7 questions, as opposed to 17 questions for all other youth. Despite the fact that $80 \%$ of the questions were not answered for these youth from the final measure, a decision was made to calculate weighted mean scores for those 17 youth based on the seven questions that had been answered. For non-scale items, each item was checked for entry errors and reconciled. Data was also examined for outliers using frequency distributions. Prior to analyzing the data, continuous variables were examined for homoscedasticity, linearity, and normality to maintain robustness of the analysis (Tabachnick \& Fidell, 2007); however, given the large sample size, there was little 
concern with violating these assumptions.

Initial examination of the ARC self-determination scale found two cases that were beyond three standard deviations from the mean. Similarly, the Daily Life Skill Engagement measure had one case that was determined to be an outlier. These cases were examined and it was determined that there were no errors in data entry and that these cases fell within the possible range of scores for the measure. Regression models were run with the outliers intact and with the outliers removed from the analysis. While removing the outliers did slightly increase the overall $\mathrm{r}$ square value (by $.5 \%$ to $3 \%$ for any given block of a model), the overall significance of the models remained the same. Thus, rather than trimming the outliers or transforming the variables, the decision was made to maintain the overall sample for ease of interpretation and the results reported below include the outlier cases.

\section{Statistical Analysis}

Question 1: Are youth with disabilities more likely to reside in restrictive placement settings than other placement types compared with youth without disabilities?

To answer this research question, a chi-square test was run for disability (as

defined by receiving special education services) by placement type (kinship, non-relative foster care, and restrictive placement).

\section{Question 2: Do transition-aged youth with and without disabilities differ in} transition preparation engagement?

Three hierarchical multiple regressions were run for each of the eight dependent variables within the seven transition preparation engagement domains: 1) perceptions of 
readiness for adulthood, 2) post-secondary preparation activities, 3) employment and career preparation activities, 4) daily life preparation activities, 5) transition planning engagement, 6) ILP participation, and 7) self-determination. Each regression was run with 3 blocks to correspond with the above noted research question. The first block of each regression included the key control variables: gender, race, age, while the second block included DHS experiences including placement instability, and length of time in care. Block three of the regression model included disability status as defined by participation in special education services. Thus, controlling for the above demographic and foster care experiences, the transition preparation indicators were examined for youth with disabilities compared with youth without disabilities.

\section{Question 3: Does restrictiveness, as defined by placement in a restrictive setting, have a negative impact on youths' transition preparation?}

Hierarchical multiple regressions was run for each of the eight dependent variables within the seven transition preparation engagement domains: 1) perceptions of readiness for adulthood, 2) post-secondary preparation activities, 3) employment and career preparation activities, 4) daily life preparation activities, 5) transition planning engagement, 6) ILP participation, and 7) self-determination. Each regression was run with three blocks to correspond with the above noted research question. The first block of each regression included the key control variables: gender, race, age, while the second block included DHS experiences including placement instability, and length of time in care. Block three of each of the regression models above included placement type, with non-relative foster care placements as a reference. Thus, results compared transition 
preparation in kinship placement type and restrictive placement type to non-relative foster care placements.

\section{Question 4: Does restrictiveness, as defined by youth self-report of restrictiveness, have a negative impact on youths' transition preparation?}

Finally, the above process was followed to run eight regression models for transition preparation with block one (demographics) and two (DHS information) remaining the same. Block three of each of these regression models included a sum score of youth perceptions of restrictiveness. This level of analysis allowed for the investigation of restrictiveness with greater variance beyond placement type alone. Theoretically for instance, a youth may reside in a kinship placement that has many rules and regulations in place while a youth in a restrictive placement setting may be allowed more freedoms than typically experienced in such a setting. 


\section{Chapter 5: Results}

The youth in this sample were an average age of 17.3 years $(\mathrm{SD}=0.61)$ and $54 \%$ female (see table 1). Nearly $58 \%$ of the sample were youth of color and $59 \%$ experienced a disability (see table 2). The average length of time in care of their most recent episode in care was approximately 11 years or 4039 days $(\mathrm{SD}=1916.47)$. During their last episode in care, $28.6 \%$ resided in 1 or 2 placements, just over a quarter resided in 3 to 4 placements (26.3\%), and $45.1 \%$ resided in 5 or more placements. Almost half resided in a non-relative foster care setting $(47.5 \%)$ while $22.9 \%$ lived in a kinship placement and $29.6 \%$ resided in a restrictive placement setting.

Examining transition preparation of the sample descriptively, only $9.6 \%$ reported feeling very prepared for life as an adult while the majority (61\%) reported feeling somewhat prepared for life as an adult. On average, over the past 12 months prior to baseline, youth reported engaging in $3.7(\mathrm{SD}=2.78)$ post-secondary preparation activities, and approximately 1 in 7 (14\%) had not engaged in any post-secondary preparation activities at all. Only $7.1 \%$ of the youth reported that that were currently working. However, nearly all had engaged in career preparation activities over the last 12 months with a mean of 5.1 activities $(\mathrm{SD}=2.59)$. Nearly all youth also engaged in daily

life skills related to the transition to adulthood with an average of 6.5 activities ( $\mathrm{SD}=3.34$ ) in the last 12 months and $43 \%$ of the youth reported participating in ILP in the last 90 days. Only $20.9 \%$ of the youth reported they currently had a transition plan to exit foster care, while $27.9 \%$ reported it was still being worked on and $49.8 \%$ said they did not have one or they did not know if they had a plan. On the transition planning measure that 
Table 1. Demographics

\begin{tabular}{|c|c|c|c|c|c|}
\hline & \multicolumn{4}{|c|}{ SPED } \\
\hline & & \multirow{2}{*}{\multicolumn{2}{|c|}{$\begin{array}{c}\text { All } \\
\mathrm{N}=294\end{array}$}} & \multirow{2}{*}{$\begin{array}{l}\text { Yes } \\
\mathbf{N}=173 \\
(\mathbf{5 8 . 8 \%})\end{array}$} & \multirow{2}{*}{$\begin{array}{c}\text { No } \\
N=121 \\
(41.2 \%)\end{array}$} \\
\hline & & & & & \\
\hline & & $\mathbf{N}$ & $\%$ & N $\%$ & $\%$ \\
\hline \multicolumn{6}{|c|}{ Gender } \\
\hline & Female & 160 & $(54.4)$ & 79 (45.7) & $81(66.9)$ \\
\hline & Male & 134 & $(45.6)$ & $94(54.3)$ & $40(33.1)$ \\
\hline \multicolumn{6}{|c|}{ 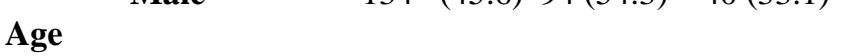 } \\
\hline & 16 & 115 & $(39.1)$ & $71(41.1)$ & $44(36.4)$ \\
\hline & 17 & 132 & $(45.0)$ & $76(43.9)$ & $55(45.5)$ \\
\hline & 18 & 47 & (15.9) & $26(15.0)$ & $22(18.1)$ \\
\hline \multicolumn{6}{|l|}{ Race } \\
\hline & Youth of Color & 171 & $(58.2)$ & $92(53.2)$ & $79(65.3)$ \\
\hline & White & 123 & (41.8) & $81(46.8)$ & $42(34.7)$ \\
\hline \multicolumn{6}{|c|}{ Time in Care } \\
\hline & 0-5 years & 51 & $(17.3)$ & $30(17.3)$ & $21(17.4)$ \\
\hline & 6-11 years & 58 & (19.7) & $43(24.9)$ & $15(12.4)$ \\
\hline & $12+$ years & 185 & (63.0) 1 & $100(57.8)$ & $85(70.2)$ \\
\hline \multicolumn{6}{|c|}{ \# of Placements } \\
\hline & $1-2$ & 35 & (11.9) & $45(26.0)$ & $39(32.3)$ \\
\hline & $3-4$ & 124 & $(42.2)$ & $47(27.2)$ & $28(23.1)$ \\
\hline & $5-7$ & 57 & (19.4) & $30(17.3)$ & $27(22.3)$ \\
\hline & $8+$ & 78 & $(26.5)$ & $51(29.5)$ & $27(22.3)$ \\
\hline \multicolumn{6}{|c|}{ Placement Type } \\
\hline & Kinship & 66 & $(22.4)$ & $29(16.8)$ & $37(30.1)$ \\
\hline & Non-Rel & 141 & $(41.8)$ & $70(40.5)$ & $71(58.7)$ \\
\hline & Restrictive & 87 & (29.6) & $74(42.7)$ & $13(11.2)$ \\
\hline
\end{tabular}

asked youth about school and DHS transition planning, youth had an average score of $25.79(\mathrm{SD}=11.5)$ out of 51 possible, indicating an average moderate level of transition planning engagement overall. On the ARC Self-Determination Scale (Wehmeyer, 1992), youth had an average score of $103.7(\mathrm{SD}=15.97)$ with a range of 54 to 145 (see table 3 ).

\section{Associations among Independent Variables}

Bivariate correlations with disability. Correlations were run to test the association of disability with seven independent variables: age, gender, race, number of placements, length of time in care, placement setting, and perceptions of restrictiveness. 
Table 2. Demographics by Placement Type

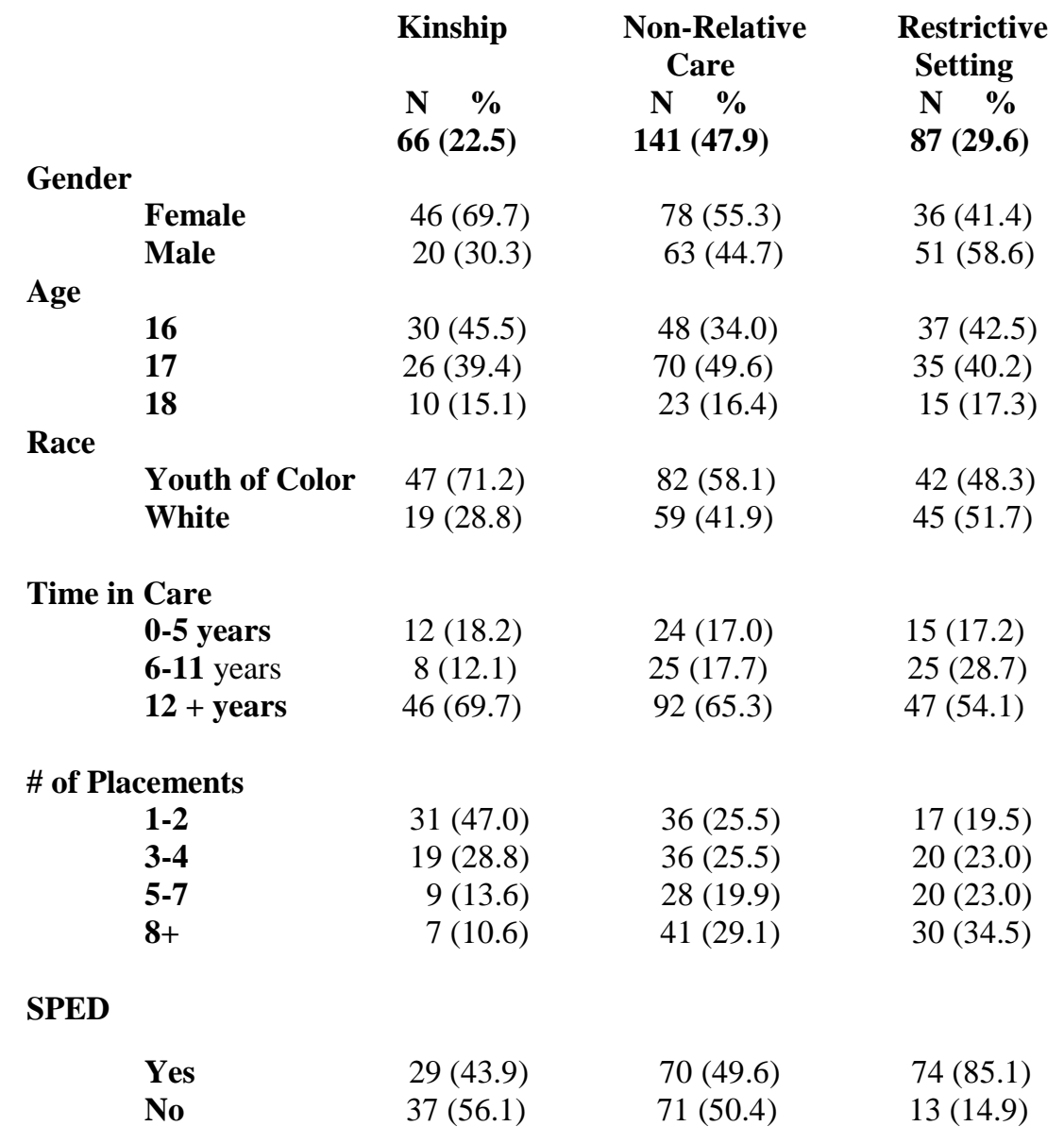

Being white $(\mathrm{r}=-.210, \mathrm{p}<.001)$ and being male $(\mathrm{r}=-.121, \mathrm{p}<.05)$ was significantly correlated with experiencing a disability. Experiencing a disability shared a negative trend level correlation with length of time in care $(\mathrm{r}=-.110, \mathrm{p}<.10)$. In addition, experiencing a disability indicated a significant positive correlation with youth perceptions of restrictiveness $(\mathrm{r}=.219, \mathrm{p}<.001)$ and residing in a restrictive placement setting $(\mathrm{r}=.345, \mathrm{p}<.001)$. Conversely, not having a disability was significantly correlated with residing in a kinship placement $(\mathrm{r}=-.163, \mathrm{p}<.01)$ and in a non-relative foster care placement $(\mathrm{r}=-.179, \mathrm{p}<.01)$. In addition, being a youth of color was significantly 
Table 3

Means, Standard Deviations and Percentages of Dependent Variables by Independent Variables

Prepared Post 2nd Prep Employed Career Prep

Adult Life

Mean SD Mean SD Percentage Mean SD

Gender

\begin{tabular}{|c|c|c|c|c|c|c|c|c|}
\hline & Female & 1.77 & 0.68 & 4.30 & $2.83 * *$ & $5.8 \%$ & 5.47 & $2.61 *$ \\
\hline & Male & 1.72 & 0.68 & 3.19 & 2.60 & $10.0 \%$ & 4.73 & 2.54 \\
\hline \multicolumn{9}{|l|}{${ }^{A}$ Age } \\
\hline & 16 & 1.62 & $0.75^{*}$ & 3.34 & $2.41 * * *$ & $6.7 \%$ & 4.39 & $2.38^{* * *}$ \\
\hline & 17 & 1.90 & 0.60 & 4.71 & 2.78 & $4.2 \%$ & 6.19 & 2.72 \\
\hline & 18 & 1.90 & 0.88 & 6.20 & 2.74 & $40.0 \%$ & 5.90 & 3.21 \\
\hline \multicolumn{9}{|l|}{ Race } \\
\hline & Youth of Color & 1.81 & $0.65^{\wedge}$ & 3.86 & 2.90 & $5.8 \%$ & 5.21 & 2.56 \\
\hline & White & 1.66 & 0.70 & 3.71 & 2.61 & $10.3 \%$ & 5.02 & 2.65 \\
\hline \multicolumn{9}{|c|}{ ATime in Care } \\
\hline & $0-5$ years & 1.71 & 0.67 & 3.65 & 2.73 & $11.8 \%^{\wedge}$ & 5.00 & 2.76 \\
\hline & $6-11$ years & 1.76 & 0.63 & 3.62 & 2.51 & $10.3 \%$ & 5.26 & 2.79 \\
\hline & $12+$ years & 1.76 & 0.69 & 3.89 & 2.88 & $5.6 \%$ & 5.13 & 2.50 \\
\hline \multicolumn{9}{|c|}{ \# of Placements } \\
\hline & $1-2$ & 1.68 & 0.71 & 3.73 & 2.75 & $5.7 \%$ & 4.93 & 2.70 \\
\hline & $3-4$ & 1.83 & 0.58 & 3.68 & 2.81 & $9.1 \%$ & 4.85 & 2.41 \\
\hline & $5-7$ & 1.86 & 0.77 & 4.19 & 2.97 & $9.3 \%$ & 5.51 & $2.44^{\wedge}$ \\
\hline & $8+$ & 1.67 & 0.64 & 3.69 & 2.67 & $5.3 \%$ & 5.35 & $2.44^{\wedge}$ \\
\hline \multicolumn{9}{|c|}{ Disability } \\
\hline & Yes & 1.68 & $0.71^{\wedge}$ & 3.18 & $2.63 * * *$ & $9.2 \%$ & 4.84 & $2.68^{\wedge}$ \\
\hline & No & 1.85 & 0.62 & 4.67 & 2.76 & $5.2 \%$ & 5.55 & 2.42 \\
\hline \multicolumn{9}{|c|}{ Placement Type } \\
\hline & Kinship & 1.88 & 0.65 & 4.61 & 3.08 & $12.3 \%^{\wedge}$ & 5.29 & 2.43 \\
\hline & Non-Relative & 1.77 & 0.63 & 4.18 & 2.68 & $6.5 \%$ & 5.72 & 2.56 \\
\hline & Restrictive & 1.62 & 0.75 & 2.53 & $2.26 * * *$ & $6.0 \%$ & 4.06 & $2.48^{* * *}$ \\
\hline \multicolumn{9}{|c|}{$\begin{array}{l}\text { APerception of } \\
\text { Restrict. Sum }\end{array}$} \\
\hline & $5-7$ & 1.82 & $0.62^{\wedge}$ & 4.21 & $3.04 *$ & $9.5 \%$ & 5.20 & $2.71 *$ \\
\hline & $8-10$ & 1.74 & 0.70 & 4.06 & 2.60 & $5.8 \%$ & 5.67 & 2.34 \\
\hline & $11+$ & 1.67 & 0.71 & 2.89 & 2.42 & $7.7 \%$ & 4.35 & 2.59 \\
\hline
\end{tabular}


Table 3 continued

$$
\begin{array}{ccccc}
\text { Daily Life Prep } & \text { ILP } & \begin{array}{c}
\text { Transition } \\
\text { Plan Engage. }
\end{array} & \begin{array}{c}
\text { Self- } \\
\text { Determination }
\end{array} \\
\text { Mean SD } & \text { Percentage } & \text { Mean SD } & \text { Mean SD }
\end{array}
$$

\begin{tabular}{|c|c|c|c|c|c|c|c|c|}
\hline \multirow{3}{*}{ AAge } & Female & 6.93 & $3.37 *$ & $50.0 \% * *$ & 26.91 & 11.82 & 107.26 & $15.37^{* * *}$ \\
\hline & Male & 5.90 & 3.22 & $34.3 \%$ & 25.28 & 11.08 & 99.38 & 15.67 \\
\hline & & & & & & & & \\
\hline & 16 & 5.52 & $2.81 * * *$ & $30.5 \% * * *$ & 26.21 & 10.55 & 103.06 & 14.79 \\
\hline & 17 & 7.48 & 3.51 & $50.0 \%$ & 25.19 & 12.29 & 104.51 & 15.76 \\
\hline & 18 & 9.50 & 4.65 & $70.0 \%$ & 34.00 & 13.58 & 104.27 & 23.16 \\
\hline \multicolumn{9}{|l|}{ Race } \\
\hline & Youth of Color & 6.52 & 3.21 & $39.2 \% *$ & 26.53 & 12.08 & 103.77 & 14.93 \\
\hline & White & 6.39 & 3.52 & $48.0 \%$ & 25.64 & 11.08 & 103.53 & 17.38 \\
\hline \multicolumn{9}{|c|}{${ }^{\mathrm{A}}$ Time in Care } \\
\hline & $0-5$ years & 6.31 & $3.32^{\wedge}$ & $47.0 \%$ & 24.81 & 11.76 & 105.65 & 16.72 \\
\hline & 6-11 years & 5.53 & 3.07 & $43.1 \%$ & 27.42 & 11.76 & 103.40 & 15.57 \\
\hline & $12+$ years & 6.80 & 3.88 & $41.6 \%$ & 26.42 & 11.65 & 103.20 & 15.93 \\
\hline \multicolumn{9}{|c|}{ \# of Placements } \\
\hline & $1-2$ & 5.70 & 3.08 & $33.3 \%$ & 23.97 & 11.78 & 100.71 & 17.05 \\
\hline & $3-4$ & 6.53 & $3.73 *$ & $48.0 \% * *$ & 25.24 & 11.43 & 103.36 & 14.98 \\
\hline & $5-7$ & 7.65 & $3.53 * *$ & $45.6 \% *$ & 27.68 & 12.75 & 107.39 & $15.95^{*}$ \\
\hline & $8+$ & 6.36 & $2.85^{*}$ & $46.2 \% *$ & 27.45 & 10.38 & 104.43 & 15.38 \\
\hline \multicolumn{9}{|c|}{ Disability } \\
\hline & Yes & 5.85 & $3.24 * *$ & $37.0 \% *$ & 25.67 & 11.51 & 101.23 & $16.37^{*}$ \\
\hline & No & 7.33 & 3.31 & $51.2 \%$ & 25.98 & 11.55 & 107.16 & 14.76 \\
\hline \multicolumn{9}{|c|}{ Placement Type } \\
\hline & Kinship & 7.26 & $3.40 *$ & $47.0 \%$ & 26.61 & 12.12 & 107.89 & 17.41 \\
\hline & Non-Relative & 6.78 & 3.18 & $48.2 \%$ & 25.43 & 11.29 & 105.11 & 14.71 \\
\hline & Restrictive & 5.34 & $3.30 * *$ & $31.0 \% * *$ & 25.74 & 11.49 & 98.13 & $16.27 * *$ \\
\hline \multicolumn{9}{|c|}{$\begin{array}{l}\text { APerception of } \\
\text { Restrict. Sum }\end{array}$} \\
\hline & $5-7$ & 6.69 & $4.43 * *$ & $48.2 \% *$ & 28.19 & $12.44 * * *$ & 107.50 & $17.27 * * *$ \\
\hline & $8-10$ & 6.87 & 3.09 & $48.5 \%$ & 26.00 & 10.93 & 104.44 & 13.87 \\
\hline & $11+$ & 5.34 & 3.31 & $8.4 \%$ & 23.56 & 10.39 & 97.48 & 12.94 \\
\hline
\end{tabular}

Gender

A: variable is continuous and represented on this table as categorical for ease of interpretation 
correlated moving placements $(r=.147, \mathrm{p}<.05)$ more often. Finally, an unexpected significant negative relationship was found between number of placements and length of time in care $(\mathrm{r}=-.129, \mathrm{p}<.05)$.

Bivariate correlations with placement type. Correlations were run to test placement type with the above with seven independent variables: age, gender, race, number of placements, length of time in care, disability, and perceptions of restrictiveness. All three placement types were significantly correlated with youth perceptions of restrictiveness with a negative association between perceptions of restrictiveness and kinship $(\mathrm{r}=-.245, \mathrm{p}<.001)$ and non-relative care $(\mathrm{r}=-.158, \mathrm{p}<.01)$ and a positive association with restrictive placements $(r=.397, \mathrm{p}<.001)$. Being female $(\mathrm{r}=$ $.165, \mathrm{p}<.01)$ and a youth of color $(\mathrm{r}=-.268, \mathrm{p}<.001)$ was significantly correlated with being in kinship care while being White $(r=-.130, \mathrm{p}<.05)$ and male $(r=-.170, \mathrm{p}<.01)$ was significantly correlated with being in a restrictive placement setting. Restrictive placement setting was also significantly correlated with moving placements more often ( $\mathrm{r}$ $=.151, \mathrm{p}=.01)$ while kinship placements were correlated with moving placements less often $(r=-.268, \mathrm{p}<.001)$.

Bivariate correlations with youth perceptions of restrictiveness. Correlations were run to test the sum score of youth perceptions of restrictiveness with the above with seven independent variables: age, gender, race, number of placements, length of time in care, placement setting, and disability. Youth perceptions of restrictiveness were only significantly correlated with the above mentioned variables for placement type and 
disability. However, there was a negative trend level association with age and perceptions of restrictiveness $(\mathrm{r}=-.10, \mathrm{p}=.089)$.

\section{Question 1: Are youth with disabilities more likely to reside in restrictive placement settings than other placement types compared with youth without disabilities?}

A chi-square test was run to compare the rate of disability with three placement settings: kinship, non-relative foster care, and restrictive placement settings. There was a significant difference for disability by the three placement types $\left(\chi^{2}(2, \mathrm{~N}=294)=35.67\right.$, $\mathrm{p}<.001)$. Youth in restrictive placement settings experienced a disability (85.1\%) at a much higher rate than youth in kinship care (43.9\%) and in non-relative foster care $(49.6 \%)$.

\section{Prepared for Adult Life}

Question 2: disability. Block one of the hierarchical linear regression (see table 4), including age, gender, and race, predicting youth self-report of preparation level for adult life was significant $(\mathrm{F}(3,290)=2.87, \mathrm{p}<.05)$ and accounted for $2.9 \%$ of the overall variance. Age was a statistically significant predictor of being prepared for adult life (beta $=.125, \mathrm{p}<.05)$ while being a youth of color had a trend level associated with positive perceptions of preparedness for adult life compared with white youth (beta $=.107, \mathrm{p}<.10$ ). Block two of the model included foster care experiences; length of time in care and number of placements, and accounted for $4.3 \%$ of the overall variance $(F(7,286)=1.86$, $\mathrm{p}<.10)$. Neither length of time in care or number of placements was a significant contributor to the model, while age remained significant and race became a significant predictor. Finally, in the last block, disability was entered into the model, the overall 
Table 4. Prepared for Adult Life

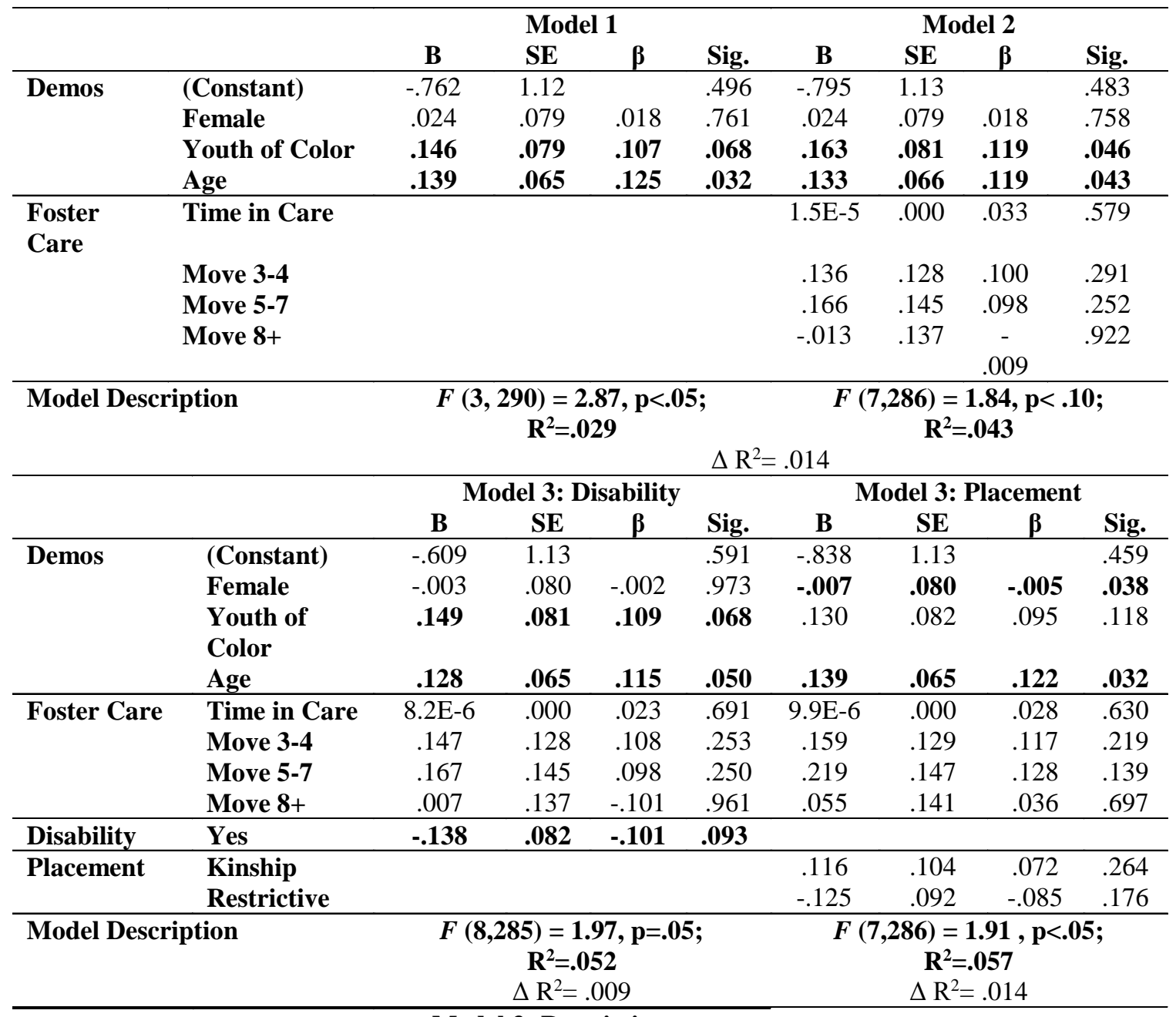

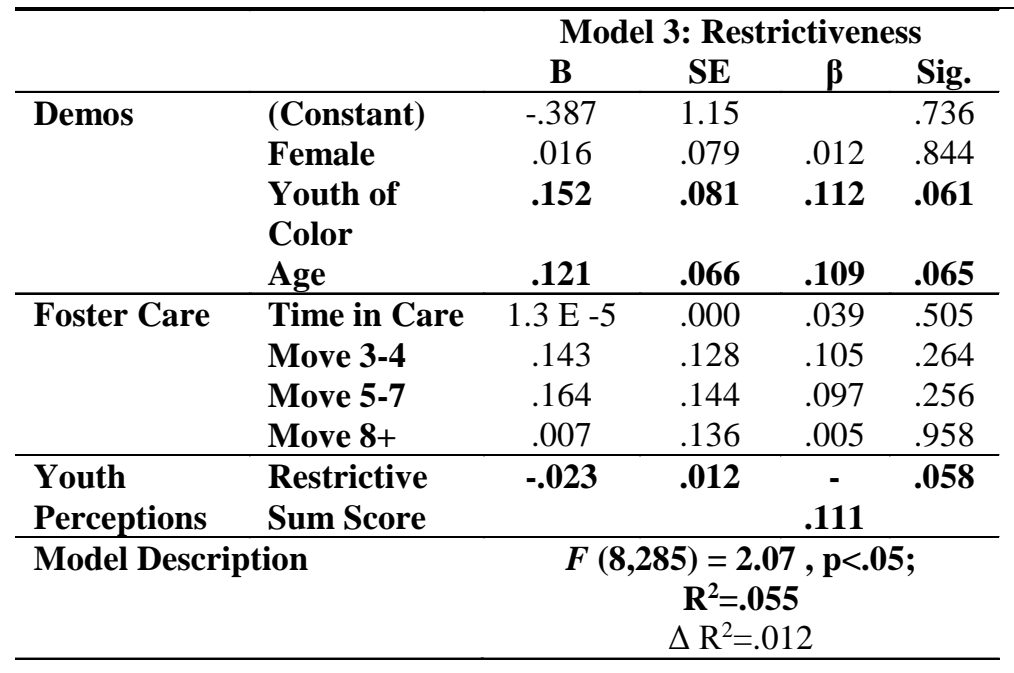


model was significant $(\mathrm{F}(8,285)=1.97, \mathrm{p}<.05)$, accounting for $5.2 \%$ of the overall variance. Disability had a negative trend level relationship with preparedness for adult life (beta $=-.101, \mathrm{p}<.10)$ while age and race also became trend level predictors.

Question 3: placement type. A second hierarchical linear regression was run with the same two blocks of control variables above to examine placement type as a predictor of youth perceptions of preparedness for adult life. With kinship and restrictive placement types (reference non-relative foster care) entered into block three, the model remained significant, $(\mathrm{F}(9,286)=1.91, \mathrm{p}<.05)$ and like the model for disability, accounted for $5.7 \%$ of the overall variance in youth perceptions. However, neither placement type was a significant predictor of preparedness for adult life. Like the model with disability as a predictor, age was a significant predictor $($ beta $=.122, \mathrm{p}<.05)$. Unlike the model above, race became non-significant when placement type was accounted for while gender became a significant predictor with males reporting more preparedness for adult life (beta $=-.005, \mathrm{p}<.05)$.

Question 4: perceptions of restrictiveness. Finally, a third hierarchical linear regression was run with the same control variables as above and the sum score for youth perceptions of restrictiveness was entered into the third block. The overall model remained significant $(\mathrm{F}(8,285)=2.07, \mathrm{p}<.05)$; however the overall variance accounted for drops slightly to $5.5 \%$. Youth perceptions of restrictiveness had a negative trend level association with youth perceptions of preparedness for adult life (beta=-.111, $\mathrm{p}<.10$ ). In this model, age became a trend level predictor and race once again became a trend level predictor. 


\section{Post-Secondary Preparation Activities}

Question 2: disability. Block one of the hierarchical linear regression model predicting post-secondary preparation (see table 5) by demographics was significant (F $(3,289)=12.48, \mathrm{p}<.001)$ with females engaging in significantly higher levels of postsecondary preparation (beta $=.189, \mathrm{p}<.01$ ) than males and age indicating a positive relationship with post-secondary preparation (beta $=.274, \mathrm{p}<.001$ ) and accounting for $11.5 \%$ of the overall variance. The next block that examined length of time in care and number of foster placements was significant $(F(7,285)=5.76, \mathrm{p}<.001)$ and accounted for $12.4 \%$ of the overall variance; however, neither foster care variable was a significant contributor to the overall model. Block three examined disability status and found a significant negative association with post-secondary preparation and experiencing a disability (beta =-.217, $\mathrm{p}<.001$ ). Both gender and age remained significant in the final block and the overall model remained significant $(\mathrm{F}(8,284)=7.15, \mathrm{p}<.001)$, with an $\mathrm{R}$ square change of .044 from block two accounting for $16.8 \%$ of the variance.

Question 3: placement type. When a second regression test was run the above control variables and placement type was entered into block three to predict postsecondary preparation engagement, the overall variance accounted for increases to $20.5 \%$ and remains significant overall $(\mathrm{F}(9,283)=8.13, \mathrm{p}<.001)$. Similar to the disability model above, both gender and age were significant predictors. Restrictive placement types compared with non-relative foster care had a significant negative association with post-secondary preparation engagement (beta $=-.259, \mathrm{p}<.001)$ while kinship settings was 
Table 5. Post-Secondary Preparation Activities

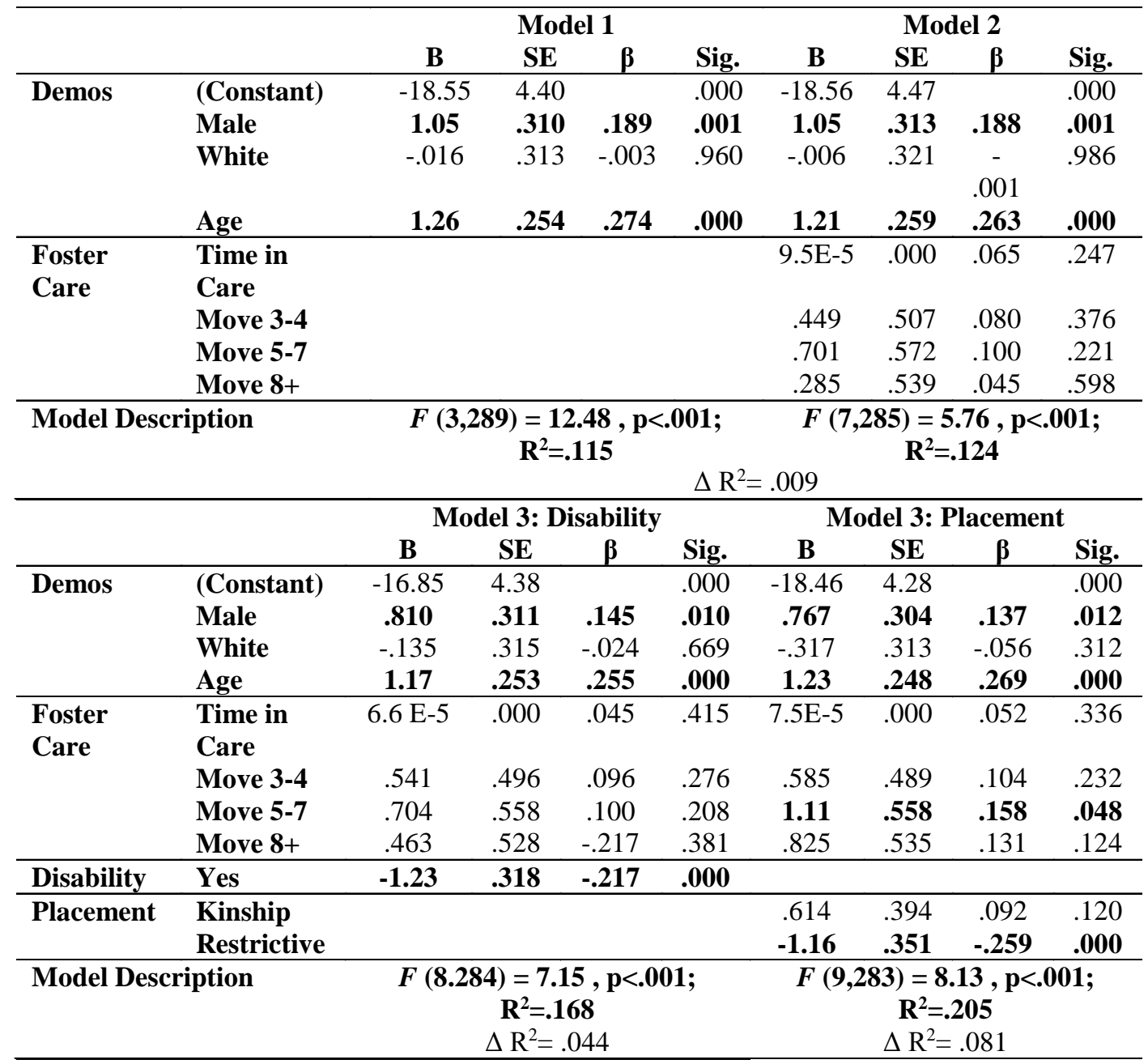

\begin{tabular}{|c|c|c|c|c|c|}
\hline & & \multicolumn{4}{|c|}{ Model 3: Restrictiveness } \\
\hline & & B & SE & $\beta$ & Sig. \\
\hline \multirow[t]{4}{*}{ Demos } & (Constant) & $\begin{array}{c}- \\
16.37\end{array}$ & 4.50 & & .000 \\
\hline & Male & 1.00 & .310 & .180 & .001 \\
\hline & White & -.067 & .319 & -.012 & .833 \\
\hline & Age & 1.15 & .257 & .250 & .000 \\
\hline \multirow[t]{4}{*}{ Foster Care } & $\begin{array}{l}\text { Time in } \\
\text { Care }\end{array}$ & .000 & .000 & .073 & .192 \\
\hline & Move 3-4 & .480 & .502 & .085 & .340 \\
\hline & Move 5-7 & .691 & .566 & .099 & .233 \\
\hline & Move 8+ & .393 & .535 & .063 & .464 \\
\hline $\begin{array}{l}\text { Youth } \\
\text { Perceptions }\end{array}$ & $\begin{array}{l}\text { Restrictive } \\
\text { Sum Score }\end{array}$ & -.122 & .048 & -.141 & .012 \\
\hline \multicolumn{2}{|c|}{ Model Description } & \multicolumn{4}{|c|}{$\begin{array}{c}F(8,284)=5.94, p<.001 \\
R^{2}=.143 \\
\Delta R^{2}=.019\end{array}$} \\
\hline
\end{tabular}


non-significant. In this model, moving 5 to 7 times, compared with 1-2 times, became a significant contributor to the model (beta $=.158, \mathrm{p}<.05)$.

Question 4: perceptions of restrictiveness. The third regression model testing youth perceptions of restrictiveness accounts for less overall variance than both the disability and placement type models at $14.3 \%$. Nevertheless, the overall model remains significant, $(\mathrm{F}(8,284)=5.94, \mathrm{p}<.001)$, and youth perceptions of restrictiveness did predict a negative relationship with post-secondary preparation engagement (beta $=-.141$, $\mathrm{p}<.05)$. As with the above two regression models, age and gender also remained significant predictors.

\section{Employment}

Question 2: disability. Logistic hierarchical regression was conducted to determine the predictors of current employment, the overall model was non-significant at every step (see table 6) and none of the demographic variables were significant. In the next block with foster care experiences, age become a positive trend level predictor (OR $=1.87, \mathrm{p}<.10)$ as did length of time in care $(\mathrm{OR}=1.0, \mathrm{p}<.10)$. Finally, block three added disability status, and age remained the only trend level predictor. Disability was not a significant predictor of employment.

Question 3: placement type. The second logistic hierarchical regression by placement type was also non-significant overall. In the final block age $(\mathrm{OR}=1.98, \mathrm{p}<.10)$ and length of time in care $(\mathrm{OR}=1.0, \mathrm{p}<.10)$ remained trend level predictors. Additionally, kinship care was a trend level predictor of employment with youth in 
Table 6. Employment

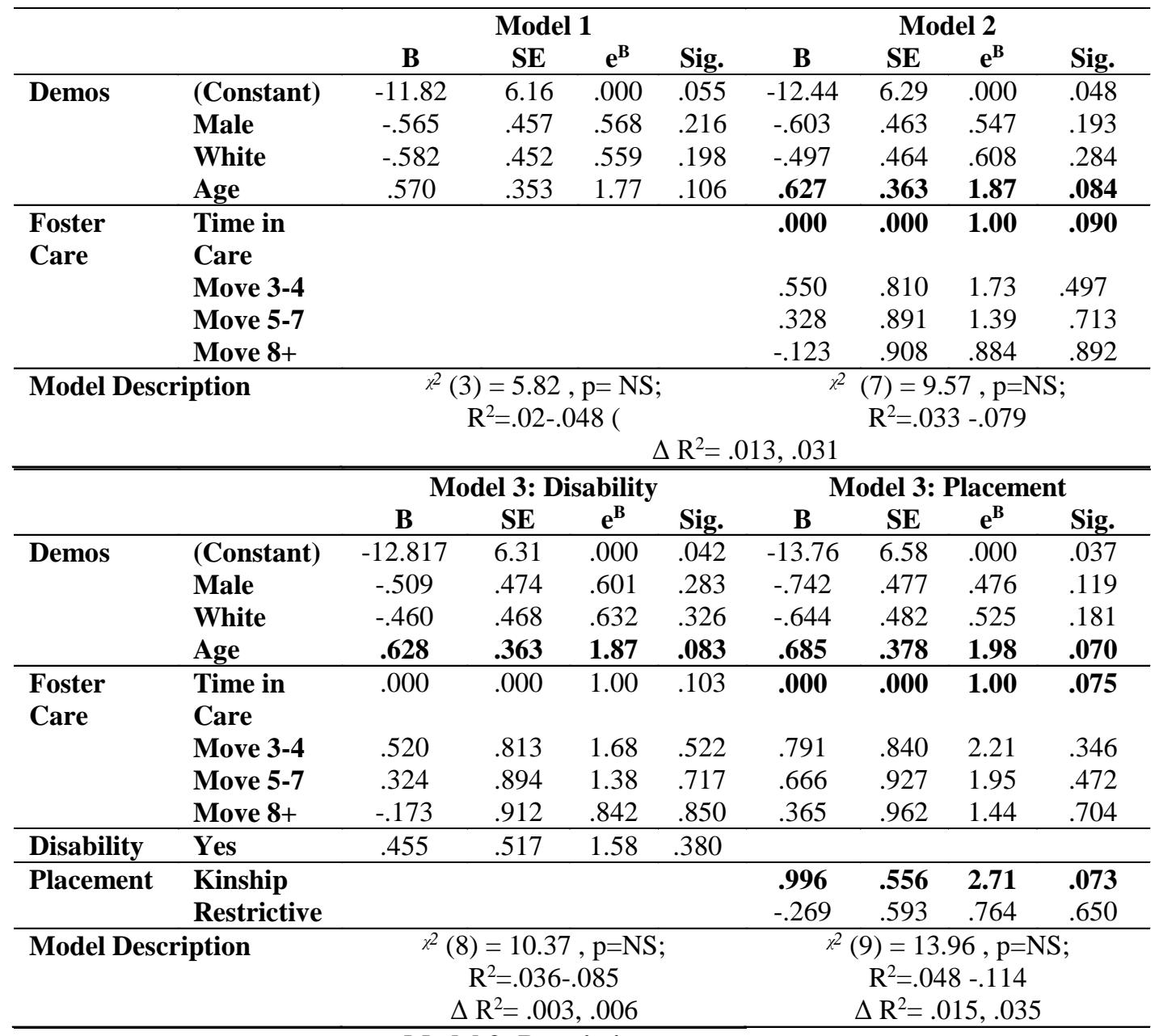

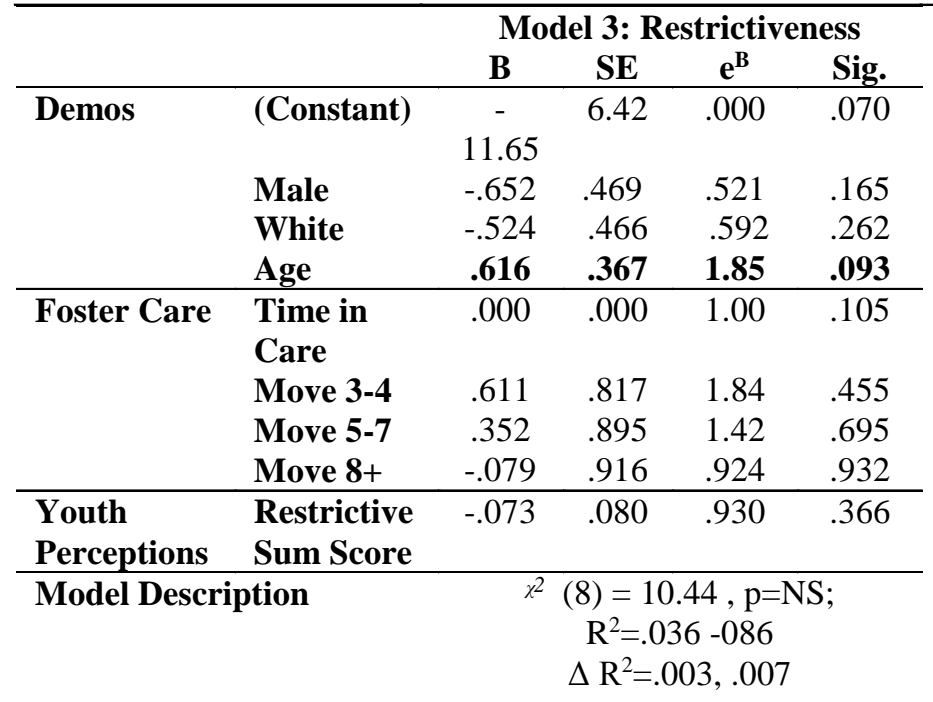


kinship care employed 2.7 times more often than youth in non-relative care $(\mathrm{OR}=2.71$, $\mathrm{p}<.10)$.

Question 4: perceptions of restrictiveness. The final logistic regression model testing youth perceptions of restrictiveness with employment rates was also nonsignificant with age the only trend level predictor of employment $(\mathrm{OR}=1.85, \mathrm{p}<.10)$. Youth perceptions of restrictiveness did not predict employment.

\section{Career Preparation Activities}

Question 2: disability. Hierarchical linear regression was conducted to examine youth career planning preparation engagement (see table 7). The overall model for block one with demographic variables entered was significant $(F(3,289)=9.07, p<.001)$ and age $($ beta $=.256, \mathrm{p}<.001)$ and gender $($ beta $=.131, \mathrm{p}<.05)$ were significant predictors of career preparation engagement with females participating in more career planning activities. Demographics accounted for $8.6 \%$ of the overall variance. Block two, which included foster care experiences was significant overall, $(\mathrm{F}(7,285)=4.39, \mathrm{p}<.001)$, and moving 5 to 7 times (beta=.143, $\mathrm{p}<.10)$ and 8 or more times (beta=.148, $\mathrm{p}<.10)$, compared with 1 to 2 times, positively predicted of career preparation engagement with a trend level relationship. Finally, the final block with disability indicated a trend level relationship with disability and career preparation engagement (beta $=-.101, \mathrm{P}<.10$ ). The overall model was significant in the final block $(\mathrm{F}(8,284)=4.25, \mathrm{p}<.001)$ and accounted for $10.0 \%$ of the overall variance with age continuing to be a significant predictor and gender, moving 5-7 times, and moving 8 or more times continued to be trend level predictors. 
Table 7. Career Preparation Activities

\begin{tabular}{|c|c|c|c|c|c|c|c|c|c|}
\hline & \multicolumn{4}{|c|}{ Model 1} & \multicolumn{4}{|c|}{ Model 2} \\
\hline & & B & SE & $\boldsymbol{\beta}$ & Sig. & B & SE & $\boldsymbol{\beta}$ & Sig. \\
\hline \multirow[t]{4}{*}{ Demos } & (Constant) & -14.31 & 4.18 & & .001 & -14.23 & 4.24 & & .001 \\
\hline & Male & .681 & .295 & .131 & .022 & .692 & .297 & .131 & .022 \\
\hline & White & .065 & .297 & .012 & .826 & .026 & .304 & .005 & .933 \\
\hline & Age & 1.10 & .242 & .256 & .000 & 1.05 & .245 & .245 & .000 \\
\hline Foster & Time in & & & & & $2.2 \mathrm{E}-5$ & .000 & .016 & .777 \\
\hline \multirow[t]{4}{*}{ Care } & Care & & & & & & & & \\
\hline & Move 3-4 & & & & & .648 & .481 & .123 & .179 \\
\hline & Move 5-7 & & & & & .938 & .542 & .143 & .085 \\
\hline & Move 8+ & & & & & .869 & .511 & .148 & .090 \\
\hline \multirow{4}{*}{\multicolumn{2}{|c|}{ Model Description }} & \multicolumn{4}{|c|}{$\begin{array}{c}F(3,289)=9.07, p<.001 ; \\
R^{2}=.086\end{array}$} & \multirow{2}{*}{\multicolumn{4}{|c|}{$\begin{array}{c}F(7,285)=4.39, p<.001 ; \\
\mathrm{R}^{2}=.097 \\
.011 \quad\end{array}$}} \\
\hline & & \multicolumn{4}{|c|}{$\Delta \mathrm{R}^{2}=.011$} & & & & \\
\hline & & \multicolumn{4}{|c|}{ Model 3: Disability } & \multicolumn{4}{|c|}{ Model 3: Placement } \\
\hline & & B & SE & $\boldsymbol{\beta}$ & Sig. & B & SE & $\boldsymbol{\beta}$ & Sig. \\
\hline \multirow[t]{4}{*}{ Demos } & (Constant) & -13.52 & 4.24 & & .002 & -13.59 & 4.09 & & .001 \\
\hline & Male & .590 & .301 & .113 & .051 & .498 & .290 & .096 & .087 \\
\hline & White & -.031 & .305 & -.006 & .920 & -.182 & .299 & -.035 & .544 \\
\hline & Age & 1.03 & .245 & .241 & .000 & 1.06 & .236 & .246 & .000 \\
\hline \multirow[t]{4}{*}{ Foster Care } & $\begin{array}{l}\text { Time in } \\
\text { Care }\end{array}$ & $9.2 \mathrm{E}-6$ & .000 & .007 & .905 & $3.6 \mathrm{E}-6$ & .000 & .003 & .961 \\
\hline & Move 3-4 & .687 & .480 & .131 & .153 & .656 & .466 & .125 & .161 \\
\hline & Move 5-7 & .940 & .540 & .143 & .083 & 1.13 & .532 & .172 & .035 \\
\hline & Move 8+ & .946 & .511 & .161 & .065 & 1.12 & .511 & .191 & .029 \\
\hline Disability & Yes & -.533 & .308 & -.101 & .084 & & & & \\
\hline \multirow[t]{2}{*}{ Placement } & Kinship & & & & & -.171 & .376 & -.027 & .650 \\
\hline & Restrictive & & & & & -1.64 & .335 & -.288 & .000 \\
\hline \multicolumn{2}{|c|}{ Model Description } & \multicolumn{4}{|c|}{$\begin{array}{c}F(\mathbf{8}, 284)=\mathbf{4 . 2 5}, \mathbf{p}<.001 ; \\
\mathbf{R}^{2}=.107 \\
\Delta \mathrm{R}^{2}=.010\end{array}$} & \multicolumn{4}{|c|}{$\begin{array}{c}F(9,283)=6.48, p<.001 \\
R^{2}=.171 \\
\Delta R^{2}=.074\end{array}$} \\
\hline
\end{tabular}

\begin{tabular}{|c|c|c|c|c|c|}
\hline & & \multicolumn{4}{|c|}{ Model 3: Restrictiveness } \\
\hline & & B & SE & $\boldsymbol{\beta}$ & Sig. \\
\hline \multirow[t]{4}{*}{ Demos } & (Constant) & -12.54 & 4.28 & & .004 \\
\hline & Male & .660 & .295 & .127 & .026 \\
\hline & White & -.204 & .303 & -.005 & .938 \\
\hline & Age & 1.00 & .245 & .234 & .000 \\
\hline \multirow[t]{4}{*}{ Foster Care } & $\begin{array}{l}\text { Time in } \\
\text { Care }\end{array}$ & $3.1 \mathrm{E}-5$ & .000 & .023 & .688 \\
\hline & Move 3-4 & .672 & .478 & .128 & .161 \\
\hline & Move 5-7 & .930 & .539 & .142 & .085 \\
\hline & Move 8+ & .955 & .509 & .163 & .062 \\
\hline $\begin{array}{l}\text { Youth } \\
\text { Perceptions }\end{array}$ & $\begin{array}{l}\text { Restrictive } \\
\text { Sum Score }\end{array}$ & -.098 & .046 & -.122 & .033 \\
\hline \multicolumn{2}{|c|}{ Model Description } & \multicolumn{4}{|c|}{$\begin{array}{c}F(8,284)=4.47, p<.001 ; \\
R^{2}=.112 \\
\Delta R^{2}=.015\end{array}$} \\
\hline
\end{tabular}


Question 3: placement type. The second regression run examining placement type with career preparation engagement showed an increase in overall accounted for variance compared with the disability model of $7.4 \%$ with an R square value of .171 and an overall significant model, $(\mathrm{F}(9,283)=6.48, \mathrm{p}<.001)$. Restrictive placement settings was a significant negative predictor of career preparation engagement (beta=-.288, $\mathrm{p}<.001)$. While age remained significant moving 5 to 7 times and moving 8 or more times became significant predictors in this model.

Question 4: perceptions of restrictiveness. The final regression model with youth perceptions of restrictiveness showed an R square similar to the disability model $(11.2 \%)$ and the overall model was significant, $(\mathrm{F}(8,284)=4.47, \mathrm{p}<.001)$. Youth perceptions of restrictiveness had a significant negative relationship with career preparation engagement $($ beta $=-.122, \mathrm{p}<.05)$, and like the disability model, age and race were also significant predictors while moving 5-7 times and 8 or more times were trend level predictors of career preparation engagement.

\section{Daily Life Preparation Activities}

Question 2: disability: Hierarchical linear regression was conducted to examine the relationship with demographics, foster care experiences and disability (see table 8). All 3 blocks had significant predictors of daily life preparation engagement and the overall model was significant at $\mathrm{p}<.001$ for all 3 blocks. The demographics block, ( $\mathrm{F}$ $(3,289)=15.18, \mathrm{p}<.001)$ accounted for $13.6 \%$ of the variance with older youth (beta $=.336, \mathrm{p}<.001)$ and females $($ beta $=.141, \mathrm{p}<.05)$ predicting more daily life preparation engagement. The next block that included length of time in care and number of 
Table 8. Daily Life Preparation Activities

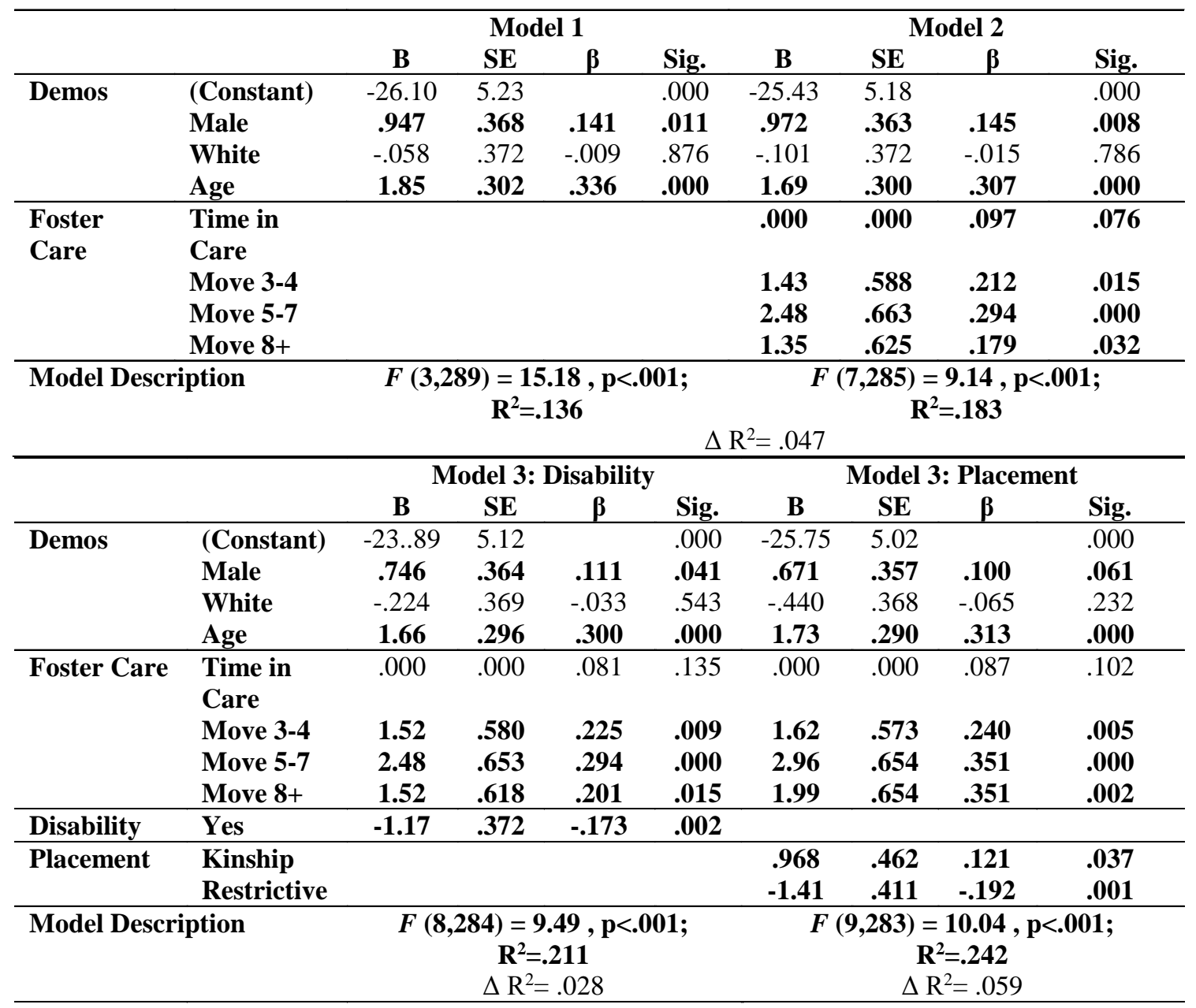

\begin{tabular}{|c|c|c|c|c|c|}
\hline & \multicolumn{4}{|c|}{ Model 3: Restrictiveness } \\
\hline & & B & SE & $\beta$ & Sig. \\
\hline \multirow[t]{4}{*}{ Demos } & (Constant) & -22.45 & 5.19 & & .000 \\
\hline & Male & .915 & .358 & .137 & .011 \\
\hline & White & -.188 & .368 & -.028 & 609 \\
\hline & Age & 1.61 & .297 & .292 & .000 \\
\hline \multirow[t]{4}{*}{ Foster Care } & $\begin{array}{l}\text { Time in } \\
\text { Care }\end{array}$ & .000 & .000 & .106 & .049 \\
\hline & Move 3-4 & 1.48 & .579 & .219 & .011 \\
\hline & Move 5-7 & 2.46 & .653 & .292 & .000 \\
\hline & Move 8+ & 1.50 & .618 & .199 & .016 \\
\hline $\begin{array}{l}\text { Youth } \\
\text { Perceptions }\end{array}$ & $\begin{array}{l}\text { Restrictive } \\
\text { Sum Score }\end{array}$ & -.172 & .055 & -.167 & .002 \\
\hline \multicolumn{2}{|c|}{ Model Description } & \multicolumn{4}{|c|}{$\begin{array}{c}F(8,284)=9.46, p<.001 ; \\
R^{2}=.210 \\
\Delta R^{2}=.027\end{array}$} \\
\hline
\end{tabular}


placements accounted for $18.3 \%$ of the variance. Youth who lived in 3-4 placements $($ beta $=.212, \mathrm{p}<.05), 5-7$ placements (beta=.294, $\mathrm{p}<.01$ ), and youth who moved 8 or more times $($ beta $=.201, \mathrm{p}<.01)$ had a significant positive relationships with daily life preparation engagement compared with the reference 1-2 placements group. Greater length of time in care also indicated a trend level increase in daily life preparation engagement (beta=.097, p<.10). Finally, block three that examined disability status had an R squared change of .028 from block two, accounting for $21.1 \%$ of the overall variance in daily life preparation, $(\mathrm{F}(8,284)=9.49, \mathrm{p}<.001)$. Disability was a significant negative predictor of daily life preparation engagement (beta=-.173, $\mathrm{p}<.01$ ). Gender remained a significant predictor as did all three indicators of placement instability. Length of time in care no longer predicted daily life preparation.

Question 3: placement type. The overall model examining placement type as predictors of daily life preparation engagement accounted for slightly more of the overall variance than the disability model, $21.0 \%$ and was significant overall $(\mathrm{F}(9,283)=9.46$, $\mathrm{p}<.001$ ). Restrictive placement type (beta=-.192, $\mathrm{p}<.01$ ) had a significant negative relationship with daily life preparation engagement while kinship placement type (beta $=$ $.121, \mathrm{p}<.10)$ had a significant positive relationship when compared with youth in nonrelative foster care. Age, gender, all 3 measures of placement instability were all positive significant predictors.

Question 4: perceptions of restrictiveness. When the model was run for the $3^{\text {rd }}$ time with youth perceptions of restrictiveness entered into the third block, the overall model remained significant, $(\mathrm{F}(8,284)=9.46, \mathrm{p}<.001)$, and the accounted for $21.0 \%$ of 
the overall variance. Youth perceptions of restrictiveness was a significant negative predictor of daily life preparation (beta $=-.167, \mathrm{p}<.01$ ). Gender, age, and all 3 indicators of placement instability remained significant while length of time in care became significant (beta $=.106, \mathrm{p}<.05)$.

\section{ILP Service Participation}

Question 2: disability. Hierarchical logistic regression was conducted to examine participation in ILP services (see table 9). Demographics accounted for $12.2 \%$ to $16.4 \%$ of the overall variance in ILP participation with a significant model at block one, $\chi^{2}(3, N$ $=294)=38.29, \mathrm{p}<.001$. All 3 demographic variables significantly predicted participation in ILP services with females being 2 times more likely than males to participate $(\mathrm{p}<.01)$ and youth of color participating at approximately two-thirds the rate of White youth $(\mathrm{p}<.05)$. Additionally, for each year older, youth became almost 3 times more likely to participate in ILP $(\mathrm{p}<.001)$. The next block examining foster care experiences indicated that placement instability at all 3 levels were significant predictors of ILP participation $(3-4$ placements: $\mathrm{OR}=3.59, \mathrm{p}<.01 ; 5-7$ placements: $\mathrm{OR}=3.06, \mathrm{p}<.05$; $8+$ placements: $\mathrm{OR}=3.59, \mathrm{p}<.05)$. Finally, when examining disability in block three, disability was a significant predictor of ILP participation with youth with disabilities participating at about half the rate of youth without disabilities $(\mathrm{OR}=.534, \mathrm{p}<.05)$. All predictors remained significant other than length of time in care. The overall model in the

final block was significant, $\chi^{2}(7, N=294)=52.83, \mathrm{p}<.001$, and accounted for $16.4 \%$ to $22.1 \%$ of the overall variance in ILP participation. 
Table 9. ILP

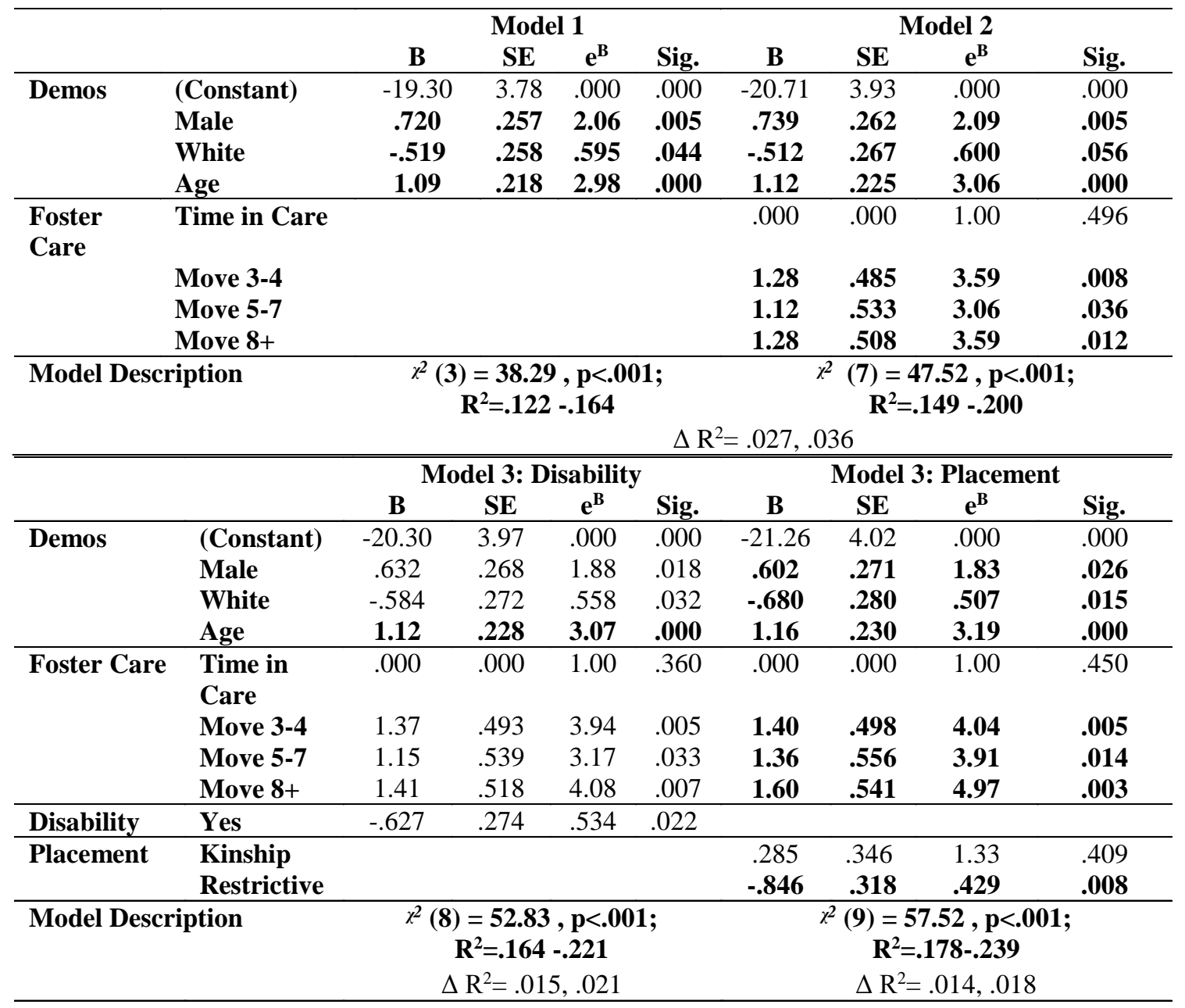

\begin{tabular}{|c|c|c|c|c|c|}
\hline & & \multicolumn{4}{|c|}{ Model 3: Restrictiveness } \\
\hline & & B & SE & $\mathbf{e}^{\mathbf{B}}$ & Sig. \\
\hline \multirow[t]{4}{*}{ Demos } & (Constant) & -19.50 & 3.99 & .000 & .000 \\
\hline & Male & .710 & .265 & 2.03 & .007 \\
\hline & White & -.560 & .271 & .571 & .039 \\
\hline & Age & 1.09 & .228 & 2.98 & .000 \\
\hline \multirow[t]{4}{*}{ Foster Care } & $\begin{array}{l}\text { Time in } \\
\text { Care }\end{array}$ & .000 & .000 & 1.00 & .593 \\
\hline & Move 3-4 & 1.34 & .488 & 3.81 & .006 \\
\hline & Move 5-7 & 1.14 & .536 & 3.12 & .034 \\
\hline & Move 8+ & 1.39 & .515 & 4.01 & .007 \\
\hline $\begin{array}{l}\text { Youth } \\
\text { Perceptions }\end{array}$ & $\begin{array}{l}\text { Restrictive } \\
\text { Sum Score }\end{array}$ & -.090 & .041 & .914 & .030 \\
\hline \multicolumn{2}{|c|}{ Model Description } & \multicolumn{4}{|c|}{$\begin{array}{c}\chi^{2}(8)=52.44, \mathbf{p}<.001 ; \\
\mathbf{R}^{2}=.163-.219 \\
\Delta R^{2}=.014, .019\end{array}$} \\
\hline
\end{tabular}


Question 3: placement type. Regression model 2 with placement type as a predictor of ILP indicates an increase in overall variance to $17.8 \%$ to $23.9 \%$ and like the above model for disability, the overall model is significant, $\chi^{2}(9, N=294)=57.52, \mathrm{p}<.001$.

Restrictive placement type was significantly negatively associated with ILP participation $(\mathrm{OR}=.429, \mathrm{p}<.01)$ and youth in these placement types participate in ILP at less than half the rate of youth in non-relative foster care. Again, all predictors remained significant other than length of time in care.

Question 4: perceptions of restrictiveness. The final regression model testing youth perceptions of restrictiveness with ILP participation was significant overall $\chi^{2}(8, N$ $=294)=52.44, \mathrm{p}<.001$, and accounted for $16.3 \%$ to $21.9 \%$ of the variance in ILP participation. Youth perceptions of restrictiveness did indicate a significant negative trend towards non ILP participation $(\mathrm{OR}=.914, \mathrm{p}<.05)$. All other variables were significant predictors of ILP participation other than length of time in care.

\section{Transition Planning Engagement}

Question 2: disability. A hierarchical linear regression was run to test transition planning engagement with the same 3 blocks: demographics, foster care experiences, and disability status (see table 10). None of the 3 blocks were significant for the overall model nor were any of the predictors, including disability status, significant.

Question 3: placement type. A hierarchical linear regression was then run to examine placement type as a predictor of transition placement engagement. Again, the 
overall model was not significant and placement type was not a significant predictor of 
Table 10. Transition Planning Engagement

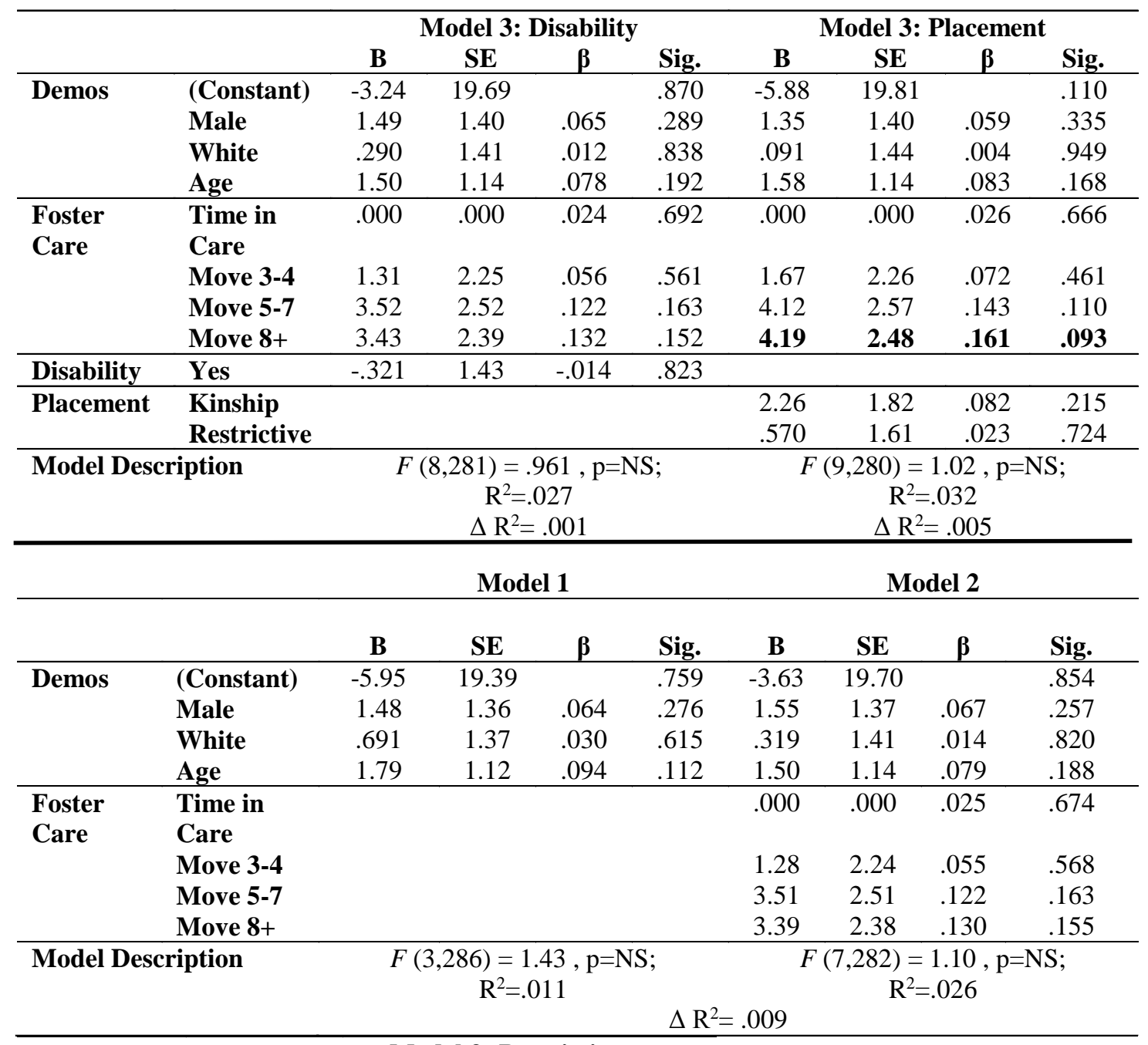

\begin{tabular}{llcccc}
\hline & & \multicolumn{3}{c}{ Model 3: Restrictiveness } \\
& & B & SE & $\boldsymbol{\beta}$ & Sig. \\
\hline Demos & (Constant) & 8.50 & 19.61 & & .665 \\
& Male & 1.24 & 1.34 & .054 & .356 \\
& White & .041 & 1.38 & .002 & .976 \\
& Age & 1.17 & 1.12 & .061 & .298 \\
\hline Foster Care & Time in & .000 & .000 & .039 & .504 \\
& Care & & & & \\
& Move 3-4 & 1.54 & 2.20 & .066 & .484 \\
& Move 5-7 & 3.51 & 2.46 & .121 & .156 \\
& Move 8+ & $\mathbf{4 . 1 2}$ & $\mathbf{2 . 3 4}$ & $\mathbf{. 1 5 9}$ & $\mathbf{. 0 7 9}$ \\
\hline Youth & Restrictive & $\mathbf{- . 7 3 1}$ & $\mathbf{. 2 0 7}$ & $\mathbf{- . 2 0 6}$ & $\mathbf{. 0 0 0}$ \\
Perceptions & Sum Score & \multicolumn{5}{c}{} \\
\hline Model Description & $\mathbf{F ~ ( 8 , 2 8 1 )}=\mathbf{2 . 5 5}, \mathbf{p}<.01 ;$ \\
& & $\mathbf{R}^{2}=.068$ \\
& & \multicolumn{5}{c}{$\Delta \mathbf{R}^{2}=.042$} \\
\hline
\end{tabular}


transition planning engagement. However, moving 8 or more times did positively predict trend level transition planning engagement (beta=.161, $\mathrm{p}<.10)$.

Question 4: perceptions of restrictiveness. Finally, the third regression was run with youth perceptions of restrictiveness entered into the third block. Unlike the other models, the overall model was significant $(F(8,281)=2.55, \mathrm{p}<.01$. Youth perceptions of restrictiveness was a significant negative predictor of transition planning engagement (beta $=-.206, \mathrm{p}<.001)$. In addition, moving 8 or more times remained a trend level predictor of transition planning.

\section{Self-Determination}

Question 2: disability: Finally, a hierarchical linear regression was run to test the predictors of self-determination (see table 11). All 3 blocks contributed significant predictors and the model remained significant throughout. Demographically, gender was a significant predictor with females showing higher levels of self-determination (beta $=.247, \mathrm{p}<.001$ ) and this block explained $6.1 \%$ of the overall variance. Youth with 5-7 placements indicated significantly higher self-determination than youth in 1-2 placements (beta $=.170, \mathrm{p}<.05)$ and with the addition of foster care experiences, this block contributed to $8.5 \%$ of the overall variance. Finally, disability was a significant predictor of self-determination with youth with disabilities experiencing less self-determination than youth without disabilities (beta $=-.145, \mathrm{p}<.05)$. The overall model, $(\mathrm{F}(8,285)$ $=4.15, \mathrm{p}<.001)$, accounted for $10.4 \%$ of the overall variance in self-determination.

Question 3: placement type. The next regression model testing placement type with self-determination was significant, $(\mathrm{F}(9,284)=5.07, \mathrm{p}<.001)$, and accounted for 
Table 11. Self-Determination

\begin{tabular}{|c|c|c|c|c|c|c|c|c|c|}
\hline & \multicolumn{4}{|c|}{ Model 1} & \multicolumn{4}{|c|}{ Model 2} \\
\hline & & B & SE & $\beta$ & Sig. & B & SE & $\beta$ & Sig. \\
\hline \multirow[t]{4}{*}{ Demos } & (Constant) & 91.15 & 26.01 & & .001 & 99.30 & 26.19 & & .000 \\
\hline & Male & 7.91 & 1.83 & .247 & .000 & 8.36 & 1.83 & .261 & .000 \\
\hline & White & -.558 & 1.85 & -.017 & .763 & -1.25 & 1.88 & -.039 & .506 \\
\hline & Age & .493 & 1.50 & .019 & .743 & -.048 & 1.52 & -.002 & .975 \\
\hline Foster & Time in & & & & & .000 & .000 & -.034 & .554 \\
\hline \multirow[t]{4}{*}{ Care } & Care & & & & & & & & \\
\hline & Move 3-4 & & & & & .852 & 2.97 & .026 & .774 \\
\hline & Move 5-7 & & & & & 6.89 & 3.36 & .170 & .042 \\
\hline & Move 8+ & & & & & 3.17 & 3.16 & .088 & .316 \\
\hline \multirow{4}{*}{\multicolumn{2}{|c|}{ Model Description }} & \multicolumn{4}{|c|}{$\begin{array}{c}F(3,289)=6.30, p<.001 \\
\mathrm{R}^{2}=.061\end{array}$} & \multicolumn{4}{|c|}{$\begin{array}{c}F(7,285)=3.80, p<.01 ; \\
\mathrm{R}^{2}=.085\end{array}$} \\
\hline & & \multicolumn{8}{|c|}{$\Delta \mathrm{R}^{2}=.024$} \\
\hline & & \multicolumn{4}{|c|}{ Model 3: Disability } & \multicolumn{4}{|c|}{ Model 3: Placement } \\
\hline & & B & SE & $\boldsymbol{\beta}$ & Sig. & $\mathbf{B}$ & SE & $\beta$ & Sig. \\
\hline \multirow[t]{4}{*}{ Demos } & (Constant) & $\begin{array}{c}105.5 \\
9\end{array}$ & 26.08 & & .000 & 98.95 & 25.59 & & .000 \\
\hline & Male & 7.44 & 1.85 & .232 & .000 & 6.96 & 1.82 & .217 & .000 \\
\hline & White & -1.73 & 1.87 & -.054 & .356 & -2.70 & 1.87 & -.083 & .150 \\
\hline & Age & -.201 & 1.51 & -.008 & .894 & .067 & 1.48 & .003 & .964 \\
\hline \multirow[t]{4}{*}{$\begin{array}{l}\text { Foster } \\
\text { Care }\end{array}$} & $\begin{array}{l}\text { Time in } \\
\text { Care }\end{array}$ & .000 & .000 & -.047 & .409 & .000 & .000 & -.047 & .409 \\
\hline & Move 3-4 & 1.22 & 2.95 & .038 & .680 & 1.67 & 2.92 & .052 & .568 \\
\hline & Move 5-7 & 6.87 & 3.33 & .170 & .040 & 8.93 & 3.34 & .221 & .008 \\
\hline & Move 8+ & 3.86 & 3.15 & -.145 & .221 & 5.91 & 3.20 & .164 & .066 \\
\hline Disability & Yes & -4.70 & 1.89 & -.145 & .014 & & & & \\
\hline \multirow[t]{2}{*}{ Placement } & Kinship & & & & & 3.69 & 2.36 & .096 & .119 \\
\hline & Restrictive & & & & & -6.85 & 2.09 & -.196 & .001 \\
\hline \multicolumn{2}{|c|}{ Model Description } & \multicolumn{4}{|c|}{$\begin{array}{c}F(8,284)=\mathbf{4 . 1 5}, \mathbf{p}<.001 \\
\mathrm{R}^{2}=.104 \\
\Delta \mathrm{R}^{2}=.019\end{array}$} & \multicolumn{4}{|c|}{$\begin{array}{c}F(9,283)=5.07, p<.001 \\
\mathbf{R}^{2}=.138 \\
\Delta R^{2}=.053\end{array}$} \\
\hline
\end{tabular}

\begin{tabular}{|c|c|c|c|c|c|}
\hline & & Moc & 3: $R$ & trictiv & \\
\hline & & B & SE & $\beta$ & Sig. \\
\hline Demos & (Constant) & 126.4 & 25.2 & & .001 \\
\hline & Male & 7.77 & 1.74 & .243 & .000 \\
\hline & White & -1.96 & 1.79 & -.060 & .275 \\
\hline & Age & -.830 & 1.45 & -.031 & .566 \\
\hline Foster Care & $\begin{array}{l}\text { Time in } \\
\text { Care }\end{array}$ & .000 & .000 & -.034 & .554 \\
\hline & Move 3-4 & 1.32 & 2.82 & .041 & .639 \\
\hline & Move 5-7 & 6.74 & 3.18 & .167 & .035 \\
\hline & Move 8+ & 4.55 & 3.01 & .126 & .132 \\
\hline $\begin{array}{l}\text { Youth } \\
\text { Perceptions }\end{array}$ & $\begin{array}{l}\text { Restrictive } \\
\text { Sum Score }\end{array}$ & -1.54 & .268 & -.313 & .000 \\
\hline Model Descr & tion & & $\Delta \mathrm{I}$ & $\begin{array}{l}\mathbf{8 3}, \mathbf{p} \\
\mathbf{1 8 0} \\
095\end{array}$ & \\
\hline
\end{tabular}


somewhat more variance than the regression model testing disability (13.8\%). Restrictive placement setting was a significant predictor of self-determination with negative implications (beta $=-.196, \mathrm{p}<.01$ ). Females continued to have significantly higher levels of self-determination as did youth who lived in 5 to 7 placements. Living in 8 or more placements became a trend level predictor of self-determination in this model (beta=.164, $\mathrm{p}<.10)$

Question 4: perceptions of restrictiveness. The model with youth perceptions of restrictiveness in the final block had the highest level of accounted for overall variance with $18.0 \%$ of the variance accounted for. This model was also significant, $(\mathrm{F}(8,285)$ $=7.83, \mathrm{p}<.001)$. Youth perceptions of restrictiveness was a significantly negative predictor of self-determination (beta=-.313, $\mathrm{p}<.001$ ). Females were also more likely to have higher levels of self-determination and youth who had lived in 5-7 placements was a significant predictor of higher levels of self-determination. 


\section{Chapter 6: Discussion}

The primary goal of this dissertation was to understand how restrictiveness impacts the transition preparation of adolescents preparing to exit foster care into adulthood, particularly for youth with disabilities who are most at risk for poor transition outcomes (Westat, 1991; Slayter \& Springer, 2011; Smithgall, Gladden, Yang \& Goerge, 2005; Geenen \& Powers, 2006; Anctil, McCubbin, O'Brien, \& Pecora, 2007; Hill, 2012) and most likely to reside in restrictive placement settings (Schmidt et al., 2013). This dissertation provided support for each of the research hypotheses related to: 1) youth with disabilities being more likely to reside in more restrictive placement settings, 2) youth who experience disabilities engaging in less transition preparation than youth without disabilities, 3) youth residing in restrictive placement settings engaging in less transition preparation than youth in non-relative foster care, and 4) youth who reported high levels of perceived restrictiveness participating in less transition preparation than youth with lower levels of perceived restrictiveness. Taken together, the findings show a pattern of substandard transition preparation for vulnerable groups of transition-aged youth in foster care: those with disabilities, in restrictive placement types, and reporting high levels of perceived restrictiveness.

\section{Question 1: Disability and Restrictive Placement Settings}

A much higher percentage of youth in restrictive placement settings (85\%) experienced a disability, almost double the rate, compared to youth in non-relative foster care $(49.6 \%)$ or kinship placements (43.9\%). This finding mirrors results from an earlier

study of a subsample of these youth, which documented the high level of restriction faced 
by youth with disabilities (Schmidt et al., 2013). Further, this finding suggests that youth with disabilities, who are identified as most at-risk as they transition out of care, are disproportionately placed in settings that offer the fewest opportunities for practicing necessary skills and activities for paving the way to success in early adulthood.

\section{Question 2: Disability}

Compared to youth without disabilities, youth with disabilities participated in transition preparation on six out of eight transition preparation variables. Within each variable are activities and experiences identified as necessary to promote positive transition preparation for adulthood. Youth with disabilities had completed significantly fewer post-secondary preparation activities, daily life preparation activities, ILP participation, and had lower levels of self-determination. In addition, there were trend level findings indicating lower perceptions of preparedness for adulthood and career preparation activities compared to youth without disabilities. Thus, youth with disabilities in foster care in this sample have largely been unexposed to opportunities that would otherwise prepare these youth for a successful transition to adulthood.

The findings in this study around disability and transition preparation echo Westat's (1991) findings that pointed towards youth with disabilities in foster care experiencing poorer outcomes than youth without disabilities in care. This study, however, did not examine other variables utilized in Westat's study (social support, highschool completion, and overall self-sufficiency). Employment was the one variable that was shared across studies. Unlike Westat's findings, however, this study did not find significant differences for youth with and without disabilities around employment. 


\section{Question 3: Placement Type}

Youth in restrictive placement settings participated in significantly less transition preparation than youth in non-relative foster care on five out of eight areas of transition preparation. Compared with youth in non-relative foster care, youth in restrictive placement settings were significantly less likely to have engaged in post-secondary preparation activities, career preparation activities, daily life preparation activities, ILP participation and had lower levels of self-determination. Despite the many areas youth in restrictive placement settings are participating in less transition preparation than youth in non-relative foster care, restrictive placement settings did not predict lower levels of youth perceptions of preparedness for adult life. This finding was in contrast to that found for youth with disabilities, who were participating in less transition preparation and indicated lower levels of perceived preparedness for adult life. It should be noted, however, that youth perceptions of readiness for adult life may in fact decrease when youth receive more exposure to activities that are necessary to successfully transition to adulthood, such as job shadowing or talking to a college advisor. In the My Life study, youth with higher levels of self-determination reported lower levels of preparedness for adult life than youth with lower levels of self-determination. The authors interpreted these findings as potential evidence that as youth became more aware of what it takes to be successful as an adult, they became more sensitive to self-assessing where they were in relationship to be prepared for adulthood (Powers et al, 2012). Therefore, it may be that youth in non-relative care who are participating in more transition preparation actually 
report lower levels of perceived preparedness for adult life due to their higher levels of self-determination, making the two groups comparable in this domain.

In two areas, employment (trend level) and daily life preparation activities (significant), residing in a kinship placement indicated a positive correlation compared with non-relative foster care. The finding for employment was particularly interesting as there were no differences on this variable for youth with disabilities, youth in restrictive placement settings, and youth perceptions of restrictiveness. Therefore, while youth in kinship care were employed at higher rates than those in non-relative foster care, the variables taken together (demographics, foster care experiences, and placement type), did not explain a very large percentage of the differences around why youth may or may not have been employed. Thus, there are likely additional variables not included in this study that would better describe differences found for those working compared to those not working.

\section{Question 4: Perceptions of Restrictiveness}

Examination of correlations of all three placement settings with the sum score of youth perceptions of restrictiveness found a high level of concordance between placement setting and youth perceptions of restrictiveness. Youth in kinship settings reported the lowest level of restrictiveness while youth in restrictive placement settings reported the highest level of restrictiveness. However, the measure of youth perceptions of restrictiveness also accounts for individual differences around restrictiveness within placement settings and appeared more sensitive to predicting the impact of restriction on transition planning engagement than placement type alone. Youth with high levels of 
perceived restrictiveness participated in less transition preparation than youth with lower levels of perceived restrictiveness on seven out of eight transition planning activity engagement variables. Youths' perceptions of restrictiveness showed a significant negative association with their participation in post-secondary preparation activities, career preparation activities, daily life preparation activities, ILP participation, transition planning engagement, and self-determination and a trend-level finding was found for youth perceptions of preparedness for adult life.

\section{Findings Across Disability, Placement Type, and Youth Perceptions}

Two variables, employment and transition planning engagement, did not differ between youth with and without disabilities and for youth in restrictive placements, compared with other placement types. However, as shown in the descriptive analysis, there were low levels of employment for the entire sample $(7.1 \%)$ and nearly all of the youth who were not working reported wanting to work $(89.1 \%)$. This finding is in stark contrast to the Midwest study's finding of youth preparing to exit foster care. Over onethird of the sample of youth in the Midwest study were currently employed at the time of the evaluation (35.1\%) (Courtney et al., 2004). One possible explanation for these differences is that the My Life data was collected during an economic recession that may have impacted youths' ability to gain employment. Nevertheless, the low rate of employment in this dissertation raises concern given the strong connection with working while in care predicting employment after exiting care (Goerge et al., 2002).

In addition, employment support for youth with disabilities has traditionally placed youth in work experiences that do not match the youth's larger career interests. 
The focus has been on learning specific job behaviors, often in segregated settings (ie: coffee cart on school campus or janitorial duties after store hours). There is a strong call to match youth interests with work experiences that will lead to meaningful careers rather than training young people utilizing stereotypical jobs; however, this shift has been slow in practice (Griffin, Hammis, Geary, \& Sullivan, 2008; Carter, Trainor, Cakiroglu, Swedeen, \& Owens, 2010). This study did not investigate the kinds of work experiences young people with disabilities are engaging in and as such it is suggested that future research examine the types of work experiences of youth in foster care with disabilities.

Similarly, only one in five youth in the overall sample reported having a transition plan in place while nearly $50 \%$ did not have a plan, were not working on a plan, or did not know if they had a plan. Federal legislation under Fostering Connections to Success and Increasing Adoptions Act of 2008 requires a transition plan to be in place for each youth exiting foster care. However, given the legislation's language around a plan being in place within 90 days before a youth's $18^{\text {th }}$ birthday, it cannot be inferred that the State is behind in meeting this benchmark, as the study included youth from 16.5 to 18.5 years of age. Nevertheless, given what is known about poor transition outcomes for youth exiting foster care and the amount of time needed to begin to plan for a successful transition into adulthood, it is questionable whether a plan that is put in place with only 90 days before one's $18^{\text {th }}$ birthday is truly meaningful to these young people. Intentional transition planning should begin much earlier in one's adolescence, particularly given the barriers and challenges this group of young people face entering adulthood, and the child welfare system is called upon to begin transition planning for all 
youth much earlier in their progression to adulthood. While restrictive placement settings did not predict lower levels of transition planning engagement, youth perceptions of restrictiveness did. As such, the results from this study are interpreted as an area of concern, particularly for youth with the highest levels of restriction.

Placement setting was a strong predictor for many of the transition preparation domains and often accounted for the highest $\mathrm{R}^{2}$ values. However, youth perceptions of restrictiveness appeared to be more sensitive in predicting differences across more variables. The exception to this pattern of placement settings more strongly accounting for overall variance when all three models (disability, placement setting, and youth perceptions of restrictiveness) were significant was around self-determination, where youth perceptions of restrictiveness and placement type accounted for similar levels of variance. Therefore, it appears that differences in overall transition planning are highly connected to the kind of placement setting a youth is residing. While this type of analysis cannot determine whether placement settings were the cause of these differences, there nonetheless exists a clear pattern of disparity. It appears useful to utilize both placement setting and youth perceptions of restrictiveness in examining the overall impact of restrictiveness on transition preparation as each variable gives slightly different information, which allows for a holistic look at the issue at hand. While differences in transition preparation in many areas were more strongly linked with where a youth resided than with their self-report of restrictiveness, examining youth self-reports of restrictiveness revealed differences in areas of transition preparation that would have otherwise gone unseen had this variable gone unexamined. 


\section{Demographics Variables}

While gender, race, and age were utilized in this study as control variables, it is worth noting how transition planning engagement varies along these indicators. As expected for youth nearing adulthood, age was positively associated on six of the variables, with higher levels of youth perceptions of preparedness for adult life, postsecondary preparation activities, career preparation activities, daily life preparation activities, and ILP participation. Females were more likely to report higher levels of postsecondary preparation activities, career preparation activities, daily life preparation activities, ILP participation, and self-determination. While this study did not test the interaction of gender and disability, previous findings utilizing a sub-sample of the current study's sample indicated that males were more likely to experience a disability and report higher levels of restriction in movement around their home, communication with others through telephone and internet, and access to the community (Schmidt et al., 2013). Thus, the findings in this study could represent the interaction between disability, restriction, and gender. Finally, youth of color reported being more prepared for adult life while participating in ILP less often than White youth. While there were findings around White youth experiencing higher levels of restriction, disability, and residing in more restrictive settings than youth of color from the above mentioned study (Schmidt, et al., 2013), these differences may not fully account for connection to lower levels of participation for youth of color in ILP services. In this study the proportion of youth of color residing in kinship care was greater than the proportion of White youth in kinship care. While residing in kinship care did not significantly impact ILP participation in this 
study, a previous study did find youth in kinship care participated in ILP less often (Lemon, Hines, \& Merdinger, 2005). Thus, there may be an interaction between being a youth of color and residing in kinship care settings that accounts for some of this variance in ILP participation. Further exploration of the connection between race, placement setting and ILP participation is recommended for future studies to examine these associations more closely.

\section{Foster Care Experiences}

Foster care experiences, represented as length of time in care and number of placements since last episode in care, also were utilized in this study as control variables. Foster care experiences represented in block two of the regression models had significant or trend-level predictor for five of the transition preparation variables. Surprisingly, length of time in care positively predicted daily life preparation activities and employment, though these associations had only trend level significance. One explanation for this is that youth residing in kinship placement settings, a factor that also promoted the above variables, were found to have been in care longer than youth in other settings. Therefore placement setting in kin care likely accounted for these differences. For employment, however, placement setting did not account for the differences found around employment and length of time in care. Rather, these results were likely driven by the fact that youth without disabilities in this sample were in foster care longer than youth with disabilities. Thus, length of time in care should not necessarily be interpreted to mean that being in foster care longer contributes to higher levels of transition preparation. 
Rather, youth without disabilities and youth in kinship placements, who participate in these activities at higher rates, have been in care for longer periods of time.

Surprisingly, placement instability (represented as the 5-7 placements and 8 or more placements groups, who taken together, represent $45.1 \%$ of the sample) also had a positive significant association with daily life preparation activities, ILP participation, and self-determination and a trend level association with career preparation activities. Given the literature around poor outcomes associated with placement instability for transition-aged youth (Anctil et al, 2007), this was particularly unexpected. While there is little evidence to support the overall efficacy of ILP services in improving transition outcomes, ILP service receipt is still theorized as a protective factor. It may be that youth who move more often are more visible to child welfare and thus are enrolled in ILP at higher rates as was found in Lemon, Hines and Merdinger's study (2005). However, this positive trend may only apply to youth residing in non-relative and kinship care placements, often the groups with lower levels of placement instability compared with youth in restrictive placement settings who move more often (Staff \& Fein, 1995;Redding, Fried \& Britner 2000; Smith et al. 2001). The results indicated that the percentage of youth in restrictive placements involved in ILP was lower than other placement settings in this study. Further this finding may not hold up with youth with disabilities as this study found experiencing a disability predicted significantly less ILP participation. Therefore, caution should also be utilized in interpreting the positive association of placement instability with transition preparation as youth who are most vulnerable, youth with disabilities, are generally moved more frequently with little say in 
where they will live (Geenen \& Powers, 2007). Nevertheless, placement instability remained significant even after disability, placement type, and youth perceptions of restrictiveness were entered into the models indicating there is evidence to suggest there is a subgroup of youth who have higher levels of transition preparation engagement despite moving often. These youth may have higher levels of self-determination and, thus, may in fact voice a choice to move from foster settings that do not serve their needs. It is also possible that these more self-determined youth are highly resilient in the face of placement instability and may engage in more transition preparation engagement on their own accord, despite the barriers and challenges they face in care. Samuels and Pryce (2007) found a similar theme in their qualitative interviews of 44 youth aging out of foster care whereby youth reported developing a sense of hyper self-reliance as a result of the instability and hardships they faced while in foster care. As the authors point out, this perspective can be a great source of resilience for young people leaving care but may also pose additional risk around the development of support networks, a factor known to promote positive adult transitions, for such highly self-reliant youth. Examination of this group of frequent movers and the associations between placement instability, transition preparation and resiliency, however, is outside of the scope of this dissertation and it is recommended that future research examine these associations more closely.

\section{Social Work Policy and Practice Implications}

While Mark Courtney (2009) surmised that older youth aging out of care experience poor young adult outcomes in part because these youth often enter care at an older age and as such are exposed to more family conflict and instability in childhood, the 
findings in this dissertation suggest an alternative hypothesis. The mean length of time since the last episode in care for this group of young people was 11 years, indicating the vast majority spent most of their childhood in foster care. Therefore, youths' level of transition preparation for adulthood was largely driven by foster care experiences for this older group. And as already discussed, residing in a restrictive placement setting and experiencing high levels of perceived restrictiveness indicated less engagement in transition preparation while in care.

The evidence found in this study calls for the need to examine the impact of practices utilized by the child welfare system, particularly the use of restrictive placements for older youth in care, in context of the overall best interest of the youth. Often such restriction is utilized as a behavior management tool designed to meet the needs of caregivers and agency licensing standards and is largely in place to protect agencies and caregivers from liability around safety concern for youth while in care. These licensing standards promote practices and policies that emphasize use of restriction, in particular, for settings serving youth identified as having higher levels of needs. Rather than placing the emphasis on liability around the potential risk of harm to youth the emphasis should shift to ensuring transition-aged youth in care are participating in developmentally appropriate levels of risk taking and independence development to support the well-being of these youth.

State child welfare agencies must begin to include in their training and discussions with foster parents and care facilities the federal legislation that allows for reasonable and prudent parenting decisions to be made by caregivers to ensure the 
normalcy of youth's experiences in foster care compared with their peers. The Act, passed in September 2014, "Preventing Sex Trafficking and Building Health Families", H.R. 4980, enables fosters parents to make decisions without prior approval from the caseworker, court, or licensing agency about the daily, age appropriate activities youth can engage in. Age appropriate behavior in adolescence allows for a healthy level of risktaking and as such, this law begins to shift liability from the caregiver to empower them to ensure youth are engaging in activities like playing sports, learning to drive, and staying overnight out of the foster home. Similar laws are been enacted at the State level in California, Utah, Florida, and Washington.

Efforts should be made to train foster parents who care for this age group with adolescent-specific and disability-related tools and information that promote selfdetermined youth behavior, provide strategic transition preparation goals and activities, and increase community inclusion and social supports of these young people. Further, child welfare agencies should provide ongoing intensive support to these families so that youth may be less likely to experience placement instability, a factor that often leads to youth being placed in highly restrictive care when families are repeatedly unable to meet youths' needs. For youth who have needs that require higher levels of care, alternatives to residential care, such as treatment foster homes or foster families who have been identified as having a high level of skill, should be considered a valuable alternative to institutionalization, which is costly and arguably harmful to older youth who will be residing independently within a short time. While some may argue that group care facilities are effective at addressing the emotional and behavioral needs of youth to 
ensure their safety while in care, it is important to focus on the well-being of young people along their life trajectory and restrictive placement settings have been correlated with poor adult outcomes around education, well-being, social support, housing and economic stability (MacDonald, Allen, Westerfelt \& Piliavan, 1996). Further, an emphasis on providing kinship placements with training similar to that provided to treatment level foster home may also increase placement success for adolescents.

Additionally, policies to promote true permanency for older youth in care must be expanded. The mean age of time in care for youth in this study, approximately 11 years, indicates that the majority of young people exiting foster care in the greater Portland metro area have spent the majority of their childhood in care. The number of older youth exiting care on a plan of long-term foster care is unacceptable. This system, designed for short-term intervention, must also be held accountable to ensuring fewer children actually grow up in foster care and that families are provided the resources and financial support to care for more youth in kinship care, provide long-term guardianship, or adopt older youth before they reach adulthood.

While the child welfare system implemented ILP programs, funded by the Chafee Foster Care Independence Act (1999), to address the gaps found for youth who do reside in foster care until adulthood, there continues to be little evidence that would indicate these programs are successfully preparing youth for the transition to adulthood. Further, these services continue to lag behind in engaging youth with disabilities, largely because such programs are underfunded and ill equipped to provide accommodations to diverse groups of youth. As such, interventions that have shown success in improving outcomes 
for youth aging out of care, such as My Life and related interventions that are focused on enhancing and supporting transition aged youth in care (Powers et al.,2012; Geenen et al., 2013, Geenen et al., 2015), should be made available to youth exiting care beyond the traditional service provision of Independent Living Services. Such services have shown that self-determination enhancement for youth in care is effective at promoting academic performance, including high-school graduation rates and post-secondary enrollment, and increased post-secondary. Additionally, self-determination enhances career planning and daily life preparation activities engagement and engagement of community-based services while in foster care and after exiting care. Further, enhanced self-determination also has been shown to increase ones' overall quality of life, decrease depression and anxiety, and increase employment rates (Powers et al., 2012; Geenen \& Powers, 2007; Geenen et al., 2015). These services should be particularly available to youth who experience a high level of need, such as those who experience disabilities and/or behavioral challenges, and to youth who reside in restrictive settings. These youth in particular need access to ample opportunities to build critical life skills necessary to navigate adulthood successfully.

Additionally, the services, skills, and experiences should be tailored in such a way as to support youth with a diverse range of needs and learning styles and orientated around the goals the youth holds for her/himself. Youth must learn skills through experiential activities and be able to practice these skills with support from adults to become proficient. For instance, learning about career options can be done through attending a job shadow to be exposed to what that job truly looks like and be introduced 
to a possible ally in the field. As another example, budgeting skills can be taught by going to the store to practice pricing and purchasing one's food. Practicing instrumental life skills) like cooking, riding public transportation, or going to the bank in one's community (rather than classroom-based learning), with the support of an ally to model these skills can be particularly helpful. The My Life study, which utilized didactic and experiential learning around youth focused goals rather than introduced in a prescriptive fashion, found significant differences for youth around independent living skills compared to youth in the control group, most of whom were participating in ILP services through child welfare (Powers et al., 2012).

Independent living skill development should be just one component, rather than the primary focus, of these programs. Successful interventions should also look to promote skills and opportunities to enhance self-determined behavior and self-advocacy. Additionally, such services should provide young people meta-cognitive skills to provide them with a framework for thinking about how to make goals, take action steps, and problem solve challenges that will be universally translatable to the broad array of situations young people may encounter as they work towards fulfilling their dreams for adulthood. Other examples of universally translatable skills useful for youth development are informed decision making, working with allies, and managing one's frustration.

A crucial intervention component in supporting youth to prepare for their transition to adulthood while in foster care is youth voice. Programs should support youth around goals and activities they have identified as important to their transition to adulthood. The transition to adulthood may look different for each youth and thus, 
supports and services must be individually tailored. The tradition of professionals planning for a youth's life after care based on the adults' values and ideas of the path a youth should take is antiquated and does very little to ensure a collaboration that is meaningful to youth. Meetings of youth's professional team, including caseworkers, foster parents, mental health professionals, IEP case managers/school staff, and DD case managers, should be anchored around youth-identified goals. Youth given education and support are capable of being facilitators of these meetings. Additionally, professionals must operate more often from a place of unconditional support around youths' goals and learn to put their own biases aside to support youth in a manner that meets the developmental level of young people preparing for adulthood. Professionals should focus on assisting youth in gaining the information and decision making skills they need so that youth are making judgments for themselves about the fit of their goals with their overall best interest. Finally, transition services must focus on helping youth identify allies and important people that can provide support well after exiting foster care. Helping youth and their allies brainstorm concrete ways for how allies will provide support and putting this plan into writing is a helpful way to ensure there is less ambiguity during a youth's transition out of care.

Child welfare policy should focus on accountability of placement decisions made for youth with disabilities in foster care to insure the use of least restrictive placement to meet the needs of each young person. A system that calls on caseworkers to provide formal reports documenting the needs of the youth and provide description on why a least restrictive placement setting does not meet the needs of youth in the context of preparing 
for their transition to adulthood must be implemented before a youth is placed in a restrictive setting. Additionally, for youth who are placed in restrictive placement settings, transition plans that document individualized services and supports for each youth must be in place. Such placement settings should be routinely monitored and reviewed for appropriateness of fit for a youth, particularly for youth who reside in such settings for 6 months or more. Again, monitoring the use of restrictive placement settings must be recognized as a priority concern in legal proceedings to ensure the child welfare system is held accountable to these goals. Further, restrictive placement settings should never be utilized as a default placement for older youth or for youth with complex needs because other placement settings have limited availability given the necessity for youth on the verge of exiting care into adulthood to be in placements that promote a high level of developmentally appropriate transition preparation engagement.

While some may argue that because this dissertation did not show causation between restrictive living environments and level of transition preparation, the results around lower levels of transition preparation are driven solely by the differential needs of youth with disabilities who largely reside in these placement. However, because we know that this group requires more support in their transition to adulthood, it is critical that these young people be heavily engaged in preparation for that transition. Contemporary models conceptualize disability as defined and shaped by the interaction of individual and environmental factors; thus, environmental conditions-foremost restricted opportunities for participation and support- are inextricably tied to the expression of disability and capacity or persons with disabilities to live inclusive, productive, and satisfying lives 
(World Health Organization, 2014). Therefore, it is less important to untangle the complex relationship between disability and restriction to determine the cause of lower levels of transition preparation found in this dissertation. Rather, it is the very fact that youth with disabilities and youth who face higher restriction are participating in less transition preparation than their peers that makes this issue so crucial. Even if this dissertation had shown that youth with disabilities were participating in transition planning that was equal to their peers without disabilities, there would have been cause for concern. These youth must be participating in transition preparation at higher rates than their peers to mitigate the complex barriers and challenges they will face exiting foster care as people who experience disabilities. Given the appropriate supports and individualized transition planning, young people with disabilities can be successful at accomplishing their dreams and goals for adulthood (Powers, Deshler, Jones, and Simon, 2006).

There is also support from special education research around the benefits of less restrictive educational settings for students with disabilities and improved youth transition planning engagement and related outcomes (Idol, 2006; Halpern, Yovanoff, Doren \& Benz, 1995; Miller, Snider, \& Rzonca, 1990; Lehman, Basset, Sands, Spencer \& Griner,1991). Lehman et al (1991) examined transition planning for students with disabilities and found that participation in general education with supports is linked with higher levels of youth engagement and action in transition planning compared to youth who receive their educational instruction in special education classrooms only. A recent study that evaluated the outcomes of high-school students attending schools that 
promoted general education classroom inclusion of students receiving special education services found a steady increase in students' state-wide testing scores, indicating an association between less restrictive educational environments and academic outcomes (Idol, 2006). Finally, a meta-analysis that examined predictors of outcomes for young adults with disabilities found that inclusion in general education classrooms predicted post-secondary education, employment, and independent living success after high-school (Test, Mazzotti, Mustian, Fowler, Kortering, \& Kohler, 2009).

While there is certainly evidence to support the promotion of transition outcomes for youth who are provided supports to learn in less restrictive educational settings, this shift to promoting least restrictive educational settings was based on the premise that young people with disabilities were entitled to basic human rights, including freedom from placement in restrictive educational settings. These rights are guaranteed by the Constitution's $14^{\text {th }}$ Amendment for rights and equal protection under the law and the Individuals with Disabilities Act that states maximum efforts must be made to include youth with disabilities in general education classrooms (IDEA, amended 2004). Additionally, legal precedents including Board of Education v. Holland (1992) which reinforced the right to full inclusion in general education for a child in opposition the school district who deemed such as placement inappropriate based on the child's 'severely disabled' label. Testimony provided in this hear illustrated that this child was thriving educationally and socially in a full general education classroom. Further, Olmestead vs L.C. (1999) established that people with disabilities have the right to community living rather than institutional care in restrictive settings, which the Supreme 
Court deemed "unjustified isolation". Thus, it has been clearly established by law that it is a basic human right that people with disabilities have access to full community and educational inclusion and to be free from restrictive environments. The child welfare system would do well to examine this legal precedence in the context of the wide use of restrictive placement settings utilized for youth in care with disabilities, many of whom lack the supports necessary to effectively advocate against being placed in such settings (Krinsky, \& Rodriguez, 2005).

\section{Limitations of the Study and Future Research Implications}

This was the first study to examine the role of restrictiveness and placement settings on the transition preparation of youth aging out of care. These findings are congruent with those from a study conducted by MacDonald and colleagues (1996) that examined adult outcomes for youth who resided in restrictive placement settings while in foster care, and found poor outcomes in the areas of education, well-being, social support, housing, and economic. However, this dissertation study was cross-sectional in design and focused primarily on youth in the process of transition; thus conclusions around the impact of lower levels of transition preparation while in foster care on adulthood outcomes cannot be made. Therefore, it is recommended that future studies examine longitudinally whether the level of transition preparation one has while in foster care directly predicts young adult outcomes after exiting foster care.

Another limitation of this study was the high number of variables included and multitude of analyses run. This study included a total of eight dependent variables, each of which was included in three regression models with six or seven predictors in each 
regression for a total of 24 regression analyses run. The high number of variables examined in this dissertation study does inflate the probability of a type I error occurring, whereby an effect was detected when in fact there was none. In other words, a variable that was shown to be a significant predictor of one of the transition preparation variables may not have in fact truly predicted differences for transition preparation.

This study did not account for selection bias around which youth are placed in restrictive placement settings and as already stated, youth are often placed in these settings because they are identified as having a higher level of need. Further, because the vast majority of youth in this study residing in restrictive placement settings experienced a disability (75 with disabilities vs 13 without disabilities), disability could not be examined as a mediator of the relationship between restrictive placement settings and transition preparation. Therefore, causation cannot be established and there may be alternative explanations that account for lower transition preparation for youth in restrictive placement settings. Nevertheless, it is this very occurrence of youth with disabilities being placed in restrictive placement settings at such high rates who have needs that indicate higher levels of transition preparation to facilitate the exit from care, that make this issue so critical. Further, the regression models that utilized the restrictiveness variables (placement type and youth perceptions of restrictiveness), accounted for higher levels of variance, or explained a greater level of differences, in transition preparation. Additionally, youth perceptions of restrictiveness explained differences on more the of transition preparation variables than the analyses that used 
disability, indicating that restrictiveness likely explains differences in transition preparation above and beyond examining disability alone.

Additionally, it was possible to examine disability as a mediator of youth perceptions of restrictiveness and transition preparation. Post-hoc regressions were run testing youth perceptions of restrictiveness on transition preparation variables while controlling for disability to determine whether youth perceptions of restrictiveness uniquely described differences in levels of transition preparation beyond what was described by disability alone. With the exception of youth perceptions of readiness for adult life which became non-significant, youth perceptions of restrictiveness did in fact uniquely describe differences found for youth in regard to post-secondary preparation, career preparation, ILP participation, daily life preparation, transition planning, and selfdetermination. While the results still cannot be interpreted to mean that restrictiveness caused these differences, one can see that results found for youth perceptions of restrictiveness were not fully mediated by disability. In other words, regardless of whether one had a disability, youth who reported higher levels of perceived restrictiveness did experience less overall transition preparation.

Another limitation around the sample was that approximately 10 youth were excluded from participating in the larger My Life study due to experiencing high levels of restriction that did not allow them to leave their place of residence to participate in experiential activities, which are a key component of the intervention. Therefore, some youth who would have presumably reported very high levels of restriction were not included in this dissertation and thus the full range of variability in restriction was not 
examined. Nevertheless, that the findings were largely significant despite missing youth facing the highest levels of restriction indicates that this is an issue that impacts youth across a continuum of restrictiveness and that this is not an issue that is unique to those who are severely restricted. Rather, this is an issue that impacts youth across a variety of placement settings and experiences in foster care.

Future research should also focus on evaluating interventions that promote selfdetermination, such as My Life, around the impact on transition preparation levels while in foster care as well as the impact on adult outcomes. The My Life intervention is the only experimentally tested intervention with evidence to support positive transition outcomes of people aging out of foster. Therefore, more studies that test innovative approaches to support youth aging out of foster care are needed. In particular, these studies should focus on whether such models diminish the lag in transition preparation for youth with disabilities and the negative consequences associated with restrictiveness while in foster care.

Additionally, this study provided data on the placement setting at the time baseline data was collected. Therefore, the number of young people who were previously in a restrictive placement setting while in care is unknown. Additionally, this study did not examine whether youth entered restrictive placement settings at entry to care, how long youth had been residing in restrictive placement settings at the time of baseline or whether these were currently assessed to have needs that indicated use of such a placement setting. James and colleagues' (2006) study that found 25\% of youth were placed in restrictive placements upon entry into care, which stands in contrast to the 
Adoptions Assistance and Child Welfare Act (1980) that mandates children be placed in the least restrictive placement necessary to meet their needs. Further, Knitzer and Olson's study (1982) found that up to $40 \%$ of some youth in residential treatment did not have a level of need to warrant such a high level of care is needed to examine the patterns of use of restrictive placement settings in this geographical region. Thus, replication of these studies that examine whether youth enter restrictive placements when they first enter care and whether youth in these placements exhibit needs that warrant such a placement are necessary to understand the utilization of such placements.

While there was some initial evidence to support alignment with findings that kinship care may provide protective capacities for young people in foster care (Conger \& Rebeck, 2001; Metzger, 2008; Courtney \& Dworsky, 2001), particularly in terms of employment and daily life preparation activities found in this study, more research should be conducted to explore the impact of kinship care outcomes both while in care and after exiting care for older youth preparing to transition out of care. Additionally, this study did not include youth who may have been residing independently while in foster care, a factor that is particularly relevant with the national emphasis on youth staying under the guardianship of the child welfare system until age 21 . Additional research should investigate the role of supported independence for transition-aged youth which stands in greater alignment with the experiences of many young people not in foster care who may leave home at 18 but are still provided a great deal of resources and support by their parents. Finally, this study did not examine the unique contribution that returning home to biological parents on the eve of one's exit into adulthood may play as the group of youth 
participating in trial reunification with parents was small and thus included under the kinship care group. While is it known that many youth reconnect with biological parents and family members after exiting care, little is known about the risk or protective factors that such contact may bring to one's transition to adulthood.

This study limited conceptualization of restrictiveness to placement settings and a sum of 5 items from the Restrictiveness Evaluation Measure for Youth (REM-Y; Rauktis, Huefner, O'Brien, Pecora, Doucette, \& Thompson, 2009) around access to one's community, movement in one's home, use of telephone and internet, restrictions around working, and rules around visiting with one's birth family. It is recommended that future studies look to broader definitions of restrictiveness to capture the broad array of ways youth experience restrictiveness in foster care. In particular, it is encouraged that researchers studying outcomes for transition aged youth utilize the REM-Y in its entirety which contains 21 items around the experiences of restrictiveness. The REM-Y should be an integral measure to explore as a moderator of young adult outcomes for youth exiting care.

Finally, this dissertation had an unexpected finding around placement instability and higher levels of self-determination, ILP participation, career preparation activities and daily life preparation activities. A study that utilizes a different method of analysis such as Structural Equation Modeling or Latent Class Analysis may be useful in exploring the subgroup of youth who appear to be experiencing a great deal of instability but are highly resilient in their transition preparation engagement. Certainly, further 
analysis should also include an investigation of restrictiveness with additional protective capacities such as social support, hope, and quality of life.

Additional research utilizing My Life data. The data collected from youth involved in the My Life study spans a period of three-years and four time points: 1) baseline, 2) post-intervention at 12 months from baseline, 3) follow-along at 24 months from baseline, and 4) follow-along two at 36 months from baseline. Thus, it is a rich source to explore several lines of study related to the transition experience of youth aging out of foster care. First, the work in this dissertation will be expanded by examining the association between transition preparation levels, as defined by the variables in this work, and key young adult outcomes at follow along. Similar to those examined in the Midwest evaluation and Westat study (1991), housing stability, educational attainment, postsecondary education participation, employment, overall quality of life, social support, drug and alcohol use, and contact with the criminal justice system can be examined. It is hypothesized that level of transition preparation will predict young adult outcomes and that differences found for youth with disabilities, youth in restrictive placement settings and youth who reported high levels of restrictiveness will be maintained when young adult outcomes are examined.

Because the follow along data will contain two distinct groups, those who received the My Life intervention and those who received community services as usual, the comparison can expand to youth with disabilities who received the intervention compared to youth with disabilities in control. Similarly youth in restrictive placement settings and youth who reported high levels of restrictiveness at baseline can be separated 
into control and treatment to test group differences. This level of analysis allows examination of the key intervention components, rooted in positive youth development (strategic mentoring that provides opportunities for enhanced self-determination and youth participation, experiential learning, increased knowledge of transition skills, and social support building), as a potential mediator of poor young adult outcomes for the groups of youth who were found to have been participating in less transition planning at baseline. In other words, this analysis would explore whether youth who were at risk for low transition preparation engagement at baseline and went on to participate in the intervention show a more positive trajectory across their transition to adulthood than those youth who did not receive the intervention.

In addition to exploring the impact of participating in the intervention over time, other protective factors such as resilience, hope, and social support will be studied. Similar to the work in this dissertation, analysis will be conducted to explore potential baseline differences for these protective factors by disability, placement type, and youth perceptions of restrictiveness. These differences can also be explored over time to determine whether increased resilience, hope, and social support at baseline remains consistent over time and whether these protective factors show an effect on the overall transition process to young adulthood. This analysis is particularly important as many youth will not experience a linear progression from foster care to young adulthood. Rather, some youth who experienced housing stability in foster care for example, may go on to experience a great deal of housing instability in young adulthood. Another example would be a young people who had positive secondary educational experiences but faces 
many barriers around post-secondary education attainment, such as needing to work fulltime, decreased access to accommodations previously provided in high-school, or obligations to caring for family members in young adulthood. By exploring the data over time along the four data points, the complex process of long-term persistence in the face of obstacles and challenges during one's journey to adulthood can be explored.

Finally, the data collected for the My Life study also includes information about psychotropic medication use for young people involved in foster care. Recent studies have found that young in foster care are taking psychotropic medications at 3 to 4 times the rates of their peers also on Medicaid (Zito et al, 2008). As previously discussed, this issue can be conceptualized as a form of behavior control or restrictiveness. Therefore, the data will be examined to determine the overall rate of psychotropic medication use for this population-based sample, particularly for youth who experience disabilities. Further, this data set allows the exploration of level of congruence among youth self-report of reasons for taking a specific medication, foster parent report of why a youth is taking a medication, and the medical indication for the reported medication. It is the experience of those involved in collecting data and disseminating the intervention that many youth do not know why they may be taking a medication or are given very limited information to understand the effect the medication may have, either positively or negatively. This has major implications for youths' ability to make informed choices about their own medication use and whether they continue to utilize these medications once they have exited foster care. 


\section{Conclusions}

Aging out of foster care is quite unlike the typical experience of emerging adulthood lacking a slow, supported transition with relative stability, role models, and access to resources that many young people not in foster care experience (Arnett 2000). As a result, youth who age out of foster care face an array of challenges and barriers that have negative implications for adult outcomes (Pecora et. al, 2006; Courtney et al., 2007). Additionally, youth in foster care who experience disabilities, a large majority of the overall population of youth aging out of care (Hill, 2013; Schmidt et. al, 2013), face compounded risk for poor young adult outcomes compared with their peers aging out of foster care without disabilities (Westat, 1991; Slayter \& Springer, 2011; Smithgall, Gladden, Yang \& Goerge, 2005; Geenen \& Powers, 2006; Anctil, McCubbin, O'Brien, \& Pecora, 2007; Hill, 2012).

The findings in this study further highlight the disparities youth with disabilities preparing to age out of care face around key transition preparation domains. Additionally, this dissertation has provided further evidence that residing in restrictive placement settings, as many youth with disabilities do, and experiencing high levels of perceived restriction, are also associated with lower levels of transition preparation while in foster care. Thus, the child welfare system, in its aim to provide 'safety' to youth identified with greater levels of need and thus most at risk for poor adult outcomes, inadvertently greatly limits opportunities for these young people to participate in key activities related to preparing for adult life, participate in system identified services (ILP) that provide additional levels of support to youth as they prepare to exit care, and build self- 
determined behavior that is necessary for the foundations of a successful transition to adulthood. While transition planning for all youth in care needs to be bolstered, youth with disabilities should be provided more of these opportunities than other youth in care. The practice of utilizing restriction for behavior management of groups of young people with high levels of need and the institutionalized practices that continue to pervade restrictive placement settings in the day-to-day care provided stand in stark contrast to opportunities that will in fact prepare youth for adulthood and as such, must be eradicated. There is no question that youth who are ill prepared for the transition to adulthood before exiting foster care, will continue to struggle as largely unsupported young adults after exiting care. With so much of the emphasis placed on safety within the child welfare system rather than true transition planning and preparation for youth, one must ask, whose safety is truly being protected and at what cost to our youth? 


\section{References}

Abery, B. H. (1994). A conceptual framework for enhancing self-determination. In M. F. Hayden \& B. H. Abery (Eds.), Challenges for a service system in transition: Ensuring quality community experiences for persons with developmental disabilities, (pp. 345-380). Baltimore, MD: Paul H. Brookes Publishing Co.

Abery, B. (2001). The self-determination of young adults with deaf-blindness: Preliminary results from a multivariate study. Paper presented at the 5th Annual Deafblind International Conference, Noordwijkerhout, The Netherlands.

Abery, B. H., McGrew K., \& Smith. J. (1994). ICI Self-Determination and Exercise Scale. Minneapolis: University of Minnesota, Research and Training Center on Community Living and Institute on Community Integration.

Abery, B. H., \& Stancliffe, R. (2003). An ecological theory of self-determination: Theoretical foundations. Theory in self-determination: Foundations for educational practice, (pp. 25-42). Springfield, Ill: Charles C. Thomas Publisher.

Abery, B., \& Stancliffe, R. (1996). The ecology of self-determination. Self-determination across the life span: Independence and choice for people with disabilities, (pp. 111-145). Baltimore, MD: Paul H. Brookes Publishing Co.

Adoption Assistance and Child Welfare Act of. 1980. H.R. 3434-96th Congress (1979).

Allen, M., \& Bissell, M. (2004). Safety and stability for foster children: The policy context. Future Child, 14(1): 48-73.

Ammerman, S. D., Ensign, J., Kirzner, R., Meininger, E. T., Tornabene, M., Warf, C. W., Zerger, S. \& Post, P. (2004). Homeless young adults ages 18-24: Examining 
Service Delivery Adaptations. Nashville, TN: National Health Care for the Homeless Council.

Anctil, T. M., McCubbin, L. D., O'Brien, K., \& Pecora, P. (2007). An evaluation of recovery factors for foster care alumni with physical or psychiatric impairments: Predictors of psychological outcomes. Children and Youth Services Review, 29(8), 1021-1034.

Anctil, T. M., McCubbin, L. D., O’Brien, K., Pecora, P., \& Anderson-Harumi, C. A. (2007). Predictors of adult quality of life for foster care alumni with physical and/or psychiatric disabilities. Child Abuse \& Neglect, 31(10), 1087-1100.

Arnett, J. J. (1997). Young people's conceptions of the transition to adulthood. Youth \& Society, 29(1), 3-23.

Arnett, J. J. (1998). Learning to stand alone: The contemporary American transition to adulthood in cultural and historical context. Human Development, 41(5-6), 295315.

Arnett, J. J. (2000). Emerging Adulthood. American Psychologist Association, Inc., 55(5), 469-480. doi:10.1037//0003-066X.55.5.469

Arnett, J. J. (2003). Conceptions of the transition to adulthood among emerging adults in American ethnic groups. New directions for child and adolescent development, 2003(100), 63-76.

Arnett, J. J. (2014). Emerging adulthood: The winding road from the late teens through the twenties. Oxford University Press.

Barnes, G. M., Hoffman, J. H., Welte, J. W., Farrell, M. P., \& Dintcheff, B. A. (2006). 
Effects of parental monitoring and peer deviance on substance use and delinquency. Journal of Marriage and Family, 68(4), 1084-1104.

Barnow, S., Schuckit, M. A., Lucht, M., John, U., \& Freyberger, H. J. (2002). The importance of a positive family history of alcoholism, parental rejection and emotional warmth, behavioral problems and peer substance use for alcohol problems in teenagers: A path analysis. Journal of Studies on Alcohol and Drugs, 63(3), 305 .

Barth, R. P. (1990). On their own: The experiences of youth after foster care. Child and Adolescent Social Work Journal, 7(5), 419-440.

Barth, R. P. (2002). Institutions vs. foster homes: The empirical base for a century of action. Chapel Hill, NC: Jordan Institute for Families.

Barth, R. P. (2005). Foster home care is more cost-effective than shelter care: Serious questions continue to be raised about the utility of group care in child welfare services. Child abuse \& neglect, 29(6), 623-625.

Baumrind, D. (1967). Child care practices anteceding three patterns of preschool behavior. Genetic Psychology Monographs, 75, 43-88.

Baumrind, D. (1991). The influence of parenting style on adolescent competence and substance use. The Journal of Early Adolescence, 11(1), 56-95.

Beeman, S. K., Kim, H., \& Bullerdick, S. K. (2000). Factors Affecting Placement of Children in Kinship and Nonkinship Foster Care, 22(1), 37-54.

Behar, L. (1990). Financing mental health services for children and adolescents. Bulletin 
of the Menninger Clinic, 54(1), 1-10.

Benard, B. (1991). Fostering resiliency in kids: Protective factors in the family, school, and community. Department of Education: Washington, D.C.

Benedict, M. I., Zuravin, S., \& Stallings, R. Y. (1996). Adult functioning of children who lived in kin versus nonrelative family foster homes. Child Welfare: Journal of Policy, Practice, and Program, 75(5), 529+.

Berrick, J. D., Courtney, M., \& Barth, R. P. (1993). Specialized foster care and group home care: Similarities and differences in the characteristics of children in care. Children and Youth Services Review, 15(6), 453-473.

Berzin, S. C., Singer, E., \& Hokanson, K. (2014). Emerging Versus Emancipating: The Transition to Adulthood for Youth in Foster Care. Journal of Adolescent Research, 29(5), 616-638. doi:10.1177/0743558414528977

Bond, L., Toumbourou, J. W., Thomas, L., Catalano, R. F., \& Patton, G. (2005). Individual, family, school, and community risk and protective factors for depressive symptoms in adolescents: A comparison of risk profiles for substance use and depressive symptoms. Prevention Science, 6(2), 73-88.

Brault, M. W. (2011). School-Aged Children with Disabilities in US Metropolitan Statistical Areas: 2010. American Community Survey Briefs. ACSBR/10-12.US Census Bureau.

Breland-Noble, A. M., Farmer, E. M. Z., Dubs, M. S., Potter, E., \& Burns, B. J. (2005). Mental Health and Other Service Use by Youth in Therapeutic Foster Care and 
Group Homes, 14(2), 167-180. doi:10.1007/s10826-005-5045-5

Briggs, E. C., Greeson, J. K. P., Layne, C. M., Fairbank, J. A., Knoverek, A. M., \& Pynoos, R. S. (2012). Trauma Exposure, Psychosocial Functioning, and Treatment Needs of Youth in Residential Care: Preliminary Findings from the NCTSN Core Data Set. Journal of Child \& Adolescent Trauma, 5(1), 1-15. doi:10.1080/19361521.2012.646413

Bronfenbrenner, U. (1974). Developmental research, public policy, and the ecology of childhood. Child Development, 1-5.

Canty-Mitchell, J., \& Zimet, G. D. (2000). Psychometric properties of the Multidimensional Scale of Perceived Social Support in urban adolescents. American Journal of Community Psychology, 28(3), 391-400.

Care, T. F., Curtis, P. A., Ph.D., Alexander, G., \& Lunghofer, L. A. (2001). A Literature Review Comparing the Outcomes of Residential Group Care and Therapeutic Foster Care, 18(5).

Carter, E. W., Trainor, A. A., Cakiroglu, O., Swedeen, B., \& Owens, L. A. (2010). Availability of and access to career development activities for transition-age youth with disabilities. Career Development for Exceptional Individuals, 33(1), 13-24.

Cartledge, G. (2005). Restrictiveness and Race in Special Education : The Failure to Prevent or to Return. Learning Disabilities: A Contemporary Journal, 3(1), 27-32.

Chafee Foster Care Independence Act $\S 121,113$ Stat. 1822, 1829-30.

Chambers, C. R., Wehmeyer, M. L., Saito, Y., Lida, K. M., Lee, Y., \& Singh, V. (2007). 
Self-Determination: What Do We Know? Where Do We Go ? Knowledge Creation Diffusion Utilization, 15(1), 3-15.

Chapman, M. V., Wall, A., \& Barth, R. P. (2004). Children's voices: The perceptions of children in foster care. American Journal of Orthopsychiatry, 74(3), 293.

Cheng, S. T., \& Chan, A. C. (2004). The multidimensional scale of perceived social support: Dimensionality and age and gender differences in adolescents. Personality and Individual Differences, 37(7), 1359-1369.

Cobb, B., Lehmann, J., Newman-Gonchar, R., \& Alwell, M. (2009). Self-Determination for Students with Disabilities: A Narrative Metasynthesis. Career Development for Exceptional Individuals, 32(2), 108-114. doi:10.1177/0885728809336654

Collins, M. E. (2001). Transition to Adulthood for Vulnerable Youths : A Review of Research and Implications for Policy. Social Service Review, 75(2).

Collins, M. E., Paris, R., \& Ward, R. L. (2008). The permanence of family ties: Implications for youth transitioning from foster care. American Journal of Orthopsychiatry, 78(1), 54-62.

Conger, D. and Rebeck, A. (2001). How children's foster care experiences affect their education. New York, NY: New York City.

Cook, R., Fleischman, E., \& Grimes, V. (1991). A National Evaluation of Title IV-E Foster Care Independent Living Programs for Youth. Phase 2 Final Report, 1. Courtney, M. E. (2009). Outcomes for older youth exiting the foster care system in the United States. In B. Kerman, M. Freundlich, \& A.N. Maluccio (Eds.), Achieving 
permanence for older children and youth in foster care (pp. 40-74). New York, NY: Columbia University Press.

Courtney, M. E. and Dworsky, A. (2006). Early outcomes for young adults transitioning from out-of-home care in the USA. Child \& Family Social Work, 11(3): 209-219.

Courtney, M. E., \& Barth, R. P. (1996). Pathways of older adolescents out of foster care: Implications for independent living services. Social Work, 41(1), 75-83.

Courtney, M. E., \& Heuring, D. H. (2005). The Transition to Adulthood for Youth “Aging Out" of the Foster Care System. On Your Own without a Net: The Transition to Adulthood for Vulnerable Populations (pp. 27-67). Chicago, IL: The University of Chicago Press.

Courtney, M. E., Dworsky, A., Cusick, G. R., Havlicek, J., Perez, A., \& Keller, T. (2007). Midwest Evaluation of the Adult Functioning of Former Foster Youth : Outcomes at Age 21. Chapin Hall Center for Children at the University of Chicago. Chicago, IL.

Courtney, M. E., Dworsky, A., Lee, J. S., \& Raap, M. (2010). Midwest Evaluation of the Adult Functioning of Former Foster Youth: Outcomes at Ages 23 and 24: Executive summary. Chapin Hall Center for Children at the University of Chicago. Chicago, IL.

Courtney, M. E., Dworsky, A., Ruth, G., Keller, T., Havlicek, J., \& Bost, N. (2005). Midwest Evaluation of the Adult Functioning of Former Foster Youth: Outcomes at Age 21. Chapin Hall Center for Children at the University of Chicago. Chicago, 
IL.

Courtney, M. E., Piliavin, I., Grogan-Kaylor, A., \& Nesmith, A. (2001). Foster youth transitions to adulthood: A longitudinal view of youth leaving care. Child WelfareNew York, 80(6), 685-718.

Courtney, M. E., Terao, S., \& Bost, N. (2004). Midwest Evaluation of the Adult Functioning of Former Foster Youth: Conditions of Youth Preparing to Leave State Care. Chapin Hall Center for Children at the University of Chicago. Chicago, IL.

Courtney, M. E., Zinn, A., Zielewski, E. H., Bess, R. J., Malm, K. E., Stagner, M., \& Pergamit, M. (2008). Evaluation of the Early Start to Emancipation Preparation Tutoring Program, Los Angeles County, California: Final Report. Administration for Children \& Families.

Courtney, M., Dworsky, A., \& Brown, A. (2009). Midwest Evaluation of the Adult Functioning of Former Foster Youth: Outcomes at Age 19. Chapin Hall Center for Children at the University of Chicago. Chicago, IL.

Courtney, M., Dworsky, A., Brown, A., Cary, C., Love, K., \& Vorhies, V. (2011). Midwest Evaluation of the Adult Functioning of Former Foster Youth: Outcomes at Age 26. Chapin Hall Center for Children at the University of Chicago. Chicago, IL.

Courtney, M., Zinn, A., Johnson, H., \& Malm, K. (2011). Evaluation of the Massachusetts Adolescent Outreach Program for Youths in Intensive Foster Care: 
Final Report (Vol. 14). OPRE Report.

Courtney, M., Zinn, A., Koralek, R., \& Bess, R. (2011). Evaluation of the Independent Living-Employment Services Program, Kern County, California: Final Report. OPRE report, 201113.

Coutinho, M. J., \& Oswald, D. P. (2005). State variation in gender disproportionality in special education findings and recommendations. Remedial and Special Education, 26(1), 7-15.

Cronce, J. M., \& Corbin, W. R. (2010). Effects of alcohol and initial gambling outcomes on within-session gambling behavior. Experimental and Clinical Psychopharmacology, 18(2), 145.

Crosland, K. A., Dunlap, G., Sager, W., Neff, B., Wilcox, C., Blanco, A., \& Giddings, T. (2008). The effects of staff training on the types of interactions observed at two group homes for foster care children. Research on Social Work Practice, 18(5), 410-420.

Cross, T., Cooke, N. L., Wood, W. M., \& Test, D. W. (1999). Comparison of the effects of MAPS and ChoiceMaker on student self-determination skills. Education and Training in Mental Retardation and Developmental Disabilities, 34(4), 499-510.

Crosse, S.B., Kaye, E., \& Ratnofsky, A.C. (1992). A Report on the Maltreatment of Children with Disabilities. National Center on Child Abuse and Neglect: Washington, D.C.

Cuddeback, G. S. (2004). Kinship family foster care: A methodological and substantive synthesis of research. Children and Youth Services Review, 26(7), 623-639. 
doi:10.1016/j.childyouth.2004.01.014

Cunninghman, M. J., \& Diversi, M. (2012). Aging out: Youths' perspectives on foster care and the transition to independence. Qualitative Social Work, 1473325012445833-. doi:10.1177/1473325012445833

Curtis, P. A., Alexander, G., \& Lunghofer, L. A. (2001). A literature review comparing the outcomes of residential group care and therapeutic foster care. Child and Adolescent Social Work Journal, 18(5), 377-392.

Curtner-Smith, M. E., \& MacKinnon-Lewis, C. E. (1994). Family process effects on adolescent males' susceptibility to antisocial peer pressure. Family Relations, $462-$ 468.

Dahlem, N. W., Zimet, G. D., \& Walker, R. R. (1991). The Multidimensional Scale of Perceived Social Support: A confirmation study. Journal of clinical psychology, (47), 756-61.

Daining, C., \& DePanfilis, D. (2007). Resilience of youth in transition from out-of-home care to adulthood. Children and Youth Services Review, 29(9), 1158-1178.

Daining, C., \& DePanfilis, D. (2007). Resilience of youth in transition from out-of-home care to adulthood. Children and Youth Services Review, 29(9), 1158-1178. doi:10.1016/j.childyouth.2007.04.006

Day, A., Dworsky, A., Fogarty, K., \& Damashek, A. (2011). An examination of postsecondary retention and graduation among foster care youth enrolled in a fouryear university. Children and Youth Services Review, 33(11), 2335-2341. 
Dennis, R. E., Williams, W., Giangreco, M. F., \& Cloninger, C. J. (1993). Quality of life as context for planning and evaluation of services for people with disabilities. Exceptional Children, 59(6), 499-512.

Dew, T., \& Huebner, E. S. (1994). Adolescents' perceived quality of life: An exploratory investigation. Journal of School psychology, 32(2), 185-199.

Dore, M. M., Wilkinson, A. N., \& Sonis, W. A. (1992). Exploring the relationship between a continuum of care and intrusiveness of children's mental health services. Psychiatric Services, 43(1), 44-48.

Dornbusch, S. M., Ritter, P. L., Leiderman, P. H., Roberts, D. F., \& Fraleigh, M. J. (1987).

The relation of parenting style to adolescent school performance. Child Development, 1244-1257.

Dowd, K., Kinsey, S., Wheeless, S., Thissen, R., Richardson, J., Suresh, R., et al. National Survey of Child and Adolescent Well-Being (NSCAW): Combined Waves 1-4 data user's manual. Research Triangle Institute; Durham, NC: 2004.

Dubowitz, H. (1990). Costs and effectiveness of interventions in child maltreatment. Child Abuse \& Neglect, 14(2), 177-186.

Dworsky, A. L., \& Courtney, M. E. (2001). Self-sufficiency of Former Foster Youth in Wisconsin: Analysis of Unemployment Insurance, Wage Data and Public Assistance Data. Institute for Research on Poverty.

Fanshel, D., Finch, S. J., \& Grundy, J. F. (1990). Foster children in a life course perspective. Columbia University Press: New York.

Farmer, E. M. Z., Ph.D., Wagner, H. R., Burns, B. J., \& Richards, J. T. (2003). Treatment 
Foster Care in a System of Care: Sequences and Correlates of Residential Placements. Journal of Child and Family Studies, 12(1), 11-25.

Fechter-Leggett, M. O., \& O’Brien, K. (2010). The effects of kinship care on adult mental health outcomes of alumni of foster care. Children and Youth Services Review, 32(2), 206-213. doi:10.1016/j.childyouth.2009.08.017

Feldman, R. A., Stiffman, A. R., \& Jung, K. G. (1987). Children at risk: In the web of parental mental illness. Rutgers University Press: Piscataway, NJ.

Festinger, T. (1983). No One Ever Asked Us: A Postscript to Foster Care. Columbia University Press.

Field, S., Hoffman, A., \& Posch, M. (1997). Self-determination during adolescence a developmental perspective. Remedial and Special Education, 18(5), 285-293.

Field, S., Hoffman, A., \& Posch, M. (1997). Self-determination during adolescence a developmental perspective. Remedial and Special Education, 18(5), 285-293.

Fields, S. A. O. (2002). The System of Care for Children and the Least Restrictive Alternative: Legal Origins and Current Concerns. , 5(2), 75-93.

Fields, S. A., \& Ogles, B. M. (2002). The system of care for children and the least restrictive alternative: Legal origins and current concerns. Children's Services: Social Policy, Research, and Practice, 5(2), 75-93.

Fierros, E. G., \& Blomberg, N. A. (2005). Restrictiveness and Race in Special Education Placements in For-Profit and Non-Profit Charter Schools in California. Learning Disabilities: A Contemporary Journal, 3(1), 1-16. 
Fierros, E. G., \& Conroy, J. W. (2002). Double jeopardy: An exploration of restrictiveness and race in special education. Racial inequity in special education, $39-70$.

Fornes, S., Rocco, T. S., \& Rosenberg, H. (2008). Improving outcomes for workers with mental retardation. Human Resource Development Quarterly, 19(4), 373-395.

Fostering Connections Act of 2008. HR 6893 (2008).

Franck, K. L. (2001). Characteristics of kinship and nonkinship care foster children and their families of origin (Doctoral dissertation, University of Tennessee, Knoxville).

Franz, C. E., McClelland, D. C., \& Weinberger, J. (1991). Childhood antecedents of conventional social accomplishment in midlife adults: A 36-year prospective study. Journal of Personality and Social Psychology, 60(4), 586.

Freeman, S., \& Alkin, M. (2000). Academic and Social Attainments of children with mental retardation in general education and special education settings. Remedial and Special Education. Retrieved from http://rse.sagepub.com/content/21/1/3.short

Frey, L. L., Greenblatt, S. B., \& Brown, J. (2007). A call to action: An integrated approach to youth permanency and preparation for adulthood. Seattle, WA: Casey Family Programs.

Friman, P. C., Evans, J., Larzelere, R., Williams, G., \& Daly, D. L. (1993). Correspondence between child dysfunction and program intrusion: Evidence of a 
continuum of care across five child mental health programs. Journal of Community Psychology, 21(3), 227-233.

Friman, P. C., Soper, S. H., Thompson, R. W., \& Daly, D. L. (1993). Do children from community-based parent training programs have clinically significant behavior problems? Journal of Community Psychology, 21(1), 56-63.

Fuligni, A. J., Tseng, V., \& Lam, M. (1999). Attitudes toward family obligations among American adolescents with Asian, Latin American, and European backgrounds. Child Development, 70(4), 1030-1044.

Furstenberg Jr, F. F. (2010). On a new schedule: Transitions to adulthood and family change. The Future of Children, 20(1), 67-87.

Furstenberg Jr, F. F., \& Hughes, M. E. (1995). Social capital and successful development among at-risk youth. Journal of Marriage and the Family, 580-592.

Geenen, S., \& Powers, L. E. (2006a). Are we ignoring youths with disabilities in foster care? An examination of their school performance. Social work, 51(3), 233-41.

Geenen, S. J., \& Powers, L. E. (2006b). Transition Planning for Foster Youth. Journal for Vocational Special Needs Education, 28(2), 4-15.

Geenen, S., \& Powers, L. E. (2007). "Tomorrow is another problem": The experiences of youth in foster care during their transition into adulthood. Children and Youth Services Review, 29(8), 1085-1101.doi:10.1016/j.childyouth.2007.04.008

Geenen, S., Powers, L. E., Powers, J., Cunningham, M., McMahon, L., Nelson, M., \& Fullerton, A. (2013). Experimental study of a self-determination intervention for youth in foster care. Career Development and Transition for Exceptional 
Individuals, 36(2), 84-95.

Geenen, S., Powers, L. E., Phillips, L. A., Nelson, M., McKenna, J., Winges-Yanez, N., \& Swank, P. (2015). Better Futures: A randomized field test of a model for supporting young people in foster care with mental health challenges to participate in higher education. The Journal of Behavioral Health Services \& Research, 42(2), 150-171.

Georgiades, S. (2005). A multi-outcome evaluation of an independent living program. Child and Adolescent Social Work Journal, 22(5-6), 417-439.

Gilligan, R. (2000). Adversity, resilience and young people: The protective value of positive school and spare time experiences. Children \& society, 14(1), 37-47.

Goerge, R. M., Bilaver, L., Lee, B. J., Needell, B., Brookhart, A., \& Jackman, W. (2002). Employment outcomes for youth aging out of foster care. Chapin Hall Center for Children, University of Chicago.

Goerge, R. M., Bilaver, L., Lee, B. J., Needell, B., Brookhart, A., \& Jackman, W. (2002). Employment outcomes for youth aging out of foster care. Chapin Hall Center for Children, University of Chicago.

Goerge, R. M., Van Voorhis, J., Grant, S., \& Casey, K. (1992). Special-education experiences of foster children: An empirical study. Child Welfare: Journal of Policy, Practice, and Program.

Goerge, R., \& Lee, B. (2000). The Entry of Children from the Welfare System into Foster Care: Differences by Race. (Available at the Children and Family Research Center, School of Social Work, University of Illinois at Urbana-Champaign, 1207 
W. Oregon, Urbana IL 68010).

Gray, M. R., \& Steinberg, L. (1999). Unpacking authoritative parenting: Reassessing a multidimensional construct. Journal of Marriage and the Family, 574-587.

Greene, A. L., Wheatley, S. M., \& Aldava, J. F. (1992). Stages on life's way adolescents' implicit theories of the life course. Journal of Adolescent Research, 7(3), 364-381.

Griffin, C., Hammis, D., Geary, T., \& Sullivan, M. (2008). Customized employment: Where we are; where we're headed. Journal of Vocational Rehabilitation, 28(3), 135.

Hahn, R. A., Bilukha, O., Lowy, J., Crosby, A., Fullilove, M. T., Liberman, A., Moscicki, E., et al. (2005). The Effectiveness of Therapeutic Foster Care for the A Systematic Review. American Journal of Preventive Medicine, 28. doi:10.1016/j.ampre.2004.10.007

Halpern, A. S. (1994). The transition of youth with disabilities to adult life: A position statement of the Division on Career Development and Transition, the Council for Exceptional Children. Career Development for Exceptional Individuals, 17(2), 115-124.

Handwerk, M. L., Friman, P. C., Mott, M. A., \& Stairs, J. M. (1998). The Relationship Between Program Restrictiveness and Youth Behavior Problems. Journal of Emotional and Behavioral Disorders, 6(3), 170-179. doi:10.1177/106342669800600305

Harris, M. S., \& Skyles, A. (2008). Kinship Care for African American Children 
Disproportionate and Disadvantageous. Journal of Family Issues, 29(8), 10131030.

Harris, M. S., Jackson, L. J., O'Brien, K., \& Pecora, P. J. (2009). Disproportionality in education and employment outcomes of adult foster care alumni. Children and Youth Services Review, 31(11), 1150-1159.

Havlicek, J. (2011). Lives in Motion: A Review of Former Foster Youth in the Context of their Experiences in the Child Welfare System. Children and Youth Services Review, 33(7), 1090-1100. doi:10.1016/j.childyouth.2011.02.007

Hegar, R. L., \& Rosenthal, J. A. (2009). Kinship care and sibling placement: Child behavior, family relationships, and school outcomes. Children and Youth Services Review, 31(6), 670-679. doi:10.1016/j.childyouth.2009.01.002

Heller, T., Miller, A. B., \& Hsieh, K. (2002). Eight-year follow-up of the impact of environmental characteristics on well-being of adults with developmental disabilities. Journal Information, 40(5).

Henig, A. (2009). Employment aid for youth aging out of foster care: Extending one-stop career centers to include a division for foster care youth. Family Court Review, $47(3), 570-585$.

Hill, K. (2012). Permanency and placement planning for older youth with disabilities in out-of-home placement. Children and Youth Services Review, 34(8), 1418-1424. doi:10.1016/j.childyouth.2012.03.012

Hill, K. (2013). Special education experience of older foster youth with disabilities: An analysis of administrative data. Journal of Public Child Welfare, 7(5), 520-535. 
Hill, R. B. (2004). Institutional racism in child welfare. Race and Society, 7(1), 17-33.

Hill, R. B. (2005). The role of race in parental reunification. Race matters in child welfare: The overrepresentation of African American children in the system, 215230.

Hiripi, E., White, C. R., Wiggins, T., \& Holmes, K. E. (2005). Improving family foster care: Findings from the Northwest Foster Care Alumni Study. Seattle, WA: Casey Family Programs.

Hobfoll, S. E., \& Spielberger, C. D. (1992). Family stress: Integrating theory and measurement. Journal of family psychology, 6(2), 99.

Hoge, C. W., Castro, C. A., Messer, S. C., McGurk, D., Cotting, D. I., \& Koffman, R. L. (2004). Combat duty in Iraq and Afghanistan, mental health problems, and barriers to care. New England Journal of Medicine, 351(1), 13-22.

Holahan, C. J., \& Moos, R. H. (1991). Life stressors, personal and social resources, and depression: A 4-year structural model. Journal of abnormal psychology, 100(1), 31.

Holahan, C. J., Valentiner, D. P., \& Moos, R. H. (1994). Parental support and psychological adjustment during the transition to young adulthood in a college sample. Journal of Family Psychology, 8(2), 215.

Hundert, J., Cassie, J. B., \& Johnston, N. (1988). Characteristics of emotionally disturbed children referred to day-treatment, special-class, outpatient, and assessment services. Journal of Clinical Child Psychology, 17(2), 121-130.

Hunter, A. J., \& Chandler, G. E. (1999). Adolescent resilience. Image: The Journal of 
Nursing Scholarship, 31(3), 243-247.

Hwang, J., \& Lee, B. R. (2013). Response agreement rates between child welfare involved youth and their caregivers. Journal of Social Service Research, 39(2), 218-232.

Hyde, J., \& Kammerer, N. (2009). Adolescents' perspectives on placement moves and congregate settings: Complex and cumulative instabilities in out-of-home care. Children and Youth Services Review, 31(2), 265-273. doi:10.1016/j.childyouth.2008.07.019.

Iglehart, A. P. (1994). Kinship foster care: Placement, service, and outcome issues. Children and Youth Services Review, 16(1-2), 107-122. doi:10.1016/01907409(94)90018-3

Iglehart, A. P. (1995). Readiness for independence: Comparison of foster care, kinship care, and non-foster care adolescents. Children and Youth Services Review, 17(3), 417-432.

James, S., Leslie, L. K., Hurlburt, M. S., Slymen, D. J., Landsverk, J., Davis, I., \& Mathiesen, S. G. (2006). Children in Out-of-Home Care: Entry into Intensive or Restrictive Mental Health and Residential Care Placements. Journal of Emotional and Behavioral Disorders, 14(4), 196-208. doi:10.1177/10634266060140040301

James, Sigrid, Landsverk, J., \& Slymen, D. J. (2004). Placement movement in out-ofhome care: Patterns and predictors. Children and Youth Services Review, 26(2), 185-206. doi:10.1016/j.childyouth.2004.01.008 
Jaskulski, T., Metzler, C., \& Zierman, S. A. (1990). Forging a new era. The 1990 report on people with developmental disabilities, Appendix. Washington, DC: National Association of Developmental Disabilities Councils.

Johnson, W., \& Krueger, R. F. (2005). Higher perceived life control decreases genetic variance in physical health: Evidence from a national twin study. Journal of personality and social psychology, 88(1), 165.

Jones, M. A., \& Moses, B. (1984). West Virginia's former foster children: Their experience in care and their lives as young adults. Child Welfare League of America.

Johnson-Reid, M., \& Barth, R. P. (2000). From placement to prison: The path to adolescent incarceration from child welfare supervised foster or group care. Children and Youth Services Review, 22(7), 493-516.

Kazdin, A. E., Rodgers, A., \& Colbus, D. (1986). The hopelessness scale for children: psychometric characteristics and concurrent validity. Journal of consulting and clinical psychology, 54(2), 241.

Keller, T. E., Salazar, A. M., \& Courtney, M. E. (2010). Prevalence and Timing of Diagnosable Mental Health, Alcohol, and Substance Use Problems among Older Adolescents in the Child Welfare System. Children and youth services review, 32(4), 626-634. doi:10.1016/j.childyouth.2009.12.010

Keller, T. E., Blakeslee, J. E., Lemon, S. C., \& Courtney, M. E. (2010). Subpopulations of older foster youths with differential risk of diagnosis for alcohol abuse or dependence. Journal of studies on alcohol and drugs, 71(6), 819. 
Kiesler, C. A. (1993). Mental health policy and the psychiatric inpatient care of children. Applied and Preventive Psychology, 2(2), 91-99.

Kiesler, C. A. (1993). Mental health policy and the psychiatric inpatient care of children. Applied and Preventive Psychology, 2(2), 91-99.

King, G. A., Baldwin, P. J., Currie, M., \& Evans, J. (2005). Planning successful transitions from school to adult roles for youth with disabilities. Children's Health Care, 34(3), 193-216.

Knitzer, J., \& Olson, L. (1982). Unclaimed Children: The Failure of Public Responsibility to Children and Adolescents in Need of Mental Health Services.

Krinsky, M. A., \& Rodriguez, J. (2005). Giving a Voice to the Voiceless: Enhancing Youth Participation in Court Proceedings. Nev. LJ, 6, 1302.

Lachapelle, Y., Wehmeyer, M. L., Haelewyck, M.-C., Courbois, Y., Keith, K. D., Schalock, R., Verdugo, M. a, et al. (2005). The relationship between quality of life and self-determination: An international study. Journal of Intellectual Disability Research : JIDR, 49(Pt 10), 740-4. doi:10.1111/j.1365-2788.2005.00743.x

Lee, B. R., \& Thompson, R. (2008). Comparing outcomes for youth in treatment foster care and family-style group care. Children and Youth Services Review, 30(7), 746757.

Lee, B. R., \& Thompson, R. (2009). Examining externalizing behavior trajectories of youth in group homes: Is there evidence for peer contagion? Journal of Abnormal Child Psychology, 37(1), 31-44. doi:10.1007/s10802-008-9254-4 
Lee, C., \& Berrick, J. D. (2014). Experiences of youth who transition to adulthood out of care: Developing a theoretical framework. Children and Youth Services Review, 46, 78-84. doi:10.1016/j.childyouth.2014.08.005

Lee, Y., Wehmeyer, M. L., Palmer, S. B., Williams-Diehm, K., Davies, D. K., \& Stock, S. E. (2010). Examining Individual and Instruction-Related Predictors of the SelfDetermination of Students with Disabilities: Multiple Regression Analyses. Remedial and Special Education, 33(3), 150-161. doi:10.1177/0741932510392053

Lemon, K., Hines, A. M., \& Merdinger, J. (2005). From foster care to young adulthood: The role of independent living programs in supporting successful transitions. Children and youth services review, 27(3), 251-270.

Leung, J. P., \& Leung, K. (1992). Life satisfaction, self-concept, and relationship with parents in adolescence. Journal of Youth and adolescence, 21(6), 653-665.

Leung, J. P., \& Zhang, L. W. (2000). Modelling life satisfaction of Chinese adolescents in Hong Kong. International Journal of Behavioral Development, 24(1), 99-104.

Lightfoot, E., Hill, K., \& LaLiberte, T. (2011). Prevalence of children with disabilities in the Child Welfare System and out of home placement: An examination of administrative records. Children and Youth Services Review, 33(11), 2069-2075.

Lightfoot, E., Hill, K., \& LaLiberte, T. (2011). Prevalence of children with disabilities in the Child Welfare System and out of home placement: An examination of administrative records. Children and Youth Services Review, 33(11), 2069-2075.

Losen, D. J., \& Orfield, G. (2002). Racial inequity in special education. Harvard 
Education Publishing Group: Cambridge, MA.

Lyons, J. S., Libman-Mintzer, L. N., Kisiel, C. L. and Shallcross, H. (1998).

Understanding the mental health needs of children and adolescents in residential treatment. Professional Psychology: Research \& Practice, 29(5), 582-587.

Maccoby, E. E., \& Martin, J. A. (1983).Socialization in the context of the family: Parentchild inter- action. In E. M. Hetherington (Ed.), Hand- book of child psychology (4th ed., Vol. 4). New York: Wiley.

MacDonald, T. P., Allen, R. I., Westerfelt, A. and Piliavin, I. 1996. Assessing the longterm effects of foster care: A research synthesis. Washington, DC: CWLA Press.

Mason, C. A., Walker-Barnes, C. J., Tu, S., Simons, J., \& Martinez-Arrue, R. (2004). Ethnic differences in the affective meaning of parental control behaviors. Journal of Primary Prevention, 25(1), 59-79.

Massinga, R., \& Pecora, P. J. (2004). Providing better opportunities for older children in the Child Welfare System. The Future of Children, 151-173.

Masten, A. N. N. S., Burt, K. B., \& Roisman, G. I. (2004). Resources and resilience in the transition to adulthood: Continuity and change, 16, 1071-1094.

McDonald, S., Erickson, L. D., Johnson, M. K., \& Elder, G. H. (2007). Informal mentoring and young adult employment. Social Science Research, 36(4), 13281347.

McGloin, J.M., Widom, C.S. (2001). Resilience among abused and neglected children grown up, Development and Psychopathology, 13, 1021-1038.

McMillen, C., Auslander, W., Elze, D., White, T., \& Thompson, R. (2003). Educational 
experiences and aspirations of older youth in foster care. Washington, DC: Child Welfare League of America.

McMillen, C., Auslander, W., Elze, D., White, T., \& Thompson, R. (2003). Educational experiences and aspirations of older youth in foster care. Child Welfare League of America, 82(4), 475-495.

McMillen, J. C., \& Tucker, J. (1999). The status of older adolescents at exit from out-ofhome care. Child Welfare: Journal of Policy, Practice, and Program.

Mech, E. V., \& Fung, C. C.-M. (1999). Placement Restrictiveness and Educational Achievement among Emancipated Foster Youth. Research on Social Work Practice, 9(2), 213-228. doi:10.1177/104973159900900206

Mech, E. V., Ludy-Dobson, D., \& Hulseman, F. S. (1994). Life-skills knowledge: A survey of foster adolescents in three placement settings. Children and Youth Services Review, 16(3/4), 181-200

Metzger, J. (2008). Resiliency in children and youth in kinship care and family foster care. Child welfare, 87(6), 115-140.

Metzger, J. (2008). Resiliency in children and youth in kinship care and family foster care. Child welfare, 87(6), 115-40. Retrieved from http://www.ncbi.nlm.nih.gov/pubmed/19534356

Milevsky, A., Schlechter, M., Klem, L., \& Kehl, R. (2008). Constellations of maternal and paternal parenting styles in adolescence: Congruity and well-being. Marriage \& Family Review, 44(1), 81-98. 
Milevsky, A., Schlechter, M., Netter, S., \& Keehn, D. (2007). Maternal and paternal parenting styles in adolescents: Associations with self-esteem, depression and lifesatisfaction. Journal of Child and Family Studies, 16(1), 39-47.

Montgomery, P., Donkoh, C., \& Underhill, K. (2006). Independent living programs for young people leaving the care system: The state of the evidence. Children and youth services review, 28(12), 1435-1448.

Montgomery, P., Donkoh, C., \& Underhill, K. (2006). Independent living programs for young people leaving the care system: The state of the evidence. Children and youth services review, 28(12), 1435-1448.doi:10.1016/j.childyouth.2006.03.002

Mortimer, J. T., \& Larson, R. W. (Eds.). (2002). The changing adolescent experience: Societal trends and the transition to adulthood. Cambridge University Press.

Munson, M. R., \& McMillen, J. C. (2009). Natural mentoring and psychosocial outcomes among older youth transitioning from foster care. Children and Youth Services Review, 31(1), 104-111.

Murry, V. M., Bynum, M. S., Brody, G. H., Willert, A., \& Stephens, D. (2001). African American single mothers and children in context: A review of studies on risk and resilience. Clinical Child and Family Psychology Review, 4(2), 133-155.

Naccarato, T., \& DeLorenzo, E. (2008). Transitional youth services: Practice implications from a systematic review. Child and Adolescent Social Work Journal, 25(4), 287308.

Naccarato, T., \& DeLorenzo, E. (2008). Transitional youth services: Practice implications from a systematic review. Child and Adolescent Social Work Journal, 25(4), 287- 
308. doi:National Survey of Child and Adolescent Well-Being (NSCAW) National Survey of Child and Adolescent Well-Being (NSCAW), Introduction to the Wave 1 General and Restricted Use Releases. 2002. [On-line].

Nelson, L. J. (2003). Rites of passage in emerging adulthood: Perspectives of young Mormons. New Directions for Child and Adolescent Development, 2003(100), 33 50.

Newman, L., Wagner, M., Knokey, A. M., Marder, C., Nagle, K., Shaver, D., \& Wei, X. (2011). The Post-High School Outcomes of Young Adults with Disabilities up to 8 Years after High School: A Report from the National Longitudinal Transition Study-2 (NLTS2). NCSER 2011-3005. National Center for Special Education Research.

Nota, L., Ferrari, L., Soresi, S., \& Wehmeyer, M. (2007). Self-determination, social abilities and the quality of life of people with intellectual disability. Journal of Intellectual Disability Research, 51(11), 850-865.

Oswald, D. P., Best, A. M., Coutinho, M. J., \& Nagle, H. A. (2003). Trends in the special education identification rates of boys and girls: A call for research and change. Exceptionality, 11(4), 223-237.

Parke, R. D., \& Buriel, R. (1998). Socialization in the family: Ethnic and ecological perspectives. Handbook of child psychology. John Wiley \& Sons, Inc.: online. doi:10.1002/9780470147658

Pecora, P. J., Kessler, R. C., O'Brien, K., White, C. R., Williams, J., Hiripi, E., \& Herrick, M. A. (2006). Educational and employment outcomes of adults formerly placed in 
foster care: Results from the Northwest Foster Care Alumni Study. Children and youth services review, 28(12), 1459-1481. doi:10.1016/j.childyouth.2006.04.003

Pecora, P. J., Kessler, R. C., Williams, J., Downs, A. C., English, D., White, J., et al. (2010). What works in family foster care? Identifying key components of success from an alumni follow-up study. New York and Oxford, England: Oxford University Press.

Pecora, P. J., Williams, J., Kessler, R. C., Downs, A. C., O'Brien, K., Hiripi. E. \& Morello, S. (2003). Assessing the effects of foster care: Early results from the Casey National Alumni Study. Seattle, WA: Casey Family Programs.

Pecora, J.P., Kessler, R.C., Williams, J., O'Brien, K., Downs, A.C., \& .... English, D. (2005). Improving family foster care: Findings from the Northwest Foster Care Alumni Study. Casey Family Programs, Seattle, WA (2005). (www.casey.org).

Peterson, R. L., Zabel, R. H., Smith, C. R., \& White, M. A. (1983). Cascade of Services Model and emotionally disabled students. Exceptional Children, 49(5), 404-408.

Petito, F., \& Cummins, R. A. (2000). Quality of life in adolescence: The role of perceived control, parenting style, and social support. Behavior Change, 17(03), 196-207.

Phinney, J. S., Ong, A., \& Madden, T. (2000). Cultural values and intergenerational value discrepancies in immigrant and non-immigrant families. Child development, 71(2), 528-539.

Powers, L. E., Deshler, D., Jones, B., Simon, M. (2006). Strategies for enhancing selfdetermination, social success and transition to adulthood. In D. Deschler \& J. Schumaker (Eds.), Teaching adolescents with disabilities: Accessing the general 
education curriculum (pp. 235-274). Thousand Oaks, CA: Corwin Press.

Powers, L. E., Geenen, S., Powers, J., Pommier-Satya, S., Turner, A., Dalton, L. D., Drummond, D., et al. (2012). My Life: Effects of a longitudinal, randomized study of self-determination enhancement on the transition outcomes of youth in foster care and special education. Children and Youth Services Review, 34(11), 2179-2187. doi:10.1016/j.childyouth.2012.07.018

Powers, L. E., Turner, A., Westwood, D., Matuszewski, J., Wilson, R., \& Phillips, A. (2001). TAKE CHARGE for the future: A controlled field-test of a model to promote student involvement in transition planning. Career Development for Exceptional Individuals, 24(1), 89-104.

Powers, S. I., Hauser, S. T., \& Kilner, L. A. (1989). Adolescent Mental Health. American Psychologist, 44(2), 200-208.

Raghavan R., \& McMillen J. C. (2008).Use of multiple psychotropic medications among adolescents aging out of foster care. Psychiatric Services, 59(9):1052-1055.

Rauktis, M. E., Huefner, J. C., O’Brien, K., Pecora, P. J., Doucette, A., \& Thompson, R. W. (2009). Measuring the Restrictiveness of Living Environments for Children and Youth: Reconceptualizing Restriction. Journal of Emotional and Behavioral Disorders, 17(3), 147-163. doi:10.1177/1063426608323371

Redding, R. E., Fried, C., \& Britner, P. A. (2000). Predictors of placement outcomes in treatment foster care: Implications for foster parent selection and service delivery. Journal of child and family studies, 9(4), 425-447. 
Reddy, L. A., \& Pfeiffer, S. I. (1997). Effectiveness of treatment foster care with children and adolescents: A review of outcome studies. Journal of the American Academy of Child and Adolescent Psychiatry, 36(5), 581-8. doi:10.1097/00004583199705000-00007

Reilly, T. (2001). Transition from care: The status and outcome of youth who have 'aged out' of the foster care system in Clark County, Nevada. Kids Count, Issue II. Las Vegas, NV: The Center for Business and Economic Research, University of Nevada, Las Vegas.

Reilly, T. (2003). Transition from care: Status and outcomes of youth who age out of foster care. Child Welfare: Journal of Policy, Practice, and Program, 82(6), 727 746.

Rice, K. G., Cole, D. A., \& Lapsley, D. K. (1990). Separation-individuation, family cohesion, and adjustment to college: Measurement validation and test of a theoretical model. Journal of Counseling Psychology, 37(2), 195.

Rindfuss, R. R. (1991). The young adult years: Diversity, structural change, and fertility. Demography, 28(4), 493-512.

Roberts, D. (2002). Shattered bonds: The color of child welfare. Children and Youth Services Review, 24(11), 877-880.

Roberts, R. E., \& Bengtson, V. L. (1996). Affective ties to parents in early adulthood and self-esteem across 20 years. Social Psychology Quarterly, 96-106.

Roche, K. M., Ensminger, M. E., \& Cherlin, A. J. (2007). Variations in parenting and adolescent outcomes among African American and Latino families living in low- 
income, urban areas. Journal of Family Issues, 28(7), 882-909.

Rubin, D. M., O'Reilly, A. L. R., Luan, X., \& Localio, a R. (2007). The impact of placement stability on behavioral well-being for children in foster care. Pediatrics, 119(2), 336-44. doi:10.1542/peds.2006-1995

Rueda, R., Gallego, M. A., \& Moll, L. C. (2000). The Least Restrictive Environment: A Place or a Context? Remedial and Special Education, 21(2), 70-78. doi:10.1177/074193250002100202

Rutter, M. (1985). Resilience in the face of adversity: Protective factors and resistance to psychiatric disorder, British Journal of Psychiatry 147, 598-611.

Rutter, M. (2006). The promotion of resilience in the face of adversity. In: A. ClarkeStewart and J. Dunn, Editors, Families count. Effects on child and adolescent development, Cambridge University Press, Cambridge.

Ryan, J. P., Hernandez, P. M., \& Herz, D. (2007). Developmental trajectories of offending for male adolescents leaving foster care. Social Work Research, 31(2), 83-93.

Ryan, J. P., Hong, J. S., Herz, D., \& Hernandez, P. M. (2010). Kinship foster care and the risk of juvenile delinquency. Children and Youth Services Review, 32(12), $1823-$ 1830. doi:10.1016/j.childyouth.2010.08.003

Ryan, J. P., Marie, J., Herz, D., \& Hernandez, P. M. (2008). Juvenile delinquency in child welfare : Investigating group home effects. doi:10.1016/j.childyouth.2008.02.004

Salazar, A. M., Keller, T. E., Gowen, L. K., \& Courtney, M. E. (2012a). Trauma exposure and PTSD among older adolescents in foster care. Social Psychiatry and 
Psychiatric Epidemiology, 1-7. doi:10.1007/s00127-012-0563-0

Salazar, A. M., Keller, T. E., Gowen, L. K., \& Courtney, M. E. (2012b). Trauma exposure and PTSD among older adolescents in foster care. Social Psychiatry and Psychiatric Epidemiology. doi;10.1007/s00127-012-0563-0

Samuels, G. M., \& Pryce, J. M. (2008). "What doesn't kill you makes you stronger”: Survivalist self-reliance as resilience and risk among young adults aging out of foster care. Children and Youth Services Review, 30(10), 1198-1210.

Sands, D. J., Spencer, K. C., Gliner, J., \& Swaim, R. (1999). Structural Equation Modeling of Student Involvement in Transition-Related Actions the Path of Least Resistance. Focus on Autism and Other Developmental Disabilities, 14(1), 17-27.

Sawyer, R. J., \& Dubowitz, H. (1994). School performance of children in kinship care. Child Abuse \& Neglect, 18(7), 587-597. doi:10.1016/0145-2134(94)90085-X

Scannapieco, M., Connell-Carrick, K., \& Painter, K. (2007). In their own words: Challenges facing youth aging out of foster care. Child and Adolescent Social Work Journal, 24(5), 423-435.

Schalock, R. L., \& Keith, K. D. (1993). Quality of life questionnaire. IDS Publishing Corporation.

Schmidt, J., Cunninghman, M. J., Dalton, L., Geenen, S., Powers, L. E., \& Orzco, C. (2013). Assessing Restrictiveness: A Closer Look at the Foster Care Placements and Perceptions of Youth With and Without Disabilities Aging Out of Care. Journal of Public Child Welfare. doi:10.1080/15548732.2013.845644 
Shin, S. H. (2002). Building evidence to promote educational competence of youth in foster care. Child welfare, 82(5), 615-632.

Shook, J. J., Vaughn, M. G., Litschge, C., Kolivoski, K., \& Schelbe, L. (2009). The importance of friends among foster youth aging out of care: Cluster profiles of deviant peer affiliations. Children and Youth Services Review, 31(2), 284-291.

Simons, L. G., \& Conger, R. D. (2007). Linking mother-father differences in parenting to a typology of family parenting styles and adolescent outcomes. Journal of Family Issues, 28(2), 212-241.

Simons, R. L., Simons, L. G., \& Wallace, L. E. (2004). Families, delinquency, and crime: Linking society's most basic institution to antisocial behavior. Los Angeles, CA: Roxbury Publishing Company.

Slayter, E., \& Springer, C. (2011). Child welfare-involved youth with intellectual disabilities: Pathways into and placements in foster care. Intellectual and developmental disabilities, 49(1), 1-13. doi:10.1352/1934-9556-49.1.1

Smith, D. K., Stormshak, E., Chamberlain, P., \& Whaley, R. B. (2001). Placement disruption in treatment foster care. Journal of emotional and behavioral disorders, 9(3), 200-205.

Smith, W. B. (2011). Youth leaving foster care: A developmental, relationship-based approach to practice. Oxford University Press.

Smithgall, C., Gladden, R.M., Yang, D.H.,\& George, R.(2005).Behavior problems and educational disruptions among children in out-of-home care. Chicago, IL: Chapin Hall Center for Children at the University of Chicago. 
Sosin, M., Piliavin, I., \& Westerfelt, H. (1990). Toward a longitudinal analysis of homelessness. Journal of Social Issues, 46(4), 157-174.

Staff, I., \& Fein, E. (1995). Stability and change: Initial findings in a study of treatment foster care placements. Children and Youth Services Review, 17(3), 379-389.

Stancliffe, R. J., Abery, B. H., \& Smith, J. (2000). Personal control and the ecology of community living settings: Beyond living-unit size and type. American Journal on Mental Retardation, 105(6), 431-454.

Steinberg, L., Lamborn, S. D., Dornbusch, S. M., \& Darling, N. (1992). Impact of parenting practices on adolescent achievement: Authoritative parenting, school involvement, and encouragement to succeed. Child development, 63(5), 12661281.

Stewart, D., Stavness, C., King, G., Antle, B., \& Law, M. (2006). A critical appraisal of literature reviews about the transition to adulthood for youth with disabilities. Physical \& occupational therapy in pediatrics, 26(4), 5-24.

Stroul, B. A., \& Friedman, R. M. (1986). A System of Care for Severely Emotionally Disturbed Children \& Youth.

Suarez-Orozco, M., \& Suarez-Orozco, C. (1996). Worlds Apart: Generational Discontinuities and the Latino Experience in School.

Substance Abuse and Mental Health Services Administration [SAMHSA]. (2010). SAMHSA's national registry of evidence-based programs and practices. Retrieved May 4, 2010, from http:// www.nrepp.samhsa.gov/.

Suldo, S. M., \& Huebner, E. S. (2004). Does life satisfaction moderate the effects of 
stressful life events on psychopathological behavior during adolescence?. School Psychology Quarterly, 19(2), 93.

Sullivan, P. M., \& Knutson, J. F. (2000). Maltreatment and disabilities: A population based epidemiological study. Child abuse \& neglect, 24(10), 1257-1273. doi:10.1016/S0145-2134(00)00190-3

Susser, E. S., Liii, S. P., Conover, S. A., \& Struening, E. L. (1991). Childhood Antecedents of Homelessness. Am J Psychiatry, 1, 48.

Tabachnick, B. G., \& Fidell, L. S. (2007). Using Multivariate Statistics (5th ed.). Boston, MA: Allyn and Bacon.

Taussig, H. N., Clyman, R. B., \& Landsverk, J. (2001). Children who return home from foster care: A 6-year prospective study of behavioral health outcomes in adolescence. Pediatrics, 108(1), e10-e10.

Trout, A. L., Hagaman, J., Casey, K., Reid, R., \& Epstein, M. H. (2008). The academic status of children and youth in out-of-home care: A review of the literature. Children and Youth Services Review, 30(9), 979-994. doi:10.1016/j.childyouth.2007.11.019

Tzawa-Hayden, A. (2004). Take me higher: Helping foster youth pursue higher education. Child Law Practice, 23(10), 163-166.

U.S. Department of Education, National Center for Education Statistics. (2015). Digest of Education Statistics, 2013 (NCES 2015-011), Chapter 2.

U.S. Department of Education, National Center for Education Statistics. (2013). Digest of Education Statistics, 2012 (NCES 2014-015), Chapter 2. 
US Department of Health and Human Services. (2013). The adoption and foster care analysis and reporting system (AFCARS) report. US Department of Health and Human Services.

U.S. General Accounting Office (GAO). (1999). Foster care: Effectiveness of independent living services unknown. Washington, DC: General Accounting Office, GAO/HEHS-00-13.

Valdés, K. A., Williamson, C. L., \& Wagner, M. M. (1990). The National Longitudinal Transition Study of Special Education Students, Statistical Almanac. SRI International.

Vaughn, M. G., Ollie, M. T., McMillen, J. C., Scott, L., \& Munson, M. (2007). Substance use and abuse among older youth in foster care. Addictive Behaviors, 32(9), 19291935.

Wade, J. (2008). The ties that bind: Support from birth families and substitute families for young people leaving care. British journal of social work, 38(1), 39-54.

Wagner, M., Newman, L., Cameto, R., Levine, P., \& Marder, C. (2007). Perceptions and expectations of youth with disabilities. A special topic report of findings from the National Longitudinal Transition Study-2 (NLTS2). Menlo Park, CA: SRI International.

Wagner, M., D’Amico, R., Marder, C., Newman, L., \& Blackorby, J. (1992). What happens next? Trends in post-secondary outcomes of youth with disabilities. Menlo Park, CA: SRI International.

Wagner, M., Newman, L., Cameto, R., Garza, N., \& Levine, P. (2005). After high school: 
A first look at the post school experiences of youth with disabilities. A report from the National Longitudinal Transition Study-2 (NLTS2). Online Submission.

Wagnild, G. M., \& Young, H. M. (2009). The resilience scale. The Official Home of the Resilience Scale.

Ward, H. (2009). Patterns of instability: Moves within the care system, their reasons, contexts and consequences. Children and Youth Services Review, 31(10), 11131118.

Wehmeyer, M. L., \& Kelchner, K. (1995). The ARC's self-determination scale. Arlington, TX: ARC.

Wehmeyer, M. L., \& Palmer, S. B. (2003). Adult Outcomes for Students with Cognitive Disabilities Three-Years After High School: The Impact of Self-Determination. Education and Training in Developmental Disabilities, 38(2), 131-144.

Wehmeyer, M. L., \& Schwartz, M. (1997). Self-determination and positive adult outcomes: A follow-up study of youth with mental retardation or learning disabilities. Exceptional Children, 63, 245-255.

Wehmeyer, M. L., Palmer, S. B., Agran, M., Mithaug, D. E., \& Martin, J. E. (2000). Promoting causal agency: The self-determined learning model of instruction. Exceptional Children, 66(4), 439-453.

Wehmeyer, M., \& Schwartz, M. (1998). The relationship between self-determination and quality of life for adults with mental retardation. Education and Training in Mental Retardation and Developmental Disabilities, 33(1), 3-12.

Wehmeyer, M. L. (1996). Self-determination across the life span: Independence and 
choice for people with disabilities, Self-determination as an educational outcome: Why is it important to children, youth and adults with disabilities? (pp. 15-34). Baltimore, MD: P. H. Brookes Publishing.

Wehmeyer, M. L. (1992). Self-determination and the Education of Students with Mental Retardation. Education and Training in Mental Retardation, 27(4), 302-314.

Wentzel, K. R. (2002). Are effective teachers like good parents? Teaching styles and student adjustment in early adolescence. Child development, 287-301.Rutter

Westat, I. (1991). A national evaluation of Title IV-E foster care independent living programs for youth: Phase 2. Rockville, MD: Author.

Werner, E.E., \& Smith, R.S. (2001). Journeys from childhood to midlife: Risk, resilience and recovery. Ithaca, NY: Cornell University Press.

Wolanin, T, 2005, Higher education opportunities for foster youth: A primer for policy makers. Institute for Higher Education Policy, Washington. Retrieved from http://hdl.voced.edu.au/10707/277385.

Wolman, J., Campeau, P., Dubois, P., Mithaug, D., \& Stolarski, V. (1994). AIR SelfDetermination Scale and user guide. Palo Alto, CA: American Institute for Research.

World Health Organization (2014). Disability and health fact sheet. Retrieved from http://www.who.int/mediacentre/factsheets/fs352/en/ on July, $23^{\text {rd }}, 2015$.

Wulczyn, F., \& Brunner Hislop, K. (2001). Children in Substitute Care at Age 16: Selected findings from the Multistate Data Archive. Chapin Hall Center for Children at University of Chicago. Chicago, IL. 
Wulczyn, F., Smithgall, C., \& Chen, L. (2009). Child Well-Being: The Intersection of Schools and Child Welfare. Review of Research in Education, 33(1), 35-62. doi:10.3102/0091732X08327208

Yates, T. M., \& Grey, I. K. (2012). Adapting to aging out: Profiles of risk and resilience among emancipated foster youth. Development and Psychopathology, 24(02), $475-492$.

Zarrett, N., \& Eccles, J. (2006). The passage to adulthood: Challenges of late adolescence. New Directions for Youth Development, 2006(111), 13-28.

Zetlin, A., Weinberg, L., \& Kimm, C. (2003). Are the educational needs of children in foster care being addressed?. Children \& Schools, 25(2), 105-119.

Zetlin, A., Weinberg, L., \& Shea, N. M. (2010). Caregivers, school liaisons, and agency advocates speak out about the educational needs of children and youths in foster care. Social work, 55(3), 245-254.

Zhang, D. (2001). The Effect of Next S.T.E.P. Instruction on the Self-Determination Skills of High School Students with Learning Disabilities. Career Development for Exceptional Individuals, 24(2), 121-132. doi:10.1177/088572880102400203

Zima, B. T., Bussing, R., Freeman, S., Yang, X., Belin, T. R., \& Forness, S. R. (2000). Behavior problems, academic skill delays and school failure among school-aged children in foster care: Their relationship to placement characteristics. Journal of Child and Family Studies, 9(1), 87-103.

Zimet, G. D., Dahlem, N. W., Zimet, S. G., \& Farley, G. K. (1988). The multidimensional 
scale of perceived social support. Journal of Personality Assessment, 52(1), 3041.

Zimet, S. G., Farley, G. K., \& Zimet, G. D. (1994). Home behaviors of children in three treatment settings: An outpatient clinic, a day hospital, and an inpatient hospital. Journal of the American Academy of Child \& Adolescent Psychiatry, 33(1), 5659.

Zimmerman, R. B. (1982). Foster care in retrospect (Vol. 14). School of Social Work, Tulane.

Zito, J. M., Safer, D. J., Sai, D., Gardner, J. F., Thomas, D., Coombes, P., ... \& MendezLewis, M. (2008). Psychotropic medication patterns among youth in foster care. Pediatrics, 121(1), e157-e163. 